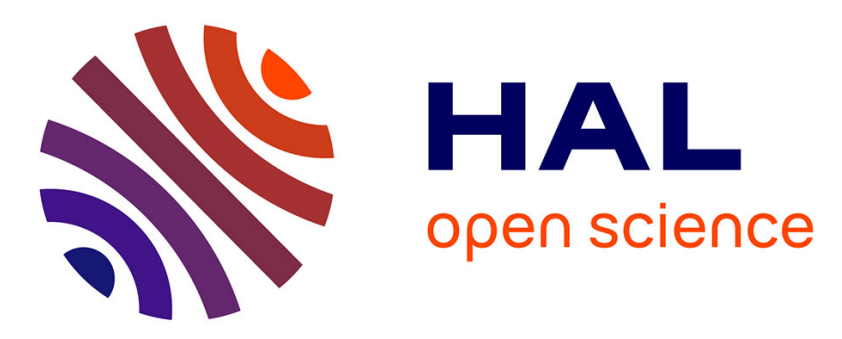

\title{
Activated lipidic cyclic carbonates for non-isocyanate polyurethane synthesis
}

Oceane Lamarzelle, Pierre-Luc Durand, Anne-Laure Wirotius, Guillaume Chollet, Etienne Grau, Henri Cramail

\section{- To cite this version:}

Oceane Lamarzelle, Pierre-Luc Durand, Anne-Laure Wirotius, Guillaume Chollet, Etienne Grau, et al. Activated lipidic cyclic carbonates for non-isocyanate polyurethane synthesis. Polymer Chemistry, 2016, 7 (7), pp.1439-1451. 10.1039/c5py01964h . hal-01364916

\section{HAL Id: hal-01364916 https://hal.science/hal-01364916}

Submitted on 26 Nov 2019

HAL is a multi-disciplinary open access archive for the deposit and dissemination of scientific research documents, whether they are published or not. The documents may come from teaching and research institutions in France or abroad, or from public or private research centers.
L'archive ouverte pluridisciplinaire HAL, est destinée au dépôt et à la diffusion de documents scientifiques de niveau recherche, publiés ou non, émanant des établissements d'enseignement et de recherche français ou étrangers, des laboratoires publics ou privés. 


\title{
Activated Lipidic Cyclic Carbonates for Non-Isocyanate Polyurethane Synthesis
}

\author{
Océane Lamarzelle, ${ }^{\mathrm{a}, \mathrm{b}}$ Pierre-Luc Durand, ${ }^{\mathrm{a}, \mathrm{b}}$ Anne-Laure Wirotius, ${ }^{\mathrm{a}, \mathrm{b}}$ Guillaume Chollet, $^{\mathrm{c}}$ Etienne \\ Grau $^{a, b}$ and Henri Cramail ${ }^{a, b *}$
}

\begin{abstract}
Activated 5-membered cyclic carbonates were prepared from glycerol and fatty acid derivatives. Ester and ether moieties were introduced in $\beta$ position to the cyclic carbonate, in order to enhance its reactivity towards amines. ${ }^{1} \mathrm{H}$ NMR kinetic investigation of the aminolysis of these cyclic carbonates demonstrated a higher reactivity compared to the one of alkyl substituted cyclic carbonates. In the case of ester-activated carbonates, a reactivity similar to the one of 6-membered ring cyclic carbonate was observed. Moreover, these carbonates exhibited amidation side-reactions with amines that could be however prevented by decreasing the temperature to room temperature. Poly(hydroxyurethane)s (PHUs) were then synthesized from these activated 5-membered ring cyclic carbonates at $70^{\circ} \mathrm{C}$ in DMF $\left(1\right.$ mol. $\left.\mathrm{L}^{-1}\right)$ and exhibited molar masses up to $13700 \mathrm{~g} \cdot \mathrm{mol}^{-1}$ with $\mathrm{Tg}$ in the ranges -26 to $-10^{\circ} \mathrm{C}$
\end{abstract}

\section{Introduction}

Thermoplastic poly(hydroxyurethane)s (PHUs) raised industrial and academic research curiosity ${ }^{1-7}$, since their synthesis is achieved via the ring opening of bis-cyclic carbonates with diamines, enabling the replacement of phosgene and isocyanates employed in the classical polyurethane (PU) manufacture. In view of the fossil fuel depletion, the use of building-blocks from renewable resources such as vegetable oils is on the rise. ${ }^{8}$ Combining PHUs synthesis and bio-based compounds, a large platform of fatty acid-based cyclic carbonates as poly(hydroxyurethane) precursors has already been synthesized by epoxidation/carbonation routes. ${ }^{3,9-11}$ However, such monomers exhibited a slow polymerization rate towards amines, due to the electron-releasing alkyl chains which deactivate the cyclic carbonates. To answer the problematic, academic research has developed larger sized-ring cyclic carbonates in order to increase their ring strain and so their reactivity towards aminolysis. ${ }^{12-17}$ Our research group has recently carried out the preparation of vegetable oil-based 6-membered cyclic carbonates from bio-sourced methyl undecenoate. ${ }^{18}$ An alternative route consists in inserting a heteroatom nearby the cyclic carbonate to improve/activate its reactivity. ${ }^{12,}{ }^{13},{ }^{19-31}$ Herein, the synthesis of new activated lipidic cyclic carbonates from glycerol carbonate and epichlorohydrin has been achieved, leading respectively to an ester or an ether linkage in $\beta$ position of the carbonate. After kinetic investigations of the cyclic carbonate aminolysis on model compounds, the corresponding activated bis-cyclic carbonates were polymerized with two diamines and exhibited enhanced reactivities. A specific focus on the side reactions that could occur in both model reaction and polymerization is also discussed.

\section{Experimental}

\section{Materials and methods}

Methyl 10-undecenoate (>96.0\%), 10-undecen-1-ol (99\%), decane1,10-diamine (10DA, >98\%), glycerol 1,2-carbonate (>90\%), 1,3dioxane-2-one (trimethylene carbonate, $>98 \%$ ), lithium aluminum hydride (LiAlH4, 95\%) and epichlorohydrin (>99\%) were supplied by $\mathrm{TCl}$, Europe. $\mathrm{N}, \mathrm{N}$-dimethylformamide (DMF, anhydrous grade), sodium hydrate $(\mathrm{NaH})(60 \%$ dispersion in mineral oil), sodium hydroxide $(\mathrm{NaOH}$, pellet), tetrabutylammonium bromide (TBABr, 99\%), ethyl chloroformate (97\%), Grubbs $1^{\text {st }}$ generation metathesis catalyst, Grubbs $3^{\text {rd }}$ generation metathesis catalyst, hexylamine (99\%), dimethyl carbonate (DMC, 99\%), 1,2,4-trichlorobenzene (TCB, 99\%), Oleoyl chloride (>80\%), 1,2-epoxydodecane (90\%) and hydrochloric acid (33\%) were obtained from Sigma-Aldrich. Triethylamine (TEA, 99\%), sebacoyl chloride (97\%) and 1,2-epoxy-9decene (96\%) were purchased from Alfa Aesar. Oleyl alcohol (99\%) and methyl oleate (99\%) were purchased from Nu-Check-Prep. ITERG kindly provided 20g of UndCC-ester. All products and solvents (reagent grade) were used as received except otherwise mentioned. The solvents were of reagent grade quality and were purified wherever necessary according to the methods reported in the literature.

${ }^{1} \mathrm{H}$ and ${ }^{13} \mathrm{C}$-NMR spectra were recorded on Bruker Avance 400 spectrometer $\left(400.20 \mathrm{MHz}\right.$ or $400.33 \mathrm{MHz}$ and $100.63 \mathrm{MHz}$ for ${ }^{1} \mathrm{H}$ and ${ }^{13} \mathrm{C}$, respectively) by using $\mathrm{CDCl}_{3}$ as a solvent at room temperature, except otherwise mentioned. ${ }^{13} \mathrm{C}$ DEPT (Distortionless Enhancement of Polarisation Transfer) and Two-dimensional analyses such as ${ }^{1} \mathrm{H}-{ }^{1} \mathrm{H}$ COSY (COrrelation SpectroscopY), ${ }^{1} \mathrm{H}-{ }^{1} \mathrm{H}$ TOCSY (TOtal Correlation SpectroscopY), ${ }^{1} \mathrm{H}_{-}{ }^{13} \mathrm{C} \quad \mathrm{HSQC}$ (Heteronuclear Single Quantum Spectroscopy) and ${ }^{1} \mathrm{H}-{ }^{13} \mathrm{C}$ HMBC (Heteronuclear Multiple Bond Correlation) were also performed. Infrared spectra (FTIR-ATR) were obtained on a Bruker-Tensor 27 spectrometer, equipped with a diamond crystal, using the attenuated total reflection mode. The spectra were acquired using 16 scans at a resolution of 4 wavenumbers. The gas chromatography analyses (GC) were performed by ITERG using a Shimadzu GC equipped with: Flame ionization detectors (FID, 380 ${ }^{\circ} \mathrm{C}$ ) and Zebron ZB-5HT (5\% phenyl - 95\% dimethylpolysiloxane) 15 $\mathrm{m} \times 0.25 \mathrm{~mm}$ ID, $0.1 \mu \mathrm{m}$ thickness capillary column. The carrier gas was hydrogen. The column temperature was initially set at $60{ }^{\circ} \mathrm{C}$ (volume injected: $1 \mu \mathrm{l}$ ), then increased to $370{ }^{\circ} \mathrm{C}$ at a rate of 10 ${ }^{\circ} \mathrm{C} . \mathrm{min}^{-1}$ and held isothermally for $10 \mathrm{~min}$. Size exclusion chromatography (SEC) analyses of PUs were performed in DMF $\left(80^{\circ} \mathrm{C}\right)$ on a PL-GPC 50 plus Integrated GPC from Polymer laboratories-Varian with a series of three columns from Polymer Laboratories (PLgel: PLgel $5 \mu \mathrm{m}$ Guard (guard column $7.5 \mathrm{~mm}$ ID $x$ $5.0 \mathrm{~cm} \mathrm{~L})$; PLgel $5 \mu \mathrm{m}$ MIXED-D $(7.5 \mathrm{~mm} \mathrm{ID} \times 30.0 \mathrm{~cm} \mathrm{~L})$ and PLgel $5 \mu \mathrm{m}$ MIXED-D $(7.5 \mathrm{~mm}$ ID $\times 30.0 \mathrm{~cm} \mathrm{~L}))$. In both cases, the elution times of the filtered samples were monitored using RI detectors. Differential scanning calorimetry (DSC) thermograms were measured using a DSC Q100 apparatus from TA instruments. For each sample, two cycles from -50 to $160{ }^{\circ} \mathrm{C}$ at $10{ }^{\circ} \mathrm{C} \cdot \mathrm{min}^{-1}$ (additional isotherm of $15 \mathrm{~min}$ at $160^{\circ} \mathrm{C}$ at the end of the first cycle to remove the residual DMF) were performed and then the glass transition and melting temperatures were calculated from the second heating run. Thermogravimetric analyses (TGA) were performed on TGA-Q50 system from TA instruments at a heating rate of $10{ }^{\circ} \mathrm{C} \cdot \mathrm{min}^{-1}$ under nitrogen atmosphere from room 
temperature to $600^{\circ} \mathrm{C}$, with an isotherm at $160^{\circ} \mathrm{C}$ for $15 \mathrm{~min}$ to remove the residual DMF. Mass spectra were performed by the Centre d'Etude Stucturale et d'Analyse des Molécules Organiques (CESAMO) on a QStar Elite mass spectrometer (Applied Biosystems). The instrument is equipped with an ESI source and spectra were recorded in the negative/positive mode. The electrospray needle was maintained at $4500 \mathrm{~V}$ and operated at room temperature. Samples were introduced by injection through a $20 \mu \mathrm{L}$ sample loop into a $400 \mu \mathrm{L} / \mathrm{min}$ flow of methanol from the LC pump. Sample was dissolved in DCM at $1 \mathrm{mg} / \mathrm{ml}$, and then $10 \mu \mathrm{l}$ of this solution was diluted in $1 \mathrm{ml}$ of methanol. DFT calculations were done using GAUSSIANO932 with the B3PLYP hybrid functional and a high quality $6-311++G(d)$ basis set.

\section{Standard procedure for kinetic experiments}

The kinetic experiments were performed in NMR tube at $1 \mathrm{~mol} . \mathrm{L}^{-1}$ in DMSO-d6, generally at $50^{\circ} \mathrm{C}$ and with a ratio $1: 1$ between cyclic carbonate and hexylamine. All reagents were dried on molecular sieves or distilled before the reaction. Hexylamine was dried under $\mathrm{CaH}_{2}$ and distilled of after drying. The cyclic carbonate was directly dried overnight in a NMR tube caped with a septum, under vacuum. $0.5 \mathrm{~mL}$ of dried DMSO-d6 and $12.5 \mu \mathrm{L}$ of TCB were added via the septum and the mixture was homogenized. The hexylamine $(66 \mu \mathrm{L}$, $0.5 \mathrm{mmol}, 1$ eq.) was then added just before putting the tube in the NMR apparatus. The reaction mixture was then heated at the reaction temperature. The reaction was monitored with ${ }^{1} \mathrm{H}$ NMR spectroscopy with the disappearance of the cyclic carbonate protons for 2 days.

\section{Standard procedure for polymerization}

PHUs were prepared from the b5CC, Und-bCC-ether and Und-bCCester with 1,10-diaminodecane (10DA) and 1,3cyclohexanebis(methylamine) (6cDA) as comonomers with a molar ratio $1: 1$. PHU syntheses were performed in DMF $\left(1 \mathrm{~mol}^{-\mathrm{L}^{-1}}\right)$ at $70^{\circ} \mathrm{C}$ into a schlenk tube under magnetic stirring and nitrogen atmosphere for 7 days. No catalysts were added for the polymerization reactions. Conversions were determined by ${ }^{1} \mathrm{H}$ NMR spectroscopy after $24 \mathrm{~h}$ and 7 days of polymerization.

\section{Mono-cyclic carbonate synthesis}

UndCC-ether synthesis : (i) In a round-bottom flask, 10-undecen-1ol $(10 \mathrm{~g}, 58.7 \mathrm{mmol})$ was stirred with epichlorohydrin $(54.35 \mathrm{~g}, 587$ $\mathrm{mmol}, 10 \mathrm{eq})$ and $\operatorname{TBABr}(1.89 \mathrm{~g}, 5.87 \mathrm{mmol}, 0.1 \mathrm{eq})$ at room temperature for $30 \mathrm{~min}$. $\mathrm{NaOH}$ was added via a $50 \%$ concentrated aqueous solution $(70 \mathrm{~mL}, 0.88 \mathrm{~mol}, 15 \mathrm{eq})$. After 24 hours of reaction at room temperature, the mixture reaction was diluted with 4 volumes of distilled water. The aqueous phase was extracted 3 times with $100 \mathrm{~mL}$ of ethyl acetate. The organic phase was then washed twice with $75 \mathrm{~mL}$ of water, dried over anhydrous magnesium sulfate, filtered and the remaining epichlorohydrin was removed on rotary evaporator. The ${ }^{1} \mathrm{H}$ NMR spectrum revealed a conversion of $72 \%$. The compound Und-epoxide was purified by flash chromatography using a mixture of cyclohexane and ethyl acetate (100:0 to $88: 12)$ and obtained as a viscous transparent liquid. Yield $=58 \% .{ }^{1} \mathrm{H}$ NMR $\left(\mathrm{CDCl}_{3}, 25^{\circ} \mathrm{C}, 400 \mathrm{MHz}\right) \delta(\mathrm{ppm}): 5.80(\mathrm{~m}$, $1 \mathrm{H}), 4.96(\mathrm{~m}, 2 \mathrm{H}), 3.70$ and $3.37(\mathrm{dd}, 2 \mathrm{H}), 3.49(\mathrm{~m}, 2 \mathrm{H}), 3.14(\mathrm{~m}, 1 \mathrm{H})$, 2.78 and $2.59(\mathrm{t}, 2 \mathrm{H}), 2.02(\mathrm{~m}, 2 \mathrm{H}), 1.58-1.28(\mathrm{~m}, 16 \mathrm{H}) .{ }^{13} \mathrm{C} \mathrm{NMR}$ $\left(\mathrm{CDCl}_{3}, 25^{\circ} \mathrm{C}, 100 \mathrm{MHz}\right) \delta(\mathrm{ppm}): 137.9\left(\underline{\mathrm{CH}}=\mathrm{CH}_{2}\right), 113.2\left(\mathrm{CH}=\underline{\mathrm{CH}}_{2}\right)$, $70.7\left(\mathrm{OCH}_{2}-\mathrm{CH}_{2}\right), 70.4\left(\underline{C}_{2} \mathrm{O}-\mathrm{CH}_{2} \mathrm{CH}_{2}\right), 49.9\left(\mathrm{CH}_{2}-\underline{\mathrm{C}}-\mathrm{CH}_{2} \mathrm{O}\right), 43.4$ $\left(\mathrm{CH}_{2}-\mathrm{CH}-\mathrm{CH}_{2} \mathrm{O}\right), 32.7\left(\mathrm{CH}_{2}-\mathrm{CH}=\mathrm{CH}_{2}\right), 28.7-25.1\left(\mathrm{CH}_{2}\right)$. (ii) The Undepoxide $(7.72 \mathrm{~g}, 34.2 \mathrm{mmol})$ was first pre-mixed with the $\mathrm{TBABr}$ $(0.24 \mathrm{~g}, 0.7 \mathrm{mmol}, 3 \mathrm{wt} \%)$ in $5 \mathrm{~mL}$ of acetone. Then the mixture was placed in a reactor and heated up at $80^{\circ} \mathrm{C}$. Once the temperature got stabilized, $\mathrm{CO}_{2}$ was slowly introduced into the reactor until 50 bars. After 3 days, the reactor was cooled down to RT and slowly depressurized to the atmospheric pressure. The mixture was reconcentrated on rotary evaporator. The ${ }^{1} \mathrm{H}$ NMR of the final mixture revealed a conversion of $98 \%$. The UndCC-ether was purified by flash chromatography using a mixture of cyclohexane and ethyl acetate (100:0 to 81:19), and obtained as a viscous transparent liquid. Yield $=82 \% .{ }^{1} \mathrm{H}$ NMR $\left(\mathrm{CDCl}_{3}, 25^{\circ} \mathrm{C}, 400 \mathrm{MHz}\right)$ $\delta(\mathrm{ppm}): 5.72(\mathrm{~m}, 1 \mathrm{H}), 4.90(\mathrm{~m}, 2 \mathrm{H}), 4.73(\mathrm{~m}, 1 \mathrm{H}), 4.42-4.32(\mathrm{t}, 2 \mathrm{H})$, $3.58(\mathrm{~m}, 2 \mathrm{H}), 3.41(\mathrm{t}, 2 \mathrm{H}), 1.98(\mathrm{dd}, 2 \mathrm{H}), 1.48(\mathrm{~m}, 2 \mathrm{H}), 1.21(\mathrm{~m}, 14 \mathrm{H})$. ${ }^{13} \mathrm{C} \mathrm{NMR}\left(\mathrm{CDCl}_{3}, 25^{\circ} \mathrm{C}, 100 \mathrm{MHz}\right) \delta$ (ppm): 155.3 (OCOO), 138.8 $\left(\underline{\mathrm{CH}}=\mathrm{CH}_{2}\right) ; 114.2\left(\mathrm{CH}=\underline{\mathrm{CH}}_{2}\right), 74.7\left(\mathrm{CH}_{2}-\underline{\mathrm{C}} \mathrm{H}-\mathrm{CH}_{2} \mathrm{O}\right), 71.8\left(\mathrm{CH}_{2} \mathrm{O}-\underline{\mathrm{CH}}_{2}-\right.$ $\left.\mathrm{CH}_{2}\right), 68.8\left(\mathrm{CH}-\mathrm{CH}_{2} \mathrm{O}-\mathrm{CH}_{2}\right), 66.1\left(\underline{\mathrm{C}} \mathrm{H}_{2}-\mathrm{CH}-\mathrm{CH}_{2} \mathrm{O}\right), 33.6\left(\underline{\mathrm{C}} \mathrm{H}_{2}-\mathrm{CH}=\mathrm{CH}_{2}\right)$, 28.7-26.2 $\left(\mathrm{CH}_{2}\right)$. IR $\left(\mathrm{cm}^{-1}\right)$ : 3075, 2979, 2928, 2850, 1760.

OleyICC-ether synthesis: (i) Oleyl-epoxide was synthesized using the same procedure than for Und-epoxide, but starting from oleyl alcohol. Viscous transparent oil was obtained and no purification was applied before carbonation. Conversion $=78 \%$. (ii) OleyICCether was synthesized using the same carbonation procedure as in UndCC-ether synthesis. Conversion $=99 \%$. Viscous transparent oil was obtained after purification by flash chromatography with a mixture of cyclohexane and ethyl acetate as eluent (100:0 to 86:14). Yield $=46 \% .{ }^{1} \mathrm{H} \mathrm{NMR}\left(\mathrm{CDCl}_{3}, 25^{\circ} \mathrm{C}, 400 \mathrm{MHz}\right) \delta(\mathrm{ppm}): 5.35(\mathrm{~m}, 2 \mathrm{H})$, $4.78(\mathrm{~m}, 1 \mathrm{H}), 4.50$ and $4.40(\mathrm{t}, 2 \mathrm{H}), 3.62(\mathrm{~m}, 2 \mathrm{H}), 3.49(\mathrm{t}, 2 \mathrm{H}), 2.02$ $(\mathrm{m}, 4 \mathrm{H}), 1.56-1.27(\mathrm{~m}, 26 \mathrm{H}), 0.88(\mathrm{t}, 3 \mathrm{H}) .{ }^{13} \mathrm{C}-\mathrm{NMR}\left(\mathrm{CDCl}_{3}, 25^{\circ} \mathrm{C}, 100\right.$ $\mathrm{MHz}) \delta(\mathrm{ppm}): 155.3$ (OCOO), $130.1\left(\mathrm{CH}_{2}-\underline{\mathrm{CH}}=\mathrm{CH}\right), 75.4(\underline{\mathrm{CH}}-$ $\left.\left.\mathrm{CH}_{2} \mathrm{OCH}\right)_{2}\right), 72.10\left(\mathrm{CH}_{2} \mathrm{O}-\mathrm{CH}_{2}-\mathrm{CH}_{2}\right), 69.6\left(\mathrm{CH}-\mathrm{CH}_{2}-\mathrm{OCH}_{2}\right), 66.3\left(\underline{\mathrm{C}} \mathrm{H}_{2}-\mathrm{CH}-\right.$ $\left.\mathrm{CH}_{2} \mathrm{O}\right), 32.0-22.8\left(\underline{\mathrm{CH}}_{2}\right), 27.3\left(\mathrm{CH}_{2}-\mathrm{CH}=\mathrm{CH}\right), 14.3\left(\mathrm{CH}_{3}\right)$. IR $\left(\mathrm{cm}^{-1}\right)$ : $3003,2917,2853,1797,1133$.

UndCC-ester synthesis: (i) Into a round-bottom flask containing 1eq (250 g, $1.34 \mathrm{~mol}$ ) of undecenoic acid, thionyl chloride $(271.5 \mathrm{~g}, 2.28$ mol) was added dropwise under inert atmosphere at $60^{\circ} \mathrm{C}$ and the formed $\mathrm{SO}_{2}$ and $\mathrm{HCl}$ were trapped during the reaction (with gas traps containing aqueous sodium hydroxide solution). When the conversion (determined by GC) was quantitative (>99\%), the excess of thionyl chloride was distilled out and the product was stored at $18^{\circ} \mathrm{C}$. Yield $=99 \%$ (ii) In a round-bottom flask, 1 eq (116.7 g, 0.99 $\mathrm{mol})$ of glycerol carbonate and $1.3 \mathrm{eq}(130.2 \mathrm{~g}, 1.29 \mathrm{~mol})$ of triethylamine were diluted in $500 \mathrm{~mL}$ of dry THF. 1 eq $(270 \mathrm{~g}, 0.99$ mol) of undecenoyl chloride was added dropwise under inert atmosphere at $0^{\circ} \mathrm{C}$. The mixture reaction was left $2 \mathrm{~h}$ at room temperature and the conversion (determined by GC) reached $96 \%$. UndCC-ester was then extracted with $250 \mathrm{~mL}$ of ethyl acetate and washed several times with $250 \mathrm{~mL}$ of water before solvent reconcentration. ITERG provided $20 \mathrm{~g}$ of the crude UndCC-ester, obtained as an oily white powder that could be purified by recrystallization in $100 \mathrm{~mL}$ of cold heptane. $73 \%$ yield was achieved after subsequent reconcentration of the recrystallization filtrate and recrystallization. ${ }^{1} \mathrm{H} \mathrm{NMR}\left(\mathrm{CDCl}_{3}, 25^{\circ} \mathrm{C}, 400 \mathrm{MHz}\right) \delta(\mathrm{ppm}): 5.82$ $(\mathrm{m}, 1 \mathrm{H}), 5.00(\mathrm{~m}, 2 \mathrm{H}), 4.91(\mathrm{~m}, 1 \mathrm{H}), 4.55(\mathrm{t}, 1 \mathrm{H}), 4.31(\mathrm{~m}, 3 \mathrm{H}), 2.36$ $(\mathrm{t}, 2 \mathrm{H}), 2.02(\mathrm{~m}, 2 \mathrm{H}), 1.59-1.29(\mathrm{~m}, 14 \mathrm{H}) .{ }^{13} \mathrm{C} \mathrm{NMR}\left(\mathrm{CDCl}_{3}, 25^{\circ} \mathrm{C}, 100\right.$ $\mathrm{MHz}) \delta(\mathrm{ppm}): 173.6\left(\mathrm{CH}_{2}-\mathrm{O} \underline{\mathrm{CO}}-\mathrm{CH}_{2}\right), 154.2$ (OCOO), 139.2 $\left(\underline{\mathrm{C}} \mathrm{H}=\mathrm{CH}_{2}\right), 114.0\left(\mathrm{CH}=\underline{\mathrm{C}} \mathrm{H}_{2}\right), 73.5\left(\underline{\mathrm{C}} \mathrm{H}-\mathrm{CH}_{2}-\mathrm{OCO}\right), 65.5\left(\underline{\mathrm{CH}}_{2}-\mathrm{CH}-\mathrm{CH}_{2}-\right.$ OCO), $62.7\left(\mathrm{CH}-\mathrm{CH}_{2}-\mathrm{OCO}\right), 34.4\left(\mathrm{OCO}-\underline{\mathrm{CH}}_{2}-\mathrm{CH}_{2}\right), 33.9\left(\underline{\mathrm{CH}}_{2}-\mathrm{CH}=\mathrm{CH}_{2}\right)$, 31.1-29.0 $\left(\mathrm{CH}_{2}\right), 24.9\left(\mathrm{OCO}-\mathrm{CH}_{2}-\mathrm{CH}_{2}\right)$. IR $\left(\mathrm{cm}^{-1}\right): 3081,3000,2920$, 2853, 1781, 1733.

OleyICC-ester synthesis: OleyICC-ester was synthesized following the procedure (ii) used for UndCC-ester synthesis, but starting from oleoyl chloride. The product was purified by flash chromatography using a mixture of cyclohexane and ethyl acetate (100:0 to $80: 20)$ 
and obtained as a viscous transparent liquid. Yield $=47 \% .{ }^{1} \mathrm{H}$ NMR $\left(\mathrm{CDCl}_{3}, 25^{\circ} \mathrm{C}, 400 \mathrm{MHz}\right) \delta(\mathrm{ppm}): 5.32(\mathrm{~m}, 2 \mathrm{H}), 4.91(\mathrm{~m}, 1 \mathrm{H}), 4.57(\mathrm{t}$, $1 \mathrm{H}), 4.34(\mathrm{~m}, 3 \mathrm{H}), 2.36(\mathrm{t}, 2 \mathrm{H}), 1.99(\mathrm{~m}, 4 \mathrm{H}), 1.62-1.29(\mathrm{~m}, 22 \mathrm{H})$, 0.85 (t, 3H). ${ }^{13} \mathrm{C} \mathrm{NMR}\left(\mathrm{CDCl}_{3}, 25^{\circ} \mathrm{C}, 100 \mathrm{MHz}\right) \delta(\mathrm{ppm}): 173.4\left(\mathrm{CH}_{2^{-}}\right.$ OCO- $\left.\mathrm{CH}_{2}\right), 154.6$ (OCOO), $130.1(\underline{\mathrm{CH}}=\mathrm{CH}), 73.8\left(\underline{\mathrm{CH}}-\mathrm{CH}_{2}-\mathrm{OCO}\right), 66.0$ $\left(\underline{\mathrm{CH}}_{2}-\mathrm{CH}-\mathrm{CH}_{2}-\mathrm{OCO}\right), 62.9\left(\mathrm{CH}-\mathrm{CH}_{2}-\mathrm{OCO}\right), 34.0\left(\mathrm{OCO}-\mathrm{CH}_{2}-\mathrm{CH}_{2}\right), 31.9-$ $29.2\left(\mathrm{CH}_{2}\right), 27.2\left(\underline{\mathrm{C}} \mathrm{H}_{2}-\mathrm{CH}=\mathrm{CH}\right), 24.9\left(\mathrm{OCO}-\mathrm{CH}_{2}-\mathrm{CH}_{2}\right), 22.7\left(\mathrm{CH}_{2}\right), 14.2$ $\left(\mathrm{CH}_{3}\right)$. IR $\left(\mathrm{cm}^{-1}\right)$ : 3000, 2920, 2858, 1792, 1738.

Und-6CC synthesis : (i) The methyl undecenoate $(20 \mathrm{~g}, 100.9 \mathrm{mmol})$ was stirred with dimethyl carbonate $(340 \mathrm{~mL}, 4.0 \mathrm{~mol}, 40 \mathrm{eq}), \mathrm{NaH}$ via a $60 \mathrm{wt} \%$ dispersion in mineral oil ( $6 \mathrm{~g}, 252.1 \mathrm{mmol}, 2.5 \mathrm{eq})$ and DMF ( $7.8 \mathrm{~mL}, 109.9 \mathrm{mmol}, 1 \mathrm{eq})$ at $60^{\circ} \mathrm{C}$. After 24 hours of reaction, $435 \mathrm{~mL}$ of diluted hydrochloric acid was slowly added to the reaction mixture. The organic phase was then washed twice with $100 \mathrm{~mL}$ of water, dried over anhydrous sodium sulfate, filtered and then the remaining dimethyl carbonate was removed on rotary evaporator. The compound Und-malonate was purified by flash chromatography using a mixture of cyclohexane and ethyl acetate (100:0 to $90: 10)$ and obtained as a viscous liquid. Yield=58\%. ${ }^{1} \mathrm{H}$ NMR $\left(\mathrm{CDCl}_{3}, 25^{\circ} \mathrm{C}, 400 \mathrm{MHz}\right) \delta(\mathrm{ppm}): 5.79(\mathrm{~m}, 1 \mathrm{H}), 4.95(\mathrm{~m}, 2 \mathrm{H})$, $3.73(\mathrm{~s}, 6 \mathrm{H}), 3.35(\mathrm{t}, 1 \mathrm{H}), 2.04(\mathrm{~m}, 2 \mathrm{H}), 1.88(\mathrm{~m}, 2 \mathrm{H}), 1.29(\mathrm{~m}, 1 \mathrm{H})$. ${ }^{13} \mathrm{C} \mathrm{NMR}\left(\mathrm{CDCl}_{3}, 25^{\circ} \mathrm{C}, 100 \mathrm{MHz}\right) \delta(\mathrm{ppm}): 170.1\left(\mathrm{COOCH}_{3}\right), 139.3$ $\left(\underline{\mathrm{C}} \mathrm{H}=\mathrm{CH}_{2}\right), 114.3\left(\mathrm{CH}=\underline{\mathrm{C}} \mathrm{H}_{2}\right), 52.6\left(\mathrm{C}=\mathrm{OO} \underline{\mathrm{C}} \mathrm{H}_{3}\right), 51.9\left(\underline{\mathrm{C}} \mathrm{H}-(\mathrm{C}=\mathrm{OOCH})_{2}\right)$, $33.9\left(\mathrm{CH}_{2}-\mathrm{CH}=\mathrm{CH}_{2}\right), 29.3-27.5\left(\mathrm{CH}_{2}\right)$. IR $\left(\mathrm{cm}^{-1}\right): 2924,2854,1734$.

(ii) A solution of Und-malonate $(10 \mathrm{~g}, 39.0 \mathrm{mmol})$ in THF $(10 \mathrm{~mL})$ was added to a solution of $\mathrm{LiAlH}_{4}(6.1 \mathrm{~g}, 160.9 \mathrm{mmol}, 4.1 \mathrm{eq}$.) in THF $(80 \mathrm{~mL})$ at $0^{\circ} \mathrm{C}$. After the addition was completed, the reaction mixture was allowed to reach slowly room temperature and was refluxed at $80^{\circ} \mathrm{C}$ for $2 \mathrm{~h}$. The reaction mixture was then cooled to $0^{\circ} \mathrm{C}$, and $10 \mathrm{~mL}$ of hydrochloric acid solution $(2 \mathrm{~N})$ was added dropwise. The product was then extracted three times with $50 \mathrm{~mL}$ of ethyl acetate. The organic layer was washed twice with $50 \mathrm{~mL}$ of $\mathrm{NaCl}$ saturated solution and water, dried over anhydrous sodium sulfate, filtered and then the solvent was removed on rotary evaporator. The Und-1,3-diol was purified by flash chromatography using a mixture of cyclohexane and ethyl acetate (100:0 to 40:60). Yield $=66 \% .{ }^{1} \mathrm{H} \mathrm{NMR}\left(\mathrm{CDCl}_{3}, 25^{\circ} \mathrm{C}, 400 \mathrm{MHz}\right) \delta(\mathrm{ppm}): 5.81(\mathrm{~m}, 1 \mathrm{H})$, $4.93(\mathrm{~m}, 2 \mathrm{H}), 3.78-3.63(\mathrm{~m}, 4 \mathrm{H}), 2.68(\mathrm{~s}, 2 . \mathrm{OH}), 2.02(\mathrm{~m}, 2 \mathrm{H}), 1.75$ $(\mathrm{m}, 1 \mathrm{H}), 1.36-1.22(\mathrm{~m}, 12 \mathrm{H}) .{ }^{13} \mathrm{C} \mathrm{NMR}\left(\mathrm{CDCl}_{3}, 25^{\circ} \mathrm{C}, 100 \mathrm{MHz}\right) \delta$ (ppm): $139.4\left(\underline{\mathrm{CH}}=\mathrm{CH}_{2}\right), 114.4\left(\mathrm{CH}=\mathrm{CH}_{2}\right), 67.0\left(\mathrm{CH}-\mathrm{CH}_{2}-\mathrm{OH}\right), 42.2$ $\left(\underline{\mathrm{C}} \mathrm{H}-\mathrm{CH}_{2}-\mathrm{OH}\right), 34.0\left(\underline{\mathrm{CH}}_{2}-\mathrm{CH}=\mathrm{CH}_{2}\right), 30.1-27.4\left(\mathrm{CH}_{2}\right) . \mathrm{IR}\left(\mathrm{cm}^{-1}\right)$ : 3277, 2919, 2850.

(iii) To a solution of triethylamine $(10.1 \mathrm{~g}, 100 \mathrm{mmol}, 2$ eq.) in THF (400 mL), Und-1,3-diol (10 g, $50 \mathrm{mmol})$ was added. Then ethyl chloroformate $(10.8 \mathrm{~g}, 100 \mathrm{mmol})$ was added to the mixture at $0^{\circ} \mathrm{C}$. The reaction mixture was stirred at room temperature for 7 hours. Precipitated triethylamine hydrochloride was filtered off, and the filtrate was concentrated under vacuum. The Und-6CC was isolated from the reaction mixture by flash chromatography using a mixture of cyclohexane and ethyl acetate (100:0 to 60:40) and obtained as a viscous liquid with $99.5 \%$ purity determined by GC-FID. Yield $=75 \%$. ${ }^{1} \mathrm{H} \mathrm{NMR}\left(\mathrm{CDCl}_{3}, 25^{\circ} \mathrm{C}, 400 \mathrm{MHz}\right) \delta(\mathrm{ppm}): 5.73(\mathrm{~m}, 1 \mathrm{H}), 4.94(\mathrm{~m}, 2 \mathrm{H})$, $4.41(\mathrm{~m}, 2 \mathrm{H}), 4.06(\mathrm{~m}, 2 \mathrm{H}), 2.17(\mathrm{~m}, 1 \mathrm{H}), 2.02(\mathrm{~m}, 2 \mathrm{H}), 1.35-1.30(\mathrm{~m}$, 12H). ${ }^{13} \mathrm{C} \mathrm{NMR}\left(\mathrm{CDCl}_{3}, 25^{\circ} \mathrm{C}, 100 \mathrm{MHz}\right) \delta(\mathrm{ppm}): 148.3$ (OCOO), $139.1\left(\underline{\mathrm{CH}}=\mathrm{CH}_{2}\right), 114.7\left(\mathrm{CH}=\underline{\mathrm{CH}}_{2}\right), 72.5\left(\underline{\mathrm{CH}}_{2}-\mathrm{OCOO}\right), 34.0\left(\underline{\mathrm{CH}}_{2}-\right.$ $\left.\mathrm{CH}=\mathrm{CH}_{2}\right), 31.4\left(\underline{\mathrm{C}} \mathrm{H}-\mathrm{CH}_{2}-\mathrm{OCOO}\right), 29.5-26.7\left(\mathrm{CH}_{2}\right) . \mathrm{IR}\left(\mathrm{cm}^{-1}\right)$ : 3075, 2979, 2928, 2850, 1760.

Oleyl-6CC synthesis: Oleyl-6CC was synthesized following the procedure used for Und-6CC synthesis, but starting from methyl oleate. Viscous transparent oil was obtained after purification by flash chromatography with a mixture of cyclohexane and ethyl acetate (100:0 to 60:40). Yield $=43 \% .{ }^{1} \mathrm{H}$ NMR $\left(\mathrm{CDCl}_{3}, 25^{\circ} \mathrm{C}, 400 \mathrm{MHz}\right)$ $\delta(\mathrm{ppm}): 5.33(\mathrm{~m}, 2 \mathrm{H}), 4.41(\mathrm{~m}, 2 \mathrm{H}), 4.13(\mathrm{~m}, 2 \mathrm{H}), 2.22(\mathrm{~m}, 1 \mathrm{H}), 2.02$ $(\mathrm{m}, 4 \mathrm{H}), 1.28(\mathrm{~m}, 22 \mathrm{H}), 0.91(\mathrm{t}, 3 \mathrm{H}) .{ }^{13} \mathrm{C}-\mathrm{NMR}\left(\mathrm{CDCl}_{3}, 25^{\circ} \mathrm{C}, 100 \mathrm{MHz}\right)$ $\delta(\mathrm{ppm}): 148.6(\mathrm{OCOO}), 130.6$ and $129.2(\underline{\mathrm{CH}}=\mathrm{CH}), 72.4\left(\mathrm{CH}_{2}-\mathrm{OCOO}\right)$, $32.0\left(\mathrm{CH}_{2}\right), 31.4\left(\underline{\mathrm{C}} \mathrm{H}-\mathrm{CH}_{2}-\mathrm{OCOO}\right), 29.9-22.7\left(\mathrm{CH}_{2}\right) .27 .3\left(\underline{\mathrm{C}} \mathrm{H}_{2}-\mathrm{CH}=\mathrm{CH}\right)$, $14.1\left(\mathrm{CH}_{3}\right)$. IR $\left(\mathrm{cm}^{-1}\right)$ : 3000, 2979, 2925, 2853, 1754.

Dec-5CC synthesis: The commercially available 1,2-epoxydodecane (3.02 g, $16.4 \mathrm{mmol})$ was first pre-mixed with $\operatorname{TBABr}(0.09 \mathrm{~g}, 0.28$ mmol, $3 \mathrm{wt} \%$ ) and $5 \mathrm{~mL}$ of acetone. Afterwards, the mixture was placed in a high-pressure autoclave and heated up at $80^{\circ} \mathrm{C}$. Once the temperature got stabilized, $\mathrm{CO}_{2}$ was slowly introduced into the reactor until 40 bars. After 3 days, the reactor was cooled down to RT and slowly depressurized to the atmospheric pressure. The ${ }^{1} \mathrm{H}$ NMR of the final mixture revealed a conversion of $98 \%$. The Dec$5 C C$ was purified by flash chromatography using a mixture of cyclohexane: ethyl acetate (100:0 to $88: 12$ ). The product was isolated as transparent viscous oil with a yield of $90 \% .{ }^{1} \mathrm{H} N \mathrm{NMR}$ $\left(\mathrm{CDCl}_{3}, 25^{\circ} \mathrm{C}, 400 \mathrm{MHz}\right) \delta(\mathrm{ppm}): 4.70(\mathrm{~m}, 1 \mathrm{H}), 4.49(\mathrm{t}, 1 \mathrm{H}), 4.06(\mathrm{t}$, $1 \mathrm{H}), 1.80(\mathrm{~m}, 1 \mathrm{H}), 1.65(1 \mathrm{H}), 1.40-1.26(16 \mathrm{H}), 0.89(\mathrm{t}, 3 \mathrm{H}) .{ }^{13} \mathrm{C}-\mathrm{NMR}$ $\left(\mathrm{CDCl}_{3}, 25^{\circ} \mathrm{C}, 100 \mathrm{MHz}\right) \delta$ (ppm): 155.3 (OCOO), 77.4 ( $\left.\mathrm{C} H-O C O O\right)$, 69.5 ( $\left.\mathrm{CH}_{2}-\mathrm{OCOO}\right), 34.0\left(\underline{\mathrm{CH}}_{2}-\mathrm{CH}-\mathrm{OCOO}\right), 31.9-22.7\left(\mathrm{CH}_{2}\right), 14.2\left(\mathrm{CH}_{3}\right)$. IR $\left(\mathrm{cm}^{-1}\right)$ : 2925, 2848, 1789 .

\section{Bis-cyclic carbonate synthesis}

Und-bCC-ether synthesis: Into a round-bottom flask, the UndCCether $(5 \mathrm{~g}, 18.5 \mathrm{mmol})$ and $1^{\text {st }}$ generation Grubbs catalyst $(76.2 \mathrm{mg}$, $0.093 \mathrm{mmol}, 0.5 \% \mathrm{~mol}$ ) were charged under nitrogen. The contents were vigorously stirred at $35^{\circ} \mathrm{C}$ for 24 hours. The equilibrium was driven thank to the removal under vacuum of the produced ethylene. The product was then purified with flash chromatography using a mixture of dichloromethane and methanol as eluent (100:0 to 95:5). Und-bcC-ether was obtained as a grey solid. Yield $=53 \% .{ }^{1} \mathrm{H}$ NMR $\left(\mathrm{CDCl}_{3}, 25^{\circ} \mathrm{C}, 400 \mathrm{MHz}\right) \delta(\mathrm{ppm}): 5.38(\mathrm{~m}, 2 \mathrm{H}), 4.80(\mathrm{~m}, 2 \mathrm{H})$, 4.49 and $4.39(\mathrm{t}, 4 \mathrm{H}), 3.64(\mathrm{~m}, 4 \mathrm{H}), 3.50(\mathrm{t}, 4 \mathrm{H}), 1.97(\mathrm{~m}, 4 \mathrm{H}), 1.56$ $(\mathrm{m}, 6 \mathrm{H}), 1.27(\mathrm{~m}, 26 \mathrm{H}) .{ }^{13} \mathrm{C} \mathrm{NMR}\left(\mathrm{CDCl}_{3}, 25^{\circ} \mathrm{C}, 100 \mathrm{MHz}\right) \delta(\mathrm{ppm})$ : 154.5 (OCOO), $130.9(\mathrm{CH}=\mathrm{CH}), 75.2\left(\mathrm{CH}_{2}-\mathrm{CH}-\mathrm{CH}_{2} \mathrm{O}\right), 72.2\left(\mathrm{CH}_{-} \mathrm{CH}_{2}-\right.$ $\left.\mathrm{O}_{-} \mathrm{H}_{2}\right), 69.6\left(\mathrm{CH}_{2}-\mathrm{CH}-\underline{\mathrm{CH}}_{2} \mathrm{O}\right), 66.3\left(\underline{\mathrm{C}} \mathrm{H}_{2} \mathrm{CH}-\mathrm{CH}_{2} \mathrm{O}\right), 32.7\left(\underline{\mathrm{CH}}_{2}-\mathrm{CH}=\mathrm{CH}\right)$, 29.9-26.1 $\left(\mathrm{CH}_{2}\right)$. IR $\left(\mathrm{cm}^{-1}\right): 2923,2850,1792,1141 . \mathrm{T}_{\mathrm{m}}=54^{\circ} \mathrm{C}$.

Und-bCC-ester synthesis: Into a round-bottom flask equipped with a mineral oil bubbler, the UndCC-ester $(3 \mathrm{~g}, 5.6 \mathrm{mmol}$ ) was mixed with $2 \mathrm{~mL}$ of dichloromethane. $1^{\text {st }}$ generation Grubbs catalyst ( 42.6 $\mathrm{mg}, 0.028 \mathrm{mmol}, 0.5 \% \mathrm{~mol}$ ) was then charged under nitrogen. The contents were vigorously stirred at room temperature for 24 hours. The ${ }^{1} \mathrm{H}$ NMR revealed of conversion of $80 \%$. The product was purified by recrystallization in $10 \mathrm{~mL}$ of cold dichloromethane $\left(-80^{\circ}\right)$ followed by a filtration and a washing with $30 \mathrm{~mL}$ of dichloromethane. Und-bCC-ester was obtained as a grey powder. Yield $=44 \% .{ }^{1} \mathrm{H}$ NMR $\left(\mathrm{CDCl}_{3}, 25^{\circ} \mathrm{C}, 400 \mathrm{MHz}\right) \delta(\mathrm{ppm}): 5.36(\mathrm{~m}, 2 \mathrm{H})$, $4.92(\mathrm{~m}, 2 \mathrm{H}), 4.55$ and $4.32(\mathrm{t}, 4 \mathrm{H}), 4.28(\mathrm{t}, 4 \mathrm{H}), 2.35(\mathrm{t}, 4 \mathrm{H}), 1.95(\mathrm{~m}$, $4 \mathrm{H}), 1.63-1.28(24 \mathrm{H}) .{ }^{13} \mathrm{C} \mathrm{NMR}\left(\mathrm{CDCl}_{3}, 25^{\circ} \mathrm{C}, 100 \mathrm{MHz}\right) \delta(\mathrm{ppm})$ : $173.0\left(\mathrm{CH}_{2}-\mathrm{O} \underline{\mathrm{CO}}-\mathrm{CH}_{2}\right), 154.5$ (OCOO), $130.5(\mathrm{CH}=\mathrm{CH}), 73.7\left(\underline{\mathrm{CH}}-\mathrm{CH}_{2}-\right.$ $\mathrm{OCO}), 65.7\left(\mathrm{C}_{2}-\mathrm{CH}-\mathrm{CH}_{2}-\mathrm{OCO}\right), 62.7\left(\mathrm{CH}-\mathrm{CH}_{2}-\mathrm{OCO}\right), 34.2\left(\mathrm{OCO}-\mathrm{CH}_{2}-\right.$ $\left.\mathrm{CH}_{2}\right), 32.0\left(\underline{\mathrm{C}}_{2}-\mathrm{CH}=\mathrm{CH}\right), 29.4-28.5\left(\mathrm{CH}_{2}\right), 24.5\left(\mathrm{OCO}-\mathrm{CH}_{2}-\mathrm{CH}_{2}\right)$. IR $\left(\mathrm{cm}^{-1}\right): 2917,2850,1784,1736 . \mathrm{T}_{\mathrm{m}}=111^{\circ} \mathrm{C}$.

Seb-bCC-ester synthesis: In a round-bottom flask, 2.6 eq $(5.14 \mathrm{~g}$, $43.4 \mathrm{mmol})$ of glycerol carbonate and 4 eq $(9.02 \mathrm{~mL}, 66.8 \mathrm{mmol})$ of triethylamine were diluted in $10 \mathrm{~mL}$ of dry dichloromethane. $2.6 \mathrm{eq}$ $(4 \mathrm{~g}, 16.7 \mathrm{mmol})$ of sebacoyl chloride was slowly added under inert atmosphere at $0^{\circ} \mathrm{C}$. The mixture reaction was left $2 \mathrm{~h}$ at room temperature. Afterwards, the mixture was reconcentrated and 50 
$\mathrm{mL}$ of petroleum ether was added to extract the Seb-bcc-ester. The triethylammonium salts formed during the reaction were filtered and the filtrate was washed three times with $25 \mathrm{~mL}$ of a $10 \% \mathrm{~mol}$ $\mathrm{HCl}$ solution, once with $25 \mathrm{~mL}$ of saturated $\mathrm{NaHCO}_{3}$ solution and finally with $25 \mathrm{~mL}$ of brine. ${ }^{1} \mathrm{H}$ NMR indicated a quantitative conversion of $100 \%$. After purification by flash chromatography using a mixture of dichloromethane and methanol (100:0 to 97:3), Seb-bCC-ester was obtained in $47 \%$ yield as a white powder. ${ }^{1} \mathrm{H}$ NMR (DMSO, $\left.25^{\circ} \mathrm{C}, 400 \mathrm{MHz}\right) \delta(\mathrm{ppm}): 5.01(\mathrm{~m}, 2 \mathrm{H}), 4.56$ and 4.25 $(\mathrm{t}, 4 \mathrm{H}), 4.29(\mathrm{t}, 4 \mathrm{H}), 2.31(\mathrm{t}, 4 \mathrm{H}), 1.53(\mathrm{~m}, 4 \mathrm{H}), 1.25(8 \mathrm{H}) .{ }^{13} \mathrm{C} N M R$ (DMSO, $\left.25^{\circ} \mathrm{C}, 100 \mathrm{MHz}\right) \delta$ (ppm): $173.8\left(\mathrm{CH}_{2}-\mathrm{OCO}-\mathrm{CH}_{2}\right), 154.1$ (OCOO), 74.3 ( $\left.\underline{\mathrm{C}} \mathrm{H}-\mathrm{CH}_{2}-\mathrm{OCO}\right), 66.4\left(\mathrm{CH}_{2}-\mathrm{CH}-\mathrm{CH}_{2}-\mathrm{OCO}\right), 62.8\left(\mathrm{CH}-\mathrm{CH}_{2}-\right.$ OCO), $33.3\left(\mathrm{OCO}-\mathrm{CH}_{2}-\mathrm{CH}_{2}\right), 28.5-28.2\left(\mathrm{CH}_{2}\right), 24.2\left(\mathrm{OCO}-\mathrm{CH}_{2}-\mathrm{CH}_{2}\right)$. IR $\left(\mathrm{cm}^{-1}\right): 2936,2845,1778,1730 . \mathrm{T}_{\mathrm{m}}=84^{\circ} \mathrm{C}$.

b5CC synthesis : (i) The commercially available 1,2-epoxy-9-decene $(7 \mathrm{~g}, 45.4 \mathrm{mmol})$ was first pre-mixed with the $\operatorname{TBABr}(0.21 \mathrm{~g}, 0.64$ $\mathrm{mmol}, 3 \mathrm{wt} \%)$. Then the mixture was placed in a reactor and heated up at $80^{\circ} \mathrm{C}$. Once the temperature got stabilized, $\mathrm{CO}_{2}$ was slowly introduced into the reactor until 50 bars. After 24 hours, the reactor was cooled down to RT and slowly depressurized to the atmospheric pressure. The ${ }^{1} \mathrm{H}$ NMR of the final mixture revealed a conversion of $94.5 \%$. The product was purified by flash chromatography using a mixture of cyclohexane: ethyl acetate (100:0 to $70: 30) . \mathrm{Y}=50 \% .{ }^{1} \mathrm{H} \mathrm{NMR}\left(\mathrm{CDCl}_{3}, 25^{\circ} \mathrm{C}, 400 \mathrm{MHz}\right) \delta$ (ppm): $5.77(\mathrm{~m}, 1 \mathrm{H}), 4.96(\mathrm{~m}, 2 \mathrm{H}), 4.71(\mathrm{~m}, 1 \mathrm{H}), 4.51(\mathrm{t}, 1 \mathrm{H}), 4.03(\mathrm{t}, 1 \mathrm{H})$, $2.04(\mathrm{~m}, 2 \mathrm{H}), 1.77(\mathrm{~m}, 1 \mathrm{H}), 1.68(\mathrm{~m}, 1 \mathrm{H}), 1.45-1.33(\mathrm{~m}, 8 \mathrm{H}) .{ }^{13} \mathrm{C}-\mathrm{NMR}$ $\left(\mathrm{CDCl}_{3}, 25^{\circ} \mathrm{C}, 100 \mathrm{MHz}\right) \delta(\mathrm{ppm}): 155.2(\mathrm{OCOO}), 139.0\left(\mathrm{CH}=\mathrm{CH}_{2}\right)$, $114.5\left(\mathrm{CH}=\mathrm{CH}_{2}\right), 77.4(\mathrm{CH}-\mathrm{OCOO}), 69.5\left(\mathrm{CH}_{2}-\mathrm{OCOO}\right), 34.0\left(\mathrm{CH}_{2}-\mathrm{CH}-\right.$ OCOO), $33.8\left(\underline{\mathrm{CH}}_{2}-\mathrm{CH}=\mathrm{CH}_{2}\right), 29.1-28.8\left(\mathrm{CH}_{2}\right), 24.5\left(\underline{\mathrm{CH}}_{2}-\mathrm{CH}_{2}-\mathrm{CH}-\right.$ OCOO). IR ( $\left.\mathrm{cm}^{-1}\right): 2924,2856,1786$. (ii) Into a round-bottom flask equipped with a mineral oil bubbler, $5 \mathrm{~g}(1 \mathrm{eq}, 25 \mathrm{mmol})$ of the carbonated 1,2-epoxy-9-decene was mixed with $50 \mathrm{~mL}$ of distilled dichloromethane. $3^{\text {rd }}$ generation Grubbs catalyst $(76 \mathrm{mg}, 0.13 \mathrm{mmol}$, $0.5 \%)$ was then charged under nitrogen. The contents were vigorously stirred at room temperature. ${ }^{1} \mathrm{H}$ NMR revealed $93 \%$ of conversion in 3 days. Viscous transparent oil was obtained after purification by flash chromatography using $100 \%$ of cyclohexane as eluent. Yield $=65 \%$. $\boldsymbol{b}_{5 \mathrm{CC}}{ }^{1} \mathrm{H} \mathrm{NMR}\left(\mathrm{CDCl}_{3}, 25^{\circ} \mathrm{C}, 400 \mathrm{MHz}\right) \delta(\mathrm{ppm})$ : $5.37(\mathrm{~m}, 2 \mathrm{H}), 4.69(\mathrm{~m}, 2 \mathrm{H}), 4.49$ and $4.03(\mathrm{t}, 4 \mathrm{H}), 1.96(\mathrm{~m}, 4 \mathrm{H}), 1.78$ and $1.66(\mathrm{~m}, 4 \mathrm{H}), 1.46-1.34(\mathrm{~m}, 16 \mathrm{H}) .{ }^{13} \mathrm{C}-\mathrm{NMR}\left(\mathrm{CDCl}_{3}, 25^{\circ} \mathrm{C}, 100\right.$ $\mathrm{MHz}) \delta(\mathrm{ppm}): 155.2$ (OCOO), $130.4(\underline{\mathrm{CH}}=\mathrm{CH}), 77.1(\underline{\mathrm{C}} \mathrm{H}-\mathrm{OCOO}), 69.4$ $\left(\underline{\mathrm{CH}}_{2}-\mathrm{OCOO}\right), 34.0\left(\underline{\mathrm{C}}_{2}-\mathrm{CH}-\mathrm{OCOO}\right), 33.8\left(\underline{\mathrm{CH}}_{2}-\mathrm{CH}=\mathrm{CH}\right), \quad 32.5-23.7$ $\left(\mathrm{CH}_{2}\right)$. IR $\left(\mathrm{cm}^{-1}\right): 2923,2850,1786 . \mathrm{T}_{\mathrm{m}}=-54^{\circ} \mathrm{C}$.

\section{Monomer synthesis}

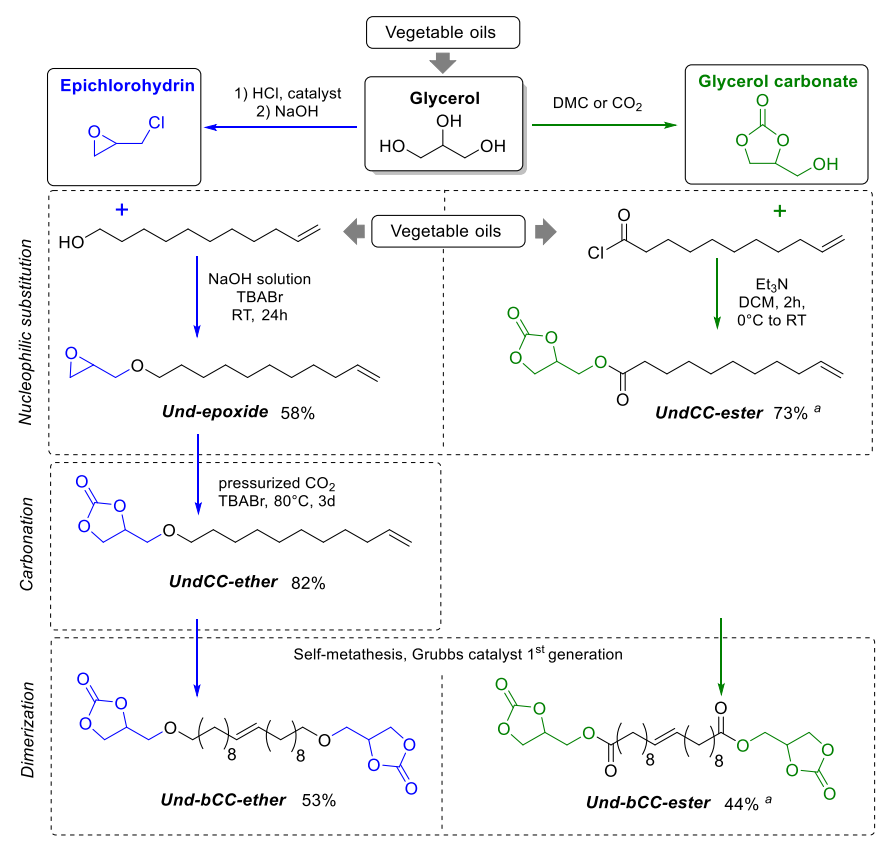

Scheme 1 - Synthesis routes to activated lipidic bis-cyclic carbonates UndCCether (left) and UndCC-ester (right) with isolated yields.

${ }^{a}$ The yield can be dramatically increased by subsequent reconcentration of the recrystallization filtrate and further recrystallizations.

Table 1 - Length of cyclic carbonate bonds and urethane formation enthalpies for different cyclic carbonate substituents $-X$ calculated by DFT.

\begin{tabular}{ccccc}
\hline & $\begin{array}{c}\text { Bond lengh } \\
(\AA)\end{array}$ & $\begin{array}{c}\text { Bond lengh } \\
(\AA)\end{array}$ & \\
$-X$ & 1.358 & 1.361 & -14.91 & -36.33 \\
$-\mathrm{CH}_{3}$ & 1.358 & 1.363 & -27.36 & -55.90 \\
$-\mathrm{OMe}$ & 1.361 & 1.363 & -57.96 & -62.83 \\
$-\mathrm{OC}(\mathbf{O}) \mathrm{Me}$ & & &
\end{tabular}

Two strategies, both using glycerol derivatives, were adopted for the synthesis of activated cyclic carbonates.

Firstly, lipidic cyclic carbonates with an ether moiety in $\beta$ position of the carbonate ring could be easily obtained using epichlorohydrin as reagent, which is produced by chlorination of glycerol. ${ }^{33}$ This "epichlorohydrin strategy" has already been adopted by several research groups for the synthesis of cyclic carbonates. $26,27,29,34,35$ As illustrated in Scheme 1, the synthesis of Und-bcC-ether from epichlorohydrin involved three steps (i) the nucleophilic substitution of the epichlorohydrin with undecen-1-ol (ii) the carbonation of the 

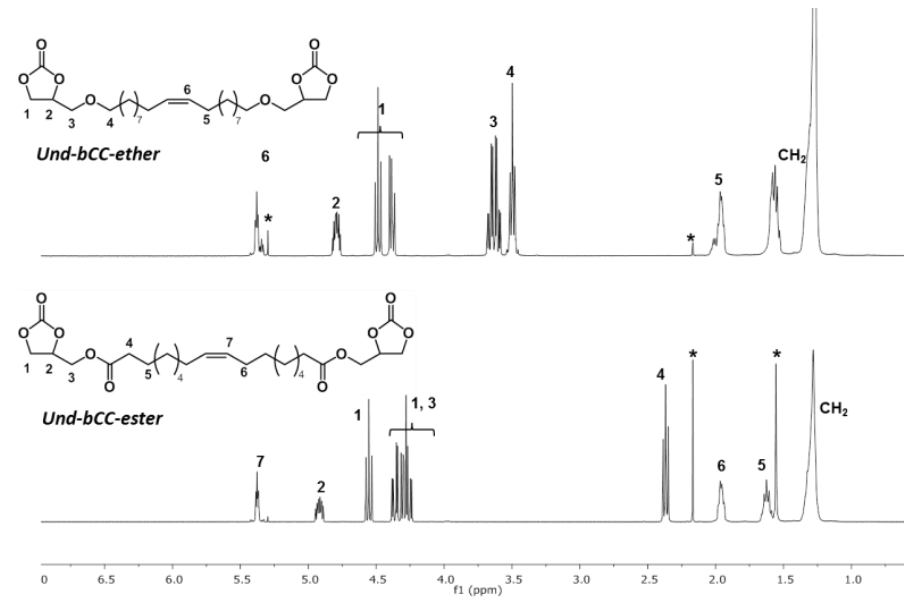

Figure 1 - Stacked ${ }^{1} \mathrm{H}$ NMR spectra of Und-bCC-ether and Und-bCC-ester in $\mathrm{CDCl}_{3}$.

resulting epoxide and finally (iii) the dimerization by metathesis reaction. The chemical structure of the resulting bis-cyclic carbonate as well as the different intermediates, were assessed by NMR spectroscopy and FTIR-ATR (see Figure 1 and ESI + ). The Und-epoxide was synthesized for $24 \mathrm{~h}$ at room temperature from 1 eq of undecen-1-ol, using 10eq of epichlorohydrin, 15 eq of $\mathrm{NaOH}$ via a $50 \%$ w solution and 0.1 eq of $\mathrm{TBABr}$ as transfer agent. The conversion reached $72 \%$ and no side reactions were observed in these conditions. After extraction with ethyl acetate, the product was purified by flash chromatography ( $58 \%$ yield). The carbonation of the Undepoxide was performed in an autoclave during 3 days at $80^{\circ} \mathrm{C}$, at 40 bars of pressurized $\mathrm{CO}_{2}$ using $3 \%$ wt TBABr as catalyst to reach full conversion. UndCC-ether was obtained as viscous transparent oil after flash chromatography ( $82 \%$ yield). The mono functional UndCC-ether was then "dimerized" via metathesis reaction of the terminal double bond. The reaction was processed at room temperature in dichloromethane under inert atmosphere using $0.5 \% \mathrm{~mol}$ of $1^{\text {st }}$ generation Grubbs metathesis catalyst for the coupling. A conversion of 99\% was achieved after 3 days as estimated by NMR spectroscopy. The Und-bcc-ether was obtained with a yield of $53 \%$ after flash chromatography (eluent: cyclohexane/ethyl acetate).

A second route to activated cyclic carbonates is based on the glycerol carbonate as building block that has been frequently employed to introduce the cyclic carbonate functionality onto different structures. ${ }^{17,36-39}$

In this case, bis-cyclic carbonates activated by an ester moiety in $\beta$ position of the cycle were obtained by esterification between fatty acid chloride from undecenoic acid and glycerol carbonate (see Figure 1 and ESI+). UndCC-ester was purified by recrystallization in heptane and obtained in $73 \%$ yield. The dimerization was successfully achieved with the same reaction conditions than for Und-bcC-ether synthesis. Pure Und-bccester was recrystallized in cold $\operatorname{DCM}\left(-20^{\circ} \mathrm{C}\right)$ with a yield of $44 \%$. It should be mentioned that this molecule was recently synthesized by Bigot et al. ${ }^{40}$ who used glycidol and undecenoic acid as starting materials.

\section{Kinetic Measurements}

In order to quantify the difference in reactivity between classical 5membered cyclic carbonates and the synthesized aotivated cyclic
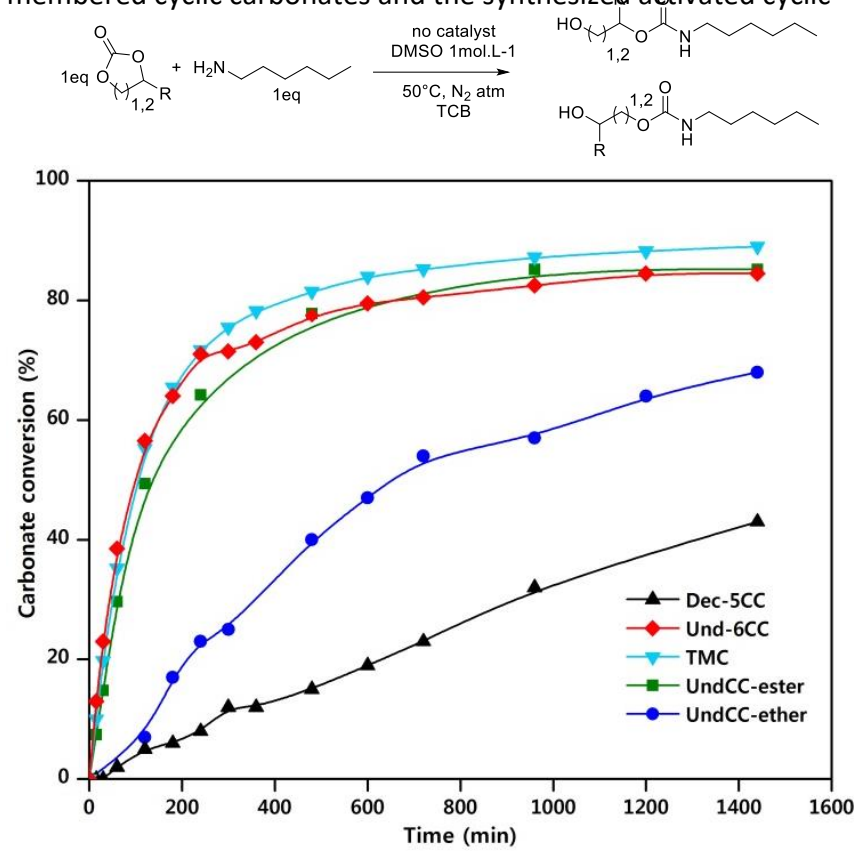

Figure 2 - Effect of various cyclic carbonates activations on the kinetic of the reactions with hexylamine followed by ${ }^{1} \mathrm{H}$ NMR. $\left(50^{\circ} \mathrm{C}, 1\right.$ mol.L $^{-1}$ in DMSO-d6, ratio $1: 1$ )

Table 2- Reaction rate constants obtained for the different model reactions between cyclic carbonates and hexylamine (ratio 1:1) in DMSO-d6 (1 $\mathrm{mol}^{-L^{-1}}$ ).

\begin{tabular}{ccc}
\hline Cyclic carbonate $(\mathrm{CC})$ & Temperature $\left({ }^{\circ} \mathrm{C}\right)$ & $\mathrm{k}_{\text {app }}\left(\mathrm{L} . \mathrm{mol}^{-1} \cdot \mathrm{h}^{-1}\right)^{[\mathrm{a}]}$ \\
\hline TMC & 50 & 0.58 \\
\hline Und-6CC & 50 & 0.44 \\
\hline UndCC-ester & 25 & 0.15 \\
& 50 & 0.44 \\
& 70 & 0.80 \\
\hline UndCC-ether & 50 & 0.09 \\
\hline Dec-5CC & 50 & 0.03 \\
\hline Oleyl-6CC & 50 & 0.58 \\
\hline OleyICC-ester & 50 & $0.65[0-1] \mathrm{h}$ \\
& 50 & $0.15[1-6] \mathrm{h}$ \\
\hline OleylCC-ether & 50 & 0.04
\end{tabular}

[a] Calculated upon the 6 first hours of the kinetics performed in NMR, using a second order kinetic law. (see $\mathrm{ESI}+$ ).

carbonates, kinetic experiments were monitored in situ by ${ }^{1} \mathrm{H}$ NMR spectroscopy. Several monocyclic carbonates such as TMC (trimethylene carbonate), UndCC-ester, UndCC-ether, Und-6CC (5(non-8-en-1-yl)-1,3-dioxan-2-one) and Dec-5CC (1-decene carbonate) were reacted with hexylamine at 25,50 or $70^{\circ} \mathrm{C}$, at 1 mol. $\mathrm{L}^{-1}$ in DMSO-d6, with trichlorobenzene (TCB) as internal reference. The cyclic carbonate conversion was followed by ${ }^{1} \mathrm{H}$ NMR for 24h. In a general trend, conversions of cyclic carbonates followed a second order kinetic law (allowing to extract $k_{a p p}$ ) until $50-60 \%$ of conversion. Then, the kinetics of the reaction slowed down and the conversion ultimately reached a plateau. This feature can be attributed to several parameters such as the limited diffusion occurring in the NMR tube, the solubility or the high amount of hydrogen-bonding due to the produced hydroxyl groups, hindering the reaction.

The UndCC-ester and UndCC-ether were compared to the reactive 6-membered ring cyclic carbonates TMC and Und-6CC from methyl undecenoate. A purely aliphatic 5 -membered ring cyclic carbonate 


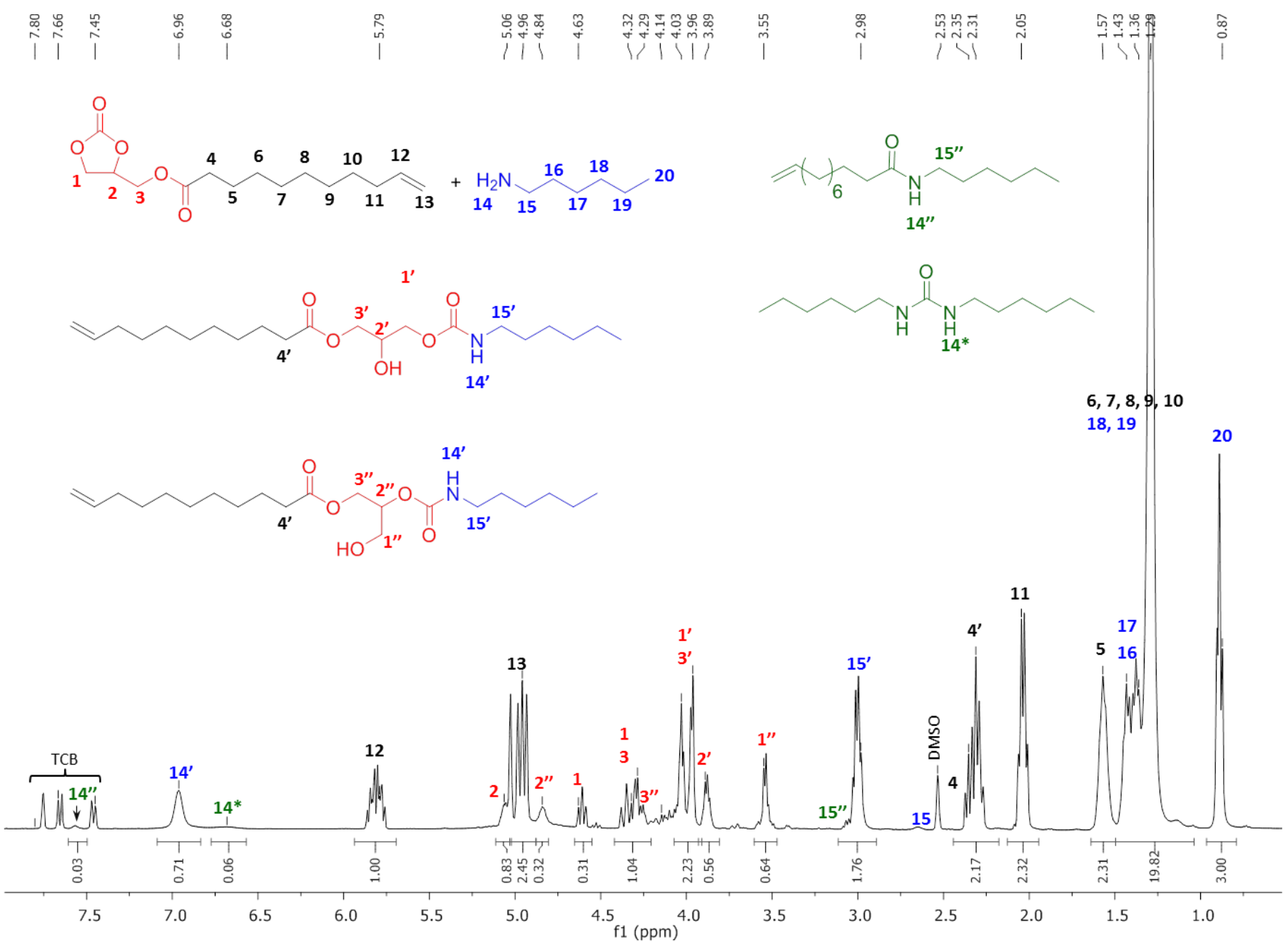

Figure $3-{ }^{1} \mathrm{H}$ NMR of the model reaction between UndCC-ester and n-hexylamine in DMSO-d6 at 1 mol. $\mathrm{L}^{-1}$ at $50^{\circ} \mathrm{C}$ after 2 days.

$$
\text { (1) }
$$

Scheme 2 - Possible side reactions between UndCC-ester and hexylamine : (1) urea formation, (2) amidification and (3) dehydration.

The enhancement of $5 \mathrm{CC}$ reactivity has already been described in the literature ${ }^{12,13,19-30}$ and was attributed to the negative inductive effect of the ester and ether groups in $\beta$ position of the cycle moiety, explaining the highest conversions obtained for UndCCether and UndCC-ester. The latest displayed a similar reactivity to the lipidic Und-6CC and followed the same kinetic tendency as TMC. On the other hand, UndCC-ether kinetic profile clearly
Table 3 - Proportions of product and by-products during the model reaction

\begin{tabular}{|c|c|c|c|c|c|}
\hline \multirow{2}{*}{$\begin{array}{c}\text { Proportions } \\
\text { (\%) }\end{array}$} & \multicolumn{3}{|c|}{ UndCC-ester } & \multirow{2}{*}{$\begin{array}{c}\text { UndCC- } \\
\text { ether } \\
50^{\circ} \mathrm{C}\end{array}$} & \multirow{2}{*}{$\begin{array}{c}\text { Dec-5CC } \\
50^{\circ} \mathrm{C}\end{array}$} \\
\hline & $25^{\circ} \mathrm{C}$ & $50^{\circ} \mathrm{C}$ & $70^{\circ} \mathrm{C}$ & & \\
\hline Urea $^{[a]}$ & 2,8 & 2,7 & $\mathrm{nd}^{*}$ & 2.9 & 4 \\
\hline Amide $^{[a]}$ & 0 & 2,1 & $\mathrm{nd}^{*}$ & 0 & 0 \\
\hline Urethane ${ }^{[a]}$ & 97.2 & 95.2 & $\mathrm{nd}^{*}$ & 97.1 & 96 \\
\hline Ratio $\mathrm{OH}_{1}: \mathrm{OH}_{\|}$ & $18: 82$ & $23: 77$ & $23: 77$ & $28: 72$ & $60: 40$ \\
\hline
\end{tabular}
of UndCC-ester and UndCC-ether with hexylamine at 50\% conversion in cyclic carbonates.

(Dec-5CC) was also synthesized from 1,2-epoxydodecane and $\mathrm{CO}_{2}$ in order to obtain a low benchmark and to see the effect of an heteroatom insertion within the aliphatic chain, on the reactivity of a $5 \mathrm{CC}$. Dec-5CC exhibited the lowest reactivity in terms of aminolysis with hexylamine, as it is depicted in Figure 2.

demonstrates a lower reactivity than UndCC-ester. This feature could be assigned to the lower negative inductive effect and the higher positive mesomeric effect of the oxygen atom, stabilizing the cycle and decreasing its subsequent reactivity. From a kinetic point of view, DFT calculations exposed in Table 1 highlight the longer bond length and the ensuing enhanced reactivity towards ringopening, when an ester moiety is placed nearby the cycle. The 
increase of the bond length correlates with the minimized mesomeric effect in the case of the ester activation.

Thermodynamically speaking, the ester moiety exhibits a lower enthalpy of urethane formation, confirming the better carbonate activation. Additionally, the chain length effect has been investigated in model reaction. For that purpose, OleyICC-ester,

OleyICC-ether and Oleyl-6CC were synthesized from methyl oleate derivatives. No influence of the chain length was observed on Und6CC and Oleyl-6CC when kinetic experiments were carried out. Nevertheless, activated 5-CC were impacted by the number of carbons of the aliphatic chain (see ESI+). As an example, OleyICCether exhibited $51 \%$ conversion after $24 \mathrm{~h}$ instead of $68 \%$ for the corresponding $\mathrm{C}_{11}$-synthon.

Model reactions on UndCC-ester were then monitored at $25^{\circ} \mathrm{C}$ and $70^{\circ} \mathrm{C}$ with regard to see the impact of the temperature on the ring opening kinetic of the cyclic carbonate. In order to estimate the reaction rate constants $\left(k_{a p p}\right), x /(1-x)$ (in which $x$ represents the cyclic carbonate conversion) was plotted as a function of time (see ESI + ). The second order kinetic law was verified upon the 6 first hours and the reaction rate constants were $0.15,0.44$ and 0.80 L.mol ${ }^{-1} \cdot h^{-1}$ at 25,50 and $70^{\circ} \mathrm{C}$ respectively (Table 2 ).

From the Arrhenius plot (see ESIt), the activation energy of this mono-cyclic carbonate could be estimated at $27 \mathrm{~kJ} \mathrm{~mol}^{-1}$. In the literature, Endo and coll. ${ }^{13}$ reported activation energies of 10.1 and $24.6 \mathrm{~kJ} \mathrm{~mol}^{-1}$ for $5 \mathrm{CC}$ and $6 \mathrm{CC}$ respectively. Additionally, Maisonneuve et al. ${ }^{18}$ calculated from the Arrhenius plot an

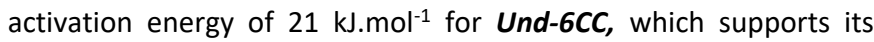
similar reactivity with UndCC-ester.

In addition to the analysis of carbonate consumption, these kinetics experiments allow us to investigate the side reactions during the aminolysis of cyclic carbonate (Scheme 2). The ${ }^{1} \mathrm{H}$ NMR proton of the UndCC-ester reaction with hexylamine is presented in Figure 3. The urethane signals appearance at $2.98 \mathrm{ppm}$ as well as the progressive disappearance of protons characterizing the cyclic carbonate $(5.06,4.63$ and $4.32 \mathrm{ppm})$ confirmed the hydroxyurethane formation. The major products from the model reaction were fully characterized using $1 D$ and 2D NMR spectroscopy (see Figure 3 and ESIt) and the ratio between primary and secondary alcohols could easily be calculated by integration of protons 2' and 2" respectively (Figure 3). Nevertheless, byproducts were also obtained during the model reaction between hexylamine and UndCC-ester. As it has already been described in prior studies, primary amines can react with urethane function to give ureas. ${ }^{9,} 41,42$ HSOC, HMBC and TOCSY NMR analysis proved the presence of urea functions in the mixture, thanks to the assignation of correlated $\mathrm{CH}-\mathrm{OH}$ (4.9 ppm) and $\mathrm{CH}_{2}-\mathrm{OH}$ (4.05-4.15 ppm), characterizing the diol obtained during the formation of urea (Scheme 2-(1)). Its existence was also confirmed by ESI analysis (see
ESI + ), as Caillol and coll. ${ }^{42}$ have recently done in a complete study about side reactions occurring during PHUs synthesis. A slight amount of oxazolidinones (Scheme 2-(3)) resulting from the dehydration of hydroxyurethanes was also detected by ESI analysis. Besides, it is also known that an ester function is prone to side reactions with primary amines. ${ }^{9}$ In our case, a few percentage of amidification was highlighted using ${ }^{1} \mathrm{H}$ NMR analysis, thanks to the distinctive labile proton of the amide at $7.6 \mathrm{ppm} .{ }^{13} \mathrm{C}$ NMR analysis (see $\mathrm{ESI}+$ ) could confirm the presence of the typical $\mathrm{O}=\mathrm{C}-\mathrm{O}$ carbon at $171.7 \mathrm{ppm}$. Percentages of major side reactions were calculated using specific labile $\mathrm{H}$ of urea $(6.7 \mathrm{ppm})$, urethane $(6.9 \mathrm{ppm})$ and amide $(7.6 \mathrm{ppm})$ functions (see ESI + ). The results are shown in the Table 3 for UndCC-ester and UndCC-ether at $50 \%$ of conversion in cyclic carbonates. Urea and amides were formed in relatively low proportions, as by-product percentages were not above $5 \%$ when $50 \%$ conversion in cyclic carbonates were reached, for all tested conditions. In the case of UndCC-ester, amidification reaction could be avoided by decreasing the temperature to $25^{\circ} \mathrm{C}$. Still at $65 \%$ conversion after $24 \mathrm{~h}$ at $25^{\circ} \mathrm{C}$, amide functions were not produced. However, urea formation appeared to be independent of the temperature and exhibited the same proportions at $25^{\circ} \mathrm{C}$ and $50^{\circ} \mathrm{C}$. For the two activated mono-cyclic carbonates, the ratio isomer $\mathrm{OH}$ I/isomer $\mathrm{OH}-\mathrm{II}$ was found to be in accordance with the DFT calculations (Table 1 ) and with the literature, which has reported a clear trend for the formation of secondary hydroxyl groups during the ring-opening of cyclic carbonates by amines. ${ }^{21}$ However, the pure aliphatic $5 \mathrm{CC}$ exhibited $60 \%$ of primary alcohols and this trend has already been observed by Maisonneuve et $a l^{11}$ in a prior study (50\% : $50 \%$ ). Additionally, lowering the temperature from $50^{\circ} \mathrm{C}$ to $25^{\circ} \mathrm{C}$ could lead to the slight increase of produced secondary hydroxyl groups.

\section{Poly(hydroxyurethane) synthesis}

After these kinetic experiments, ether- and ester- activated 5membered cyclic carbonates were tested in polymerization. PHUs were synthesized from Und-bcc-ether, Und-bcc-ester, Seb-bccester (bis((2-oxo-1,3-dioxolan-4-yl)methyl) decanedioate) and b5CC (4,4'-(tetradec-7-ene-1,14-diyl)bis(1,3-dioxolan-2-one)) with 1,10diaminodecane (10DA) and 1,3- cyclohexanebis(methylamine) (6CDA) as comonomers. The polymerizations were performed in DMF at $1 \mathrm{~mol}^{-\mathrm{L}^{-1}}$ at $70^{\circ} \mathrm{C}$ under nitrogen atmosphere without any catalyst. 


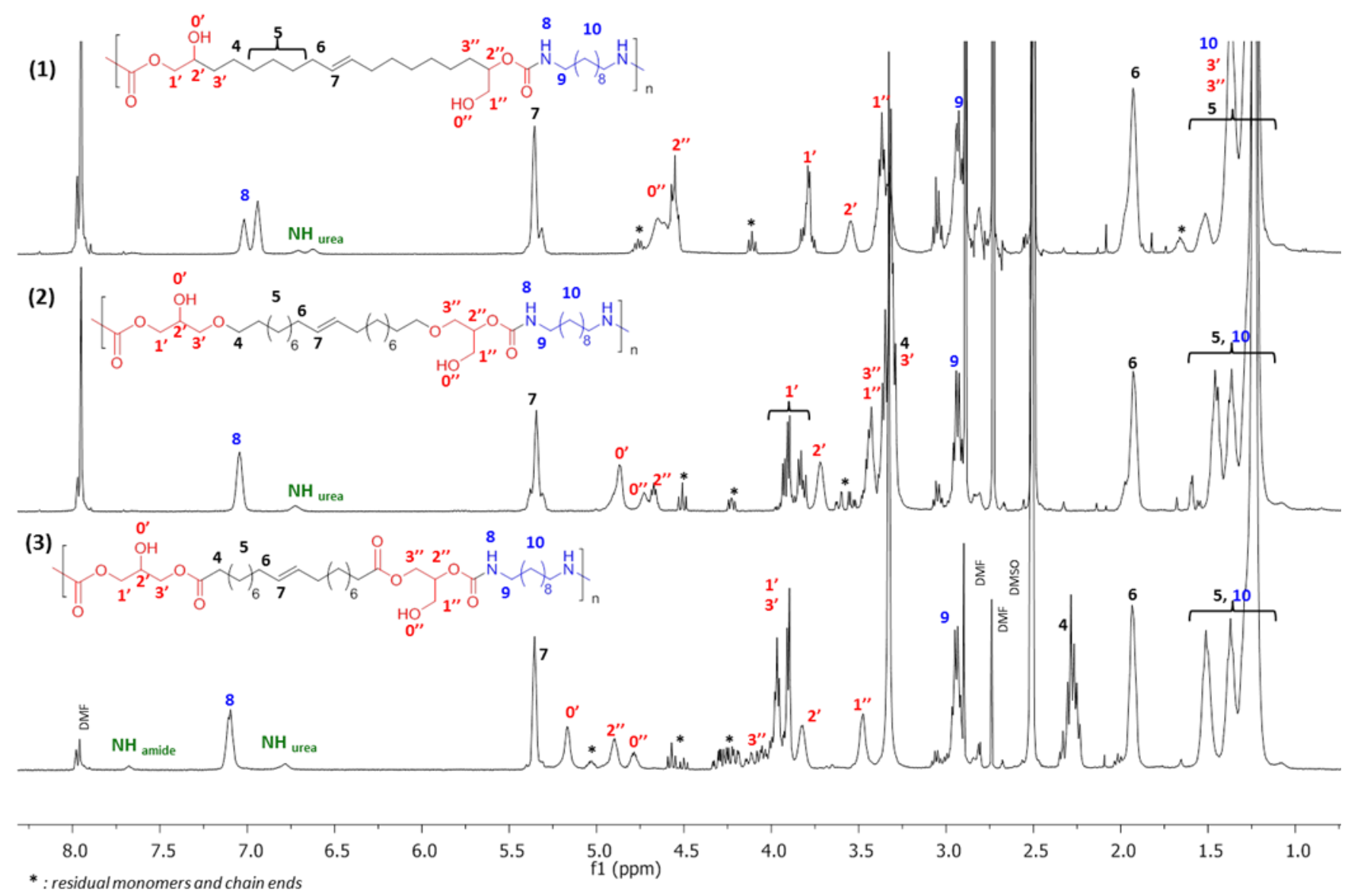

Figure 4 - Stacked ${ }^{1}$ H NMR spectra of (1) PHU 1, (2) PHU2 and (3) PHU 3 in DMSO-d6 at the end of the polymerizations.

Table 4 - Characterization of PHUs obtained from bis-cyclic carbonates and diamines, in DMF $\left(1 \mathrm{~mol} . \mathrm{L}^{-1}\right)$ at $70^{\circ} \mathrm{C}$ under nitrogen.

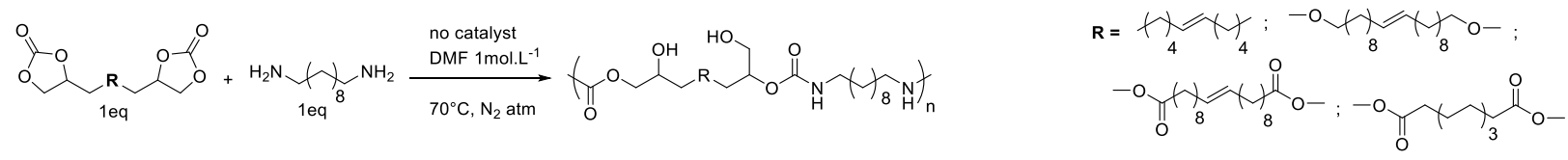

\begin{tabular}{|c|c|c|c|c|c|c|c|c|}
\hline PHU & Bis-CC & $\begin{array}{c}\text { Conversion } \\
24 \mathrm{~h} / 7 \mathrm{~d} \\
(\%) \\
\end{array}$ & $\begin{array}{c}\text { Ratio } \\
\mathrm{OH}_{1}: \mathrm{OH}_{\| I}{ }^{1}\end{array}$ & $\begin{array}{c}\text { Ratio } \\
\text { Urea /Amide/Urethane }{ }^{1,2}\end{array}$ & $\begin{array}{c}\mathrm{Mn}\left(\mathrm{g} \cdot \mathrm{mol}^{-1}\right) \\
{[\mathrm{D}]^{1}}\end{array}$ & $\begin{array}{c}\mathrm{T}_{\mathrm{g}} \\
\left({ }^{\circ} \mathrm{C}\right)^{\mathrm{a}}\end{array}$ & $\begin{array}{c}T_{f} \\
\left({ }^{\circ} \mathrm{C}\right)^{\mathrm{a}}\end{array}$ & $\begin{array}{l}T_{d 5 \%} \\
\left({ }^{\circ} \mathrm{C}\right)^{b}\end{array}$ \\
\hline 1 & $b 5 c c$ & $84 / 89$ & $59: 41$ & $11 / 0$ / 89 & 6000 [1.6] & -11 & - & 264 \\
\hline 2 & Und-bCC-ether & $90 / 90$ & $28: 72$ & $12 / 0 / 88$ & 7500 [1.7] & -26 & $54 / 77$ & 270 \\
\hline 3 & Und-bcC-ester & $88 / 91.5$ & 41:59 & $9.6 / 2.6 / 87.8$ & 12000 [1.9] & -10 & $69 / 83$ & 274 \\
\hline 4 & Seb-bcc-ester & nd /93.5 & $44: 56$ & $10.1 / 5.9 / 84$ & 13700 [3.7] & -17 & - & 251 \\
\hline 5 & Und-bCc-ester ${ }^{3}$ & nd /91.5 & $39: 61$ & $5.5 / 2.8 / 91.7$ & 8800 [1.8] & -10 & - & 253 \\
\hline
\end{tabular}

${ }^{1}$ : Determined at the end of the polymerization (7 days) ${ }^{2}$ : Determined using the relations $(E),\left(E^{\prime}\right)$ and ( $\left.E^{\prime \prime}\right)$ (see ESI $\left.{ }^{\dagger}\right) .{ }^{3}$ : polymerized with $6 c D A$

a: Determined by DSC at $10^{\circ} \mathrm{C} \cdot \mathrm{min}^{-1}$ from the second cycle. ; ${ }^{b}$ : Determined by TGA at $10^{\circ} \mathrm{C} \cdot \mathrm{min}^{-1}$ under nitrogen.;

Bulk polymerizations could not be achieved due to the high melting point of monomers. Besides, the temperature used was explained by solubility issues of the monomers in DMF at room temperature. Afterwards, the polymers were characterized without prior quenching and precipitation after 7 days. PHUs formation was followed by ${ }^{1} \mathrm{H}$ NMR with the disappearance of the signals in $\alpha$ position nearby the cycle in the ranges $4.2-4.6 \mathrm{ppm}$, and with the presence of the characteristic protons $\mathrm{CH}_{2}-\mathrm{NHC}(\mathrm{O}) \mathrm{O}$ at $2.98 \mathrm{ppm}$. The PHU formation was confirmed by FTIR thanks to the appearance of bands at $1663-1684 \mathrm{~cm}^{-1}$ and $1505-1545 \mathrm{~cm}^{-1}$, which are attributed to the urethane function. The formation of $-\mathrm{NH}$ and-
$\mathrm{OH}$ groups was verified by the presence of a wide signal between 3600 and $3100 \mathrm{~cm}^{-1}$. Besides, the chemical structures of PHU 1, PHU 2 and PHU 3 were elucidated thanks to ${ }^{1} \mathrm{H},{ }^{13} \mathrm{C}$ NMR and $2 \mathrm{D}$ NMR (COSY, HSQC) as illustrated in Figure 4. SEC data given in Table 4 presents molar masses in the range 6000 to $13700 \mathrm{~g} . \mathrm{mol}^{-1}$ with dispersity comprised between 1.6 and 3.7. In all cases, more secondary hydroxyl groups were formed during PHU synthesis as it 


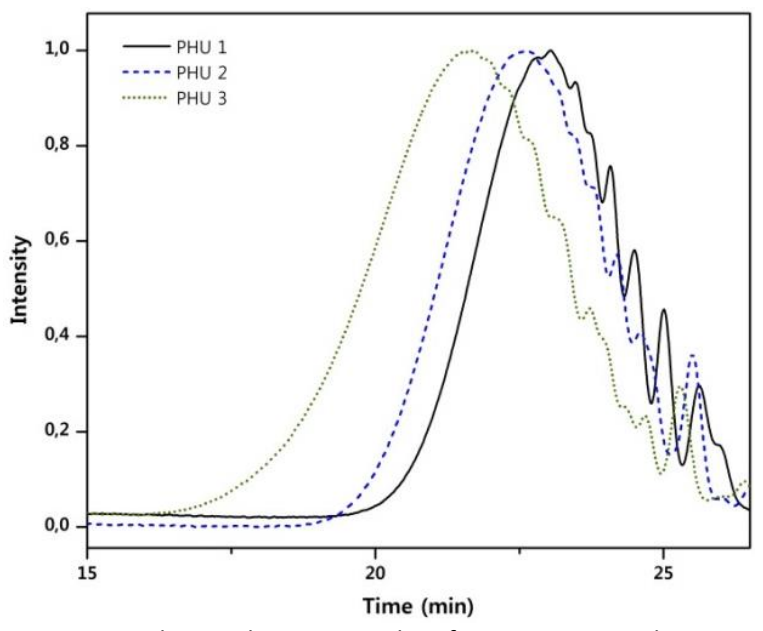

Figure 5 - Size exclusion chromatography of PHU1, PHU2 and PHU3 at the end of the polymerization (DMF, LiBr, PS standrads).

has already been noticed in the prior art. ${ }^{25,43,44}$ As expected, the SEC chromatogram depicted in Figure 5 and the data given in Table 4 highlight the high molar masses obtained for PHU 2 ( $M n=7500$ g. mol $\left.{ }^{-1}\right)$ and PHU $3\left(\mathrm{Mn}=12000 \mathrm{~g} \cdot \mathrm{mol}^{-1}\right)$, using respectively UndCCether and UndCC-ester as bis-cyclic carbonate; contrarily to PHU 1 which exhibits a molar mass of $6000 \mathrm{~g} \cdot \mathrm{mol}^{-1}$. The latest results corroborate the prior kinetic measurements and the enhancement of the reactivity by adding ether or ester moieties nearby the cyclic carbonate.

In view of the equivalent structures and molar masses of Und-bCcether and Und-bCC-ester, the polymerization SEC profiles confirm the lower reactivity of the ether-activated dimer.

However, the formation of urea was observed in all cases (Table 4) and demonstrated the inevitable side reaction highlighted in the kinetic measurement part. MALDI-TOF analysis supports the formation of urea at the chain ends and inside the PHU $\mathbf{3}$ backbone (see ESIt). Moreover, the amidification reaction, taking place during Und-bCC-ester polymerization, was detected with the characteristic labile proton of the amide $(7.6 \mathrm{ppm})$ and by mean of MALDI-TOF analysis. Und-bCC-ester showed in polymerization a similar proportion of formed-amides than UndCC-ester in model reaction.

The effect of the cyclic-carbonate structure on properties was investigated through PHU $\mathbf{3}$ and PHU $\mathbf{4}$ formation using respectively a $\mathrm{C}_{20}$ and a $\mathrm{C}_{10}$-ester activated dimer. PHU 4 made with the shorter Seb-CC-ester displayed a molar mass of $13700 \mathrm{~g} \cdot \mathrm{mol}^{-1}$ with a dispersity of 3.7 that support its high reactivity. Nonetheless, the PHU 4 demonstrated a proportion of $5.9 \%$ of amide functions, probably due to the higher density of ester linkages along the polymer backbone. The amidification reaction tended to decrease molar masses and to increase the dispersity by cleaving the polymer chains.

The thermal properties of the as-prepared PHUs were examined by DSC and TGA, using a prior isothermal procedure at $160^{\circ} \mathrm{C}$ for 15 min in order to remove DMF traces from the samples. The PHUs were semi-crystalline or amorphous depending on the monomer used. Relatively low $\mathrm{Tg}$ in the ranges -26 to $-10^{\circ} \mathrm{C}$ conferred by the aliphatic monomer backbones were obtained. PHU 2 and PHU 3 showed two melting peaks (see ESI ${ }^{\dagger}$ ) that could reveal two types of crystalline clusters or a segregation between soft and hard segments. Moreover, a cold recrystallization is observed at $33^{\circ} \mathrm{C}$ for the PHU 3 due to the possible reorganization of polymer chains above the $\mathrm{Tg}$. When the less reactive cyclic diamine $6 \mathrm{cDA}^{45}$ was used as comonomer with Und-bCC-ester, molar masses were significantly lowered from 12000 to $8800 \mathrm{~g} \cdot \mathrm{mol}^{-1}$ and no enhancement of thermal properties was detected. Besides, the ether-rotula structure of Und-bCC-ether conferred to PHU 2 a Tg of $-26^{\circ} \mathrm{C}$, whereas PHU 3 displayed a higher Tg imparted with a harder segmented monomer.

In addition, PHU 4 was expected to reach higher $\operatorname{Tg}$ than $-17^{\circ} \mathrm{C}$, still this feature was assigned to the possible PHU plastification by shorter chains arising from amidification reaction.

\section{Conclusions}

In conclusion, activated 5-membered cyclic carbonates were synthesized from glycerol carbonate, epichlorohydrin and fatty acid derivatives. The two routes imply both 3 steps and the monomers result from green processes such as the carbonation of epoxides and glycerol with $\mathrm{CO}_{2}$, or the metathesis reaction which enable the use of mild conditions. ${ }^{46}$ Focusing on the epichlorohydrin route, the inherent toxicity of this compound stands in contradiction with the production of isocyanate-free polyurethanes, which avoids the use of toxic phosgene. Nevertheless, the nucleophilic substitution between alcohols and epichlorohydrin has been extensively used for bringing an ether moiety nearby the cyclic carbonate in mild conditions. ${ }^{26,27,29,34,35}$ On the other hand, the glycerol route finds its limitation in the use of the reactive and dangerous thionyl chloride, especially in industrial processes.

The ester-activated monomers displayed a similar reactivity than 6membered cyclic carbonates in model reaction with hexylamine. The lipidic activated 5-membered bis-cyclic carbonates were then successfully polymerized, with improved reactivity and molar masses, thanks to the insertion of a heteroatom in $\beta$ position nearby the cyclic carbonate. Amidification side reaction occurring with ester-activated monomers could be controlled by decreasing the temperature or by minimizing the ester function content along the polymer backbone. Nevertheless, urea formation is unavoidable and remains the major side-reaction for both PHUs and PUs synthesis.

\section{Acknowledgements}

This work was performed, in partnership with the SAS PIVERT, within the frame of the French Institute for the Energy Transition (Institut pour la Transition Energétique - ITE) P.I.V.E.R.T. (www.institut-pivert.com) selected as an Investment for the Future ("Investissements d'Avenir"). This work was supported, as part of the Investments for the Future, by the French Government under the reference ANR-001-01. Computer time for this study was provided by the computing facilities MCIA (Mésocentre de Calcul Intensif Aquitain) of the Université de Bordeaux and of the Université de Pau et des Pays de l'Adour.

\section{Notes and references}

¥ Footnotes relating to the main text should appear here. These might include comments relevant to but not central to the matter under discussion, limited experimental and spectral data, and crystallographic data.

1. J. Guan, Y. Song, Y. Lin, X. Yin, M. Zuo, Y. Zhao, X. Tao and Q. Zheng, Industrial \& Engineering Chemistry Research, 2011, 50, 6517-6527.

2. M. S. Kathalewar, P. B. Joshi, A. S. Sabnis and V. C. Malshe, RSC Advances, 2013, 3, 4110-4129.

3. B. Nohra, L. Candy, J.-F. Blanco, C. Guerin, Y. Raoul and Z. Mouloungui, Macromolecules, 2013, 46, 3771-3792. 
4. H. Blattmann, M. Fleischer, M. Bähr and R. Mülhaupt, Macromolecular Rapid Communications, 2014, 35, 1238-1254.

5. O. Figovsky, L. Shapovalov, A. Leykin, O. Birukova and R. Potashnikova, Chemistry and Chemical Technology, 2013, 7, 7987.

6. G. Rokicki, P. G. Parzuchowski and M. Mazurek, Polymers for Advanced Technologies, 2015, 26, 707-761.

7. L. Maisonneuve, O. Lamarzelle, E. Rix, E. Grau and H. Cramail, Chemical Reviews, 2015, 115, 12407-12439.

8. L. De Espinosa and M. A. R. Meier, European Polymer Journal, 2011, 47, 837-852.

9. A. Boyer, E. Cloutet, T. Tassaing, B. Gadenne, C. Alfos and H. Cramail, Green Chemistry, 2010, 12, 2205-2213.

10. L. Maisonneuve, T. Lebarbe, E. Grau and H. Cramail, Polymer Chemistry, 2013, 4, 5472-5517.

11. L. Maisonneuve, A. S. More, S. Foltran, C. Alfos, F. Robert, Y. Landais, T. Tassaing, E. Grau and H. Cramail, RSC Advances, 2014, 4, 25795-25803.

12. V. Besse, G. Foyer, R. Auvergne, S. Caillol and B. Boutevin, Journal of Polymer Science Part A: Polymer Chemistry, 2013, 51, 3284-3296.

13. H. Tomita, F. Sanda and T. Endo, Journal of Polymer Science Part A: Polymer Chemistry, 2001, 39, 860-867.

14. H. Tomita, F. Sanda and T. Endo, Journal of Polymer Science Part A: Polymer Chemistry, 2001, 39, 4091-4100.

15. H. Tomita, F. Sanda and T. Endo, Journal of Polymer Science Part A: Polymer Chemistry, 2000, 39, 162-168.

16. Y. He, H. Keul and M. Möller, Reactive and Functional Polymers, 2011, 71, 175-186.

17. B. Nohra, L. Candy, J.-F. Blanco, Y. Raoul and Z. Mouloungui, European Journal of Lipid Science and Technology, 2012, 115, 111-122.

18. L. Maisonneuve, A.-L. Wirotius, C. Alfos, E. Grau and H. Cramail, Polymer Chemistry, 2014, 5, 6142-6147.

19. N. Kihara, Y. Kushida and T. Endo, Journal of Polymer Science Part A: Polymer Chemistry, 1996, 34, 2173-2179.

20. N. Kihara and T. Endo, Journal of Polymer Science Part A Polymer Chemistry, 1993, 31, 2765-2773.

21. A. Steblyanko, W. Choi, F. Sanda and T. Endo, Journal of Polymer Science Part A: Polymer Chemistry, 2000, 38, 23752380.

22. M.-R. Kim, H.-S. Kim, C.-S. Ha, D.-W. Park and J.-K. Lee, Journal of Applied Polymer Science, 2001, 81, 2735-2743.

23. S. Benyahya, B. Boutevin, S. Caillol, V. Lapinte and J.-P. Habas, Polymer International, 2012, 61, 918-925.

24. H. Tomita, F. Sanda and T. Endo, Journal of Polymer Science Part A: Polymer Chemistry, 2001, 39, 3678-3685.

25. G. Proempers, H. Keul and H. Hoecker, Designed Monomers and Polymers, 2005, 8, 547-569.

26. V. Besse, R. Auvergne, S. Carlotti, G. Boutevin, B. Otazaghine, S. Caillol, J.-P. Pascault and B. Boutevin, Reactive and Functional Polymers, 2013, 73, 588-594.

27. M. Fleischer, H. Blattmann and R. Mulhaupt, Green Chemistry, 2013, 15, 934-942.

28. H. Keul, S. Mommer and M. Möller, European Polymer Journal, 2013, 49, 853-864.

29. Q. Chen, K. Gao, C. Peng, H. Xie, Z. K. Zhao and M. Bao, Green

Chemistry, 2015, 17, 4546-4551.
30. J. L. J. van Velthoven, L. Gootjes, D. S. van Es, B. A. J. Noordover and J. Meuldijk, European Polymer Journal, 2015, 70, 125-135.

31. Y. He, V. Goel, H. Keul and M. Möller, Macromolecular Chemistry and Physics, 2010, 211, 2366-2381.

32. M. J. Frisch, G. W. Trucks, H. B. Schlegel, G. E. Scuseria, M. A. Robb, J. R. Cheeseman, G. Scalmani, V. Barone, B. Mennucci, G. A. Petersson, H. Nakatsuji, M. Caricato, X. Li, H. P. Hratchian, A. F. Izmaylov, J. Bloino, G. Zheng, J. L. Sonnenberg, M. Hada, M. Ehara, K. Toyota, R. Fukuda, J. Hasegawa, M. Ishida, T. Nakajima, Y. Honda, O. Kitao, H. Nakai, T. Vreven, J. A. Montgomery Jr., J. E. Peralta, F. Ogliaro, M. J. Bearpark, J. Heyd, E. N. Brothers, K. N. Kudin, V. N. Staroverov, R. Kobayashi, J. Normand, K. Raghavachari, A. P. Rendell, J. C. Burant, S. S. Iyengar, J. Tomasi, M. Cossi, N. Rega, N. J. Millam, M. Klene, J. E. Knox, J. B. Cross, V. Bakken, C. Adamo, J. Jaramillo, R. Gomperts, R. E. Stratmann, O. Yazyev, A. J. Austin, R. Cammi, C. Pomelli, J. W. Ochterski, R. L. Martin, K. Morokuma, V. G. Zakrzewski, G. A. Voth, P. Salvador, J. J. Dannenberg, S. Dapprich, A. D. Daniels, Ö. Farkas, J. B. Foresman, J. V. Ortiz, J. Cioslowski and D. J. Fox, Gaussian, Inc., Wallingford, CT, USA, 2009.

33. Solvay, EPICEROL ${ }^{\circledR}$ Solvay technology protected by numerous patents.

34. B. Ochiai, K. Koda and T. Endo, Journal of Polymer Science Part A: Polymer Chemistry, 2012, 50, 47-51.

35. M. Fache, E. Darroman, V. Besse, R. Auvergne, S. Caillol and B. Boutevin, Green Chemistry, 2014, 16, 1987-1998.

36. M. Helou, J.-F. Carpentier and S. M. Guillaume, Green Chemistry, 2011, 13, 266-271.

37. L. Annunziata, A. K. Diallo, S. Fouquay, G. Michaud, F. Simon, J.-M. Brusson, J.-F. Carpentier and S. M. Guillaume, Green Chemistry, 2014, 16, 1947-1956.

38. C. Carre, L. Bonnet and L. Averous, RSC Advances, 2014, 4, 54018-54025.

39. C. Duval, N. Kébir, R. Jauseau and F. Burel, Journal of Polymer Science Part A: Polymer Chemistry, 2015, 10.1002/pola.27908.

40. S. Bigot, M. Daghrir, A. Mhanna, G. Boni, S. Pourchet, L. Lecamp and L. Plasseraud, European Polymer Journal, 2016, 74, 26-37.

41. T. Bürgel, M. Fedtke and M. Franzke, Polymer Bulletin, 1993, 30, 155-162.

42. V. Besse, F. Camara, F. Méchin, E. Fleury, S. Caillol, J.-P. Pascault and B. Boutevin, European Polymer Journal, 2015, 71, 111.

43. M. Blain, L. Jean-Gerard, R. Auvergne, D. Benazet, S. Caillol and B. Andrioletti, Green Chemistry, 2014, 16, 4286-4291.

44. B. Ochiai, S. Yuriko and E. Takeshi, Journal of Polymer Science, Part A: Polymer Chemistry, 2009, 47, 4629-4635.

45. C. D. Diakoumakos and D. L. Kotzev, Macromolecular Symposia, 2004, 216, 37-46.

46. O. Türünç and M. A. R. Meier, European Journal of Lipid Science and Technology, 2012, 115, 41-54. 


\title{
SUPPLEMENTARY INFORMATION
}

\section{Activated Lipidic Cyclic Carbonates for Non-Isocyanate Polyurethane Synthesis.}

\author{
$\underline{\text { Océane Lamarzelle }}^{\mathrm{a}, \mathrm{b}}$, Pierre-Luc Durand ${ }^{\mathrm{a}, \mathrm{b}}$, Anne-Laure Wirotius ${ }^{\mathrm{a} b}$, Guillaume Chollet ${ }^{\mathrm{c}}$, \\ Etienne Grau ${ }^{a, b}$ and Henri Cramail a,b* \\ ${ }^{a}$ Univ. Bordeaux, LCPO, UMR 5629, F-33600, Pessac, France, ${ }^{b}$ CNRS, LCPO, UMR 5629, F-33600, \\ Pessac, France, ${ }^{c}$ ITERG, F-33600, Pessac, France
}

\section{Supplementary Information Contents}

1. Graphical data of mono-cyclic carbonates and bis-cyclic carbonates

1.1. Und-bCC-ether synthesis

1.2. Und-bCC-ester synthesis

1.3. Seb-bcC-ester synthesis

1.4. OleyICC-ether synthesis

1.5. OleyICC-ester synthesis

1.6. Oley/CC-ester synthesis

1.7. b5CC synthesis

1.8. Und-6CC synthesis

1.9. Oleyl-6CC synthesis

2. Graphical data of kinetic measurements

3. Graphical data of Poly(hydroxyurethane)s 
$\underbrace{\mathrm{O}}$
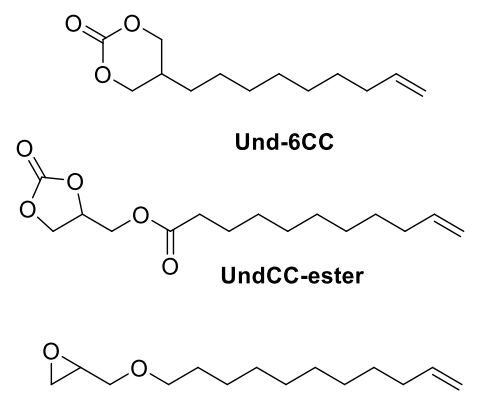

Und-epoxide

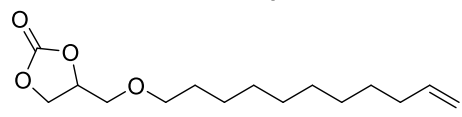

UndCC-ether
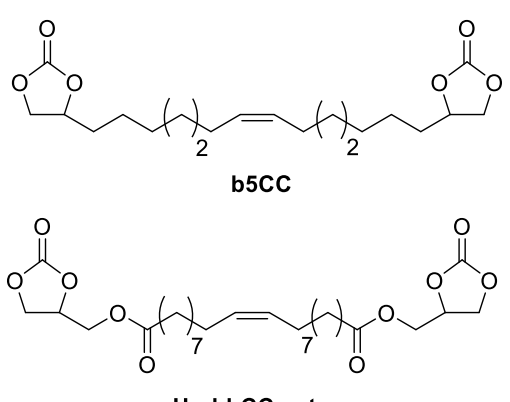

Und-bcC-ester

$\mathrm{H}_{2} \mathrm{~N} \smile \gamma_{8} \mathrm{NH}_{2}$

10DA
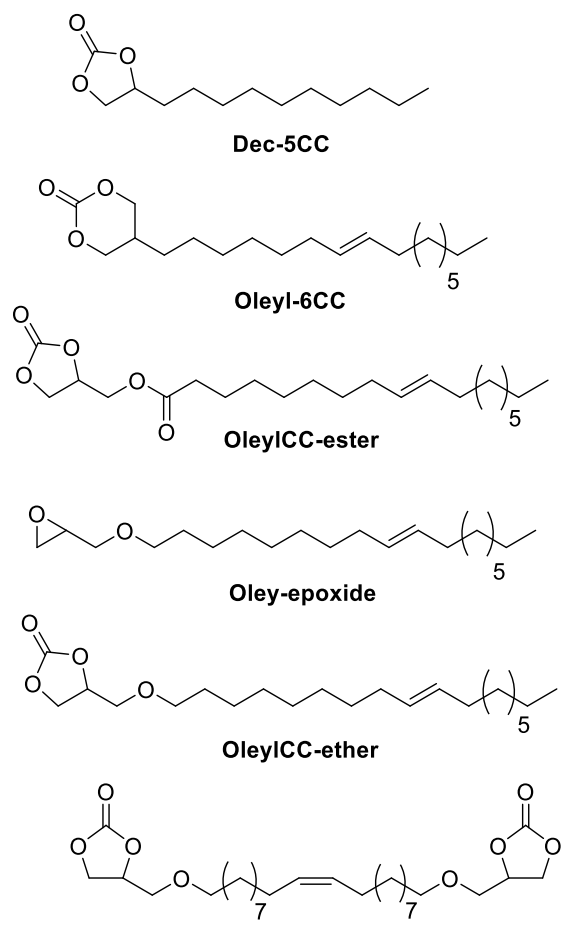

Und-bCC-ether

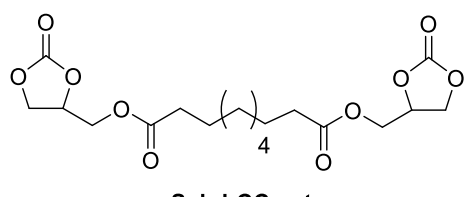

Seb-bCC-ester

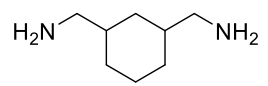

6cDA

ESI Figure 1- Abbreviations and structures of epoxides, mono-cyclic carbonates, bis-cyclic carbonates and diamines. 
1. Graphical data of mono-cyclic carbonates and bis-cyclic carbonates

\subsection{Und-bCc-ether synthesis}

(1)<smiles>C=CCCCCCCCCOCCOCCOCCOCCOCCO</smiles>

Und-epoxide
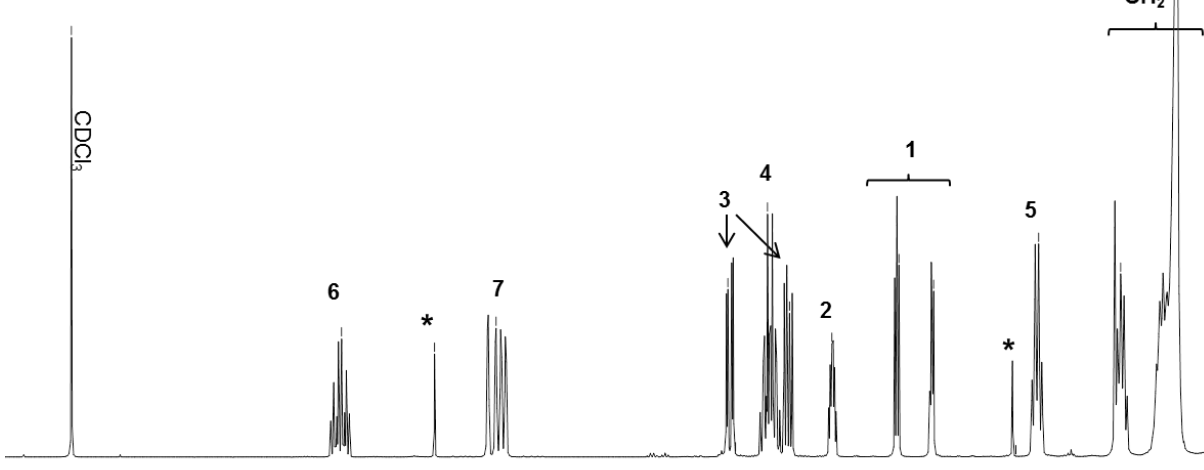

$\begin{array}{lllllll}7.5 & 7.0 & 6.5 & 6.0 & 5.5 & 5.0 & \begin{array}{l}4.5 \\ \mathrm{f} 1\end{array}(\mathrm{ppm}) \\ 4.0\end{array}$

(2)

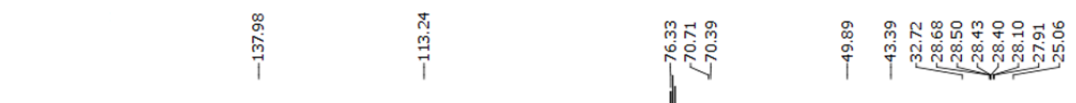<smiles>C=CCCCCCCCCC(C)OCC1CO1</smiles>

(2)
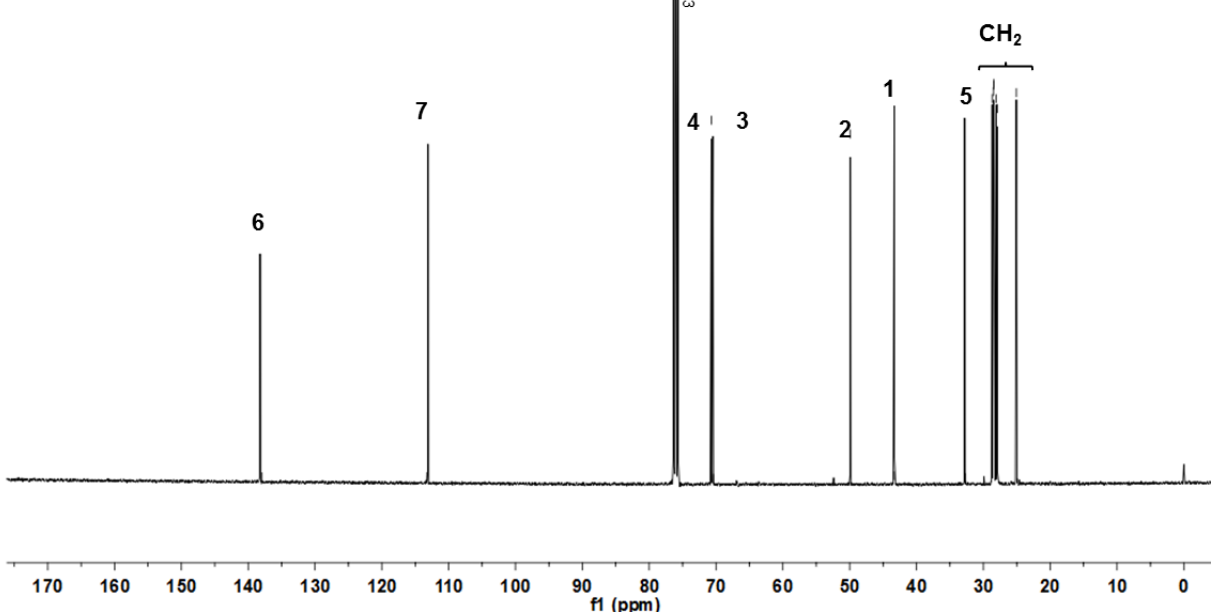

ESI Figure 2- Evidence of the formation of Und-epoxide: $(1)^{1} \mathrm{H} N M R$ and $(2)^{13} \mathrm{CNMR}$. (Analysis performed in $C D C{ }_{3}$.) $\left({ }^{*}\right.$ : residual solvents) 


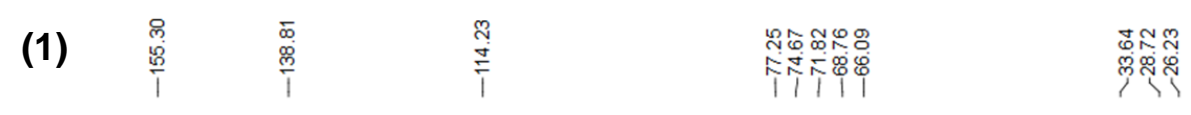<smiles>C=CCCCCCCCCCOCC(C)OCC1OC(=O)OC1C</smiles>

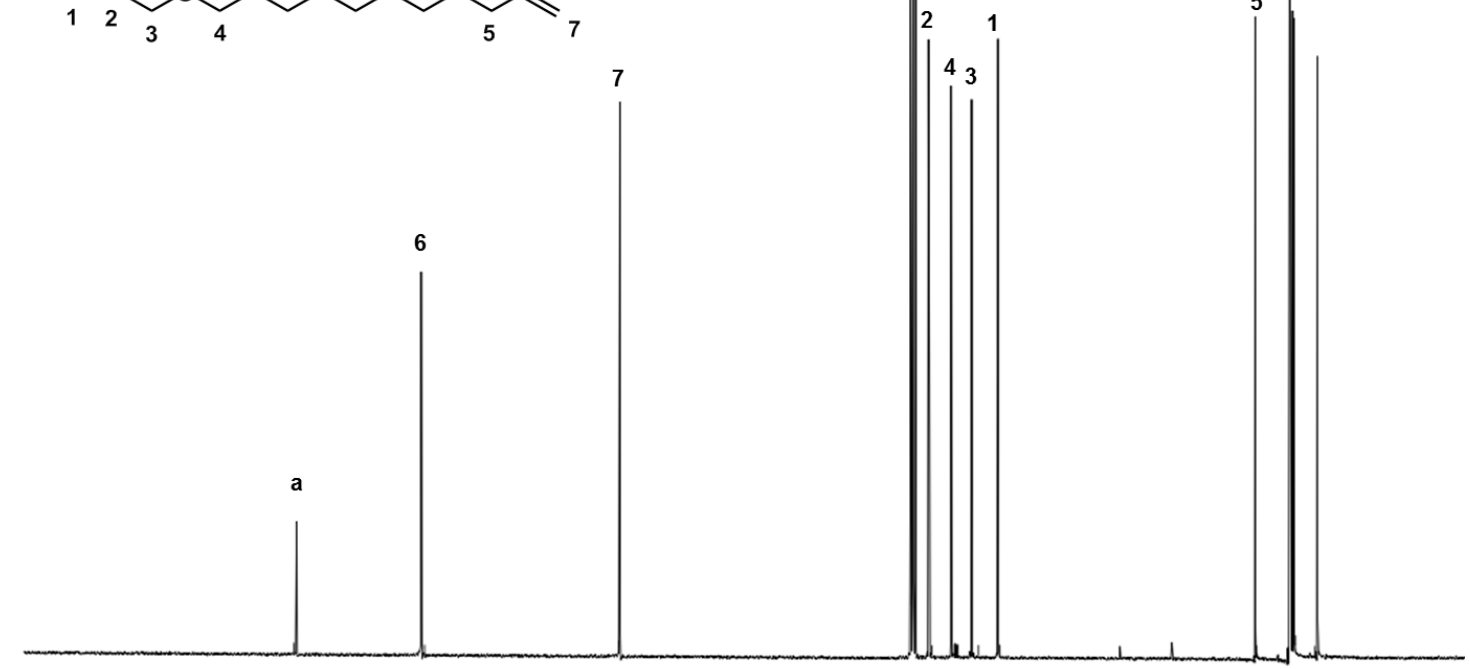

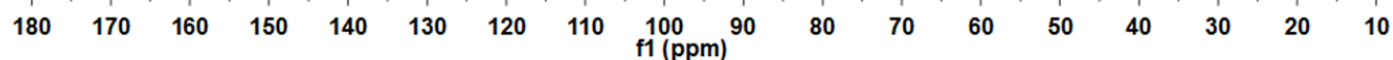

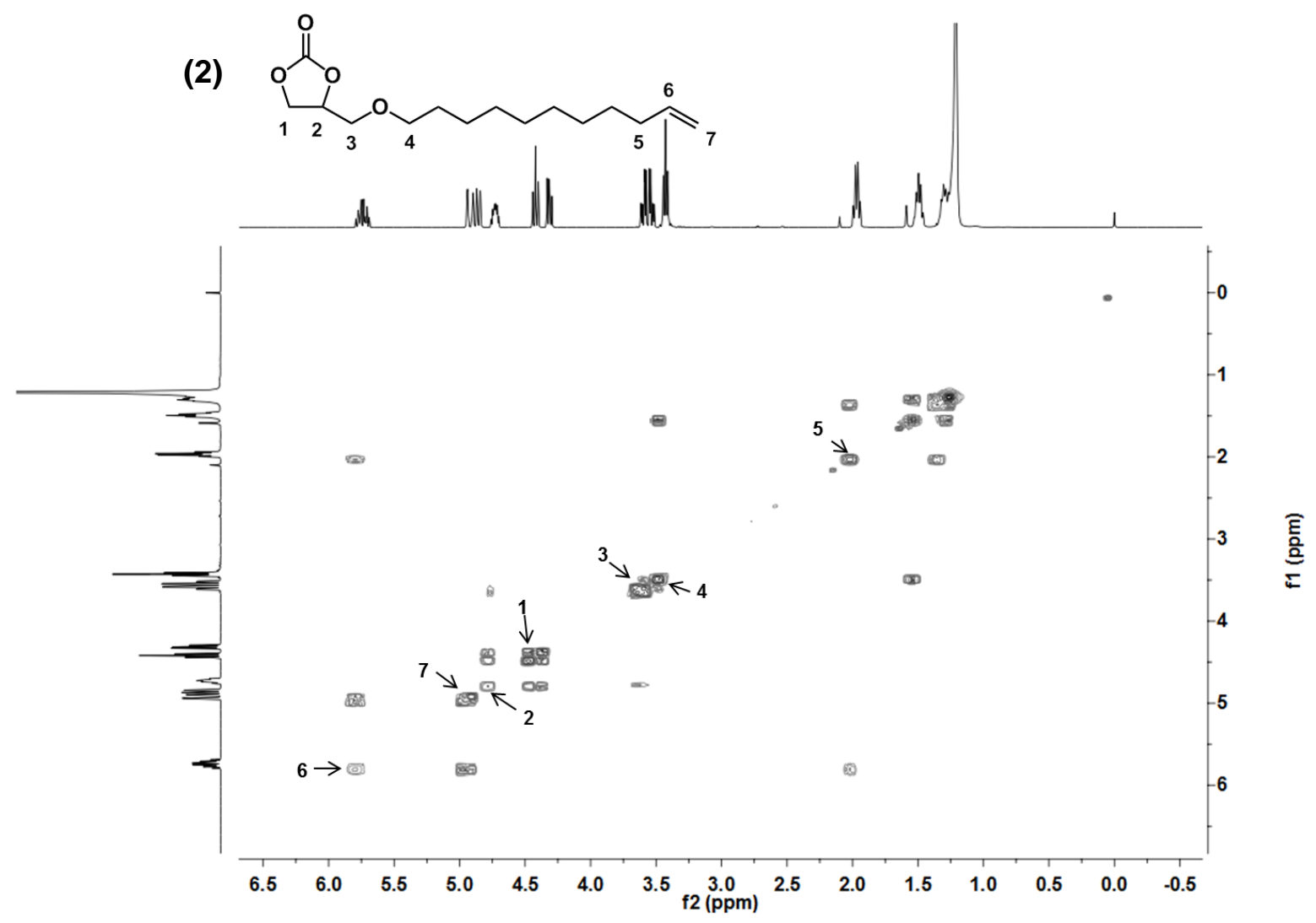




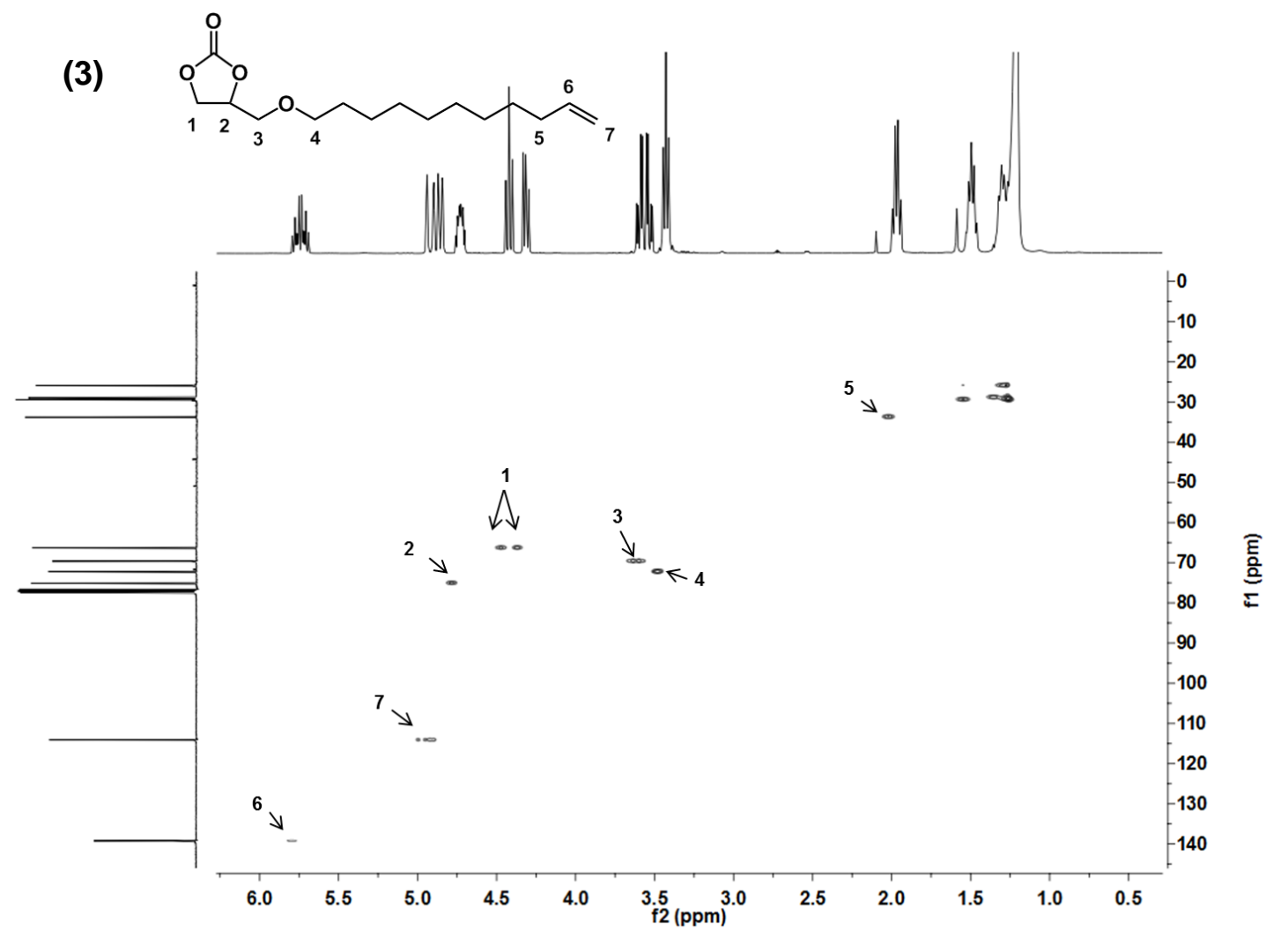

ESI Figure 3 - NMR analysis of purified UndCC-ether: (1) ${ }^{13} \mathrm{C} \mathrm{NMR,}(2){ }^{1} \mathrm{H}-{ }^{1} \mathrm{H}$ COSY NMR and (3) ${ }^{1} \mathrm{H}-{ }^{13} \mathrm{C} \mathrm{HSQC-NMR}$. (Analysis performed in $\mathrm{CDCl}_{3 .}$ )

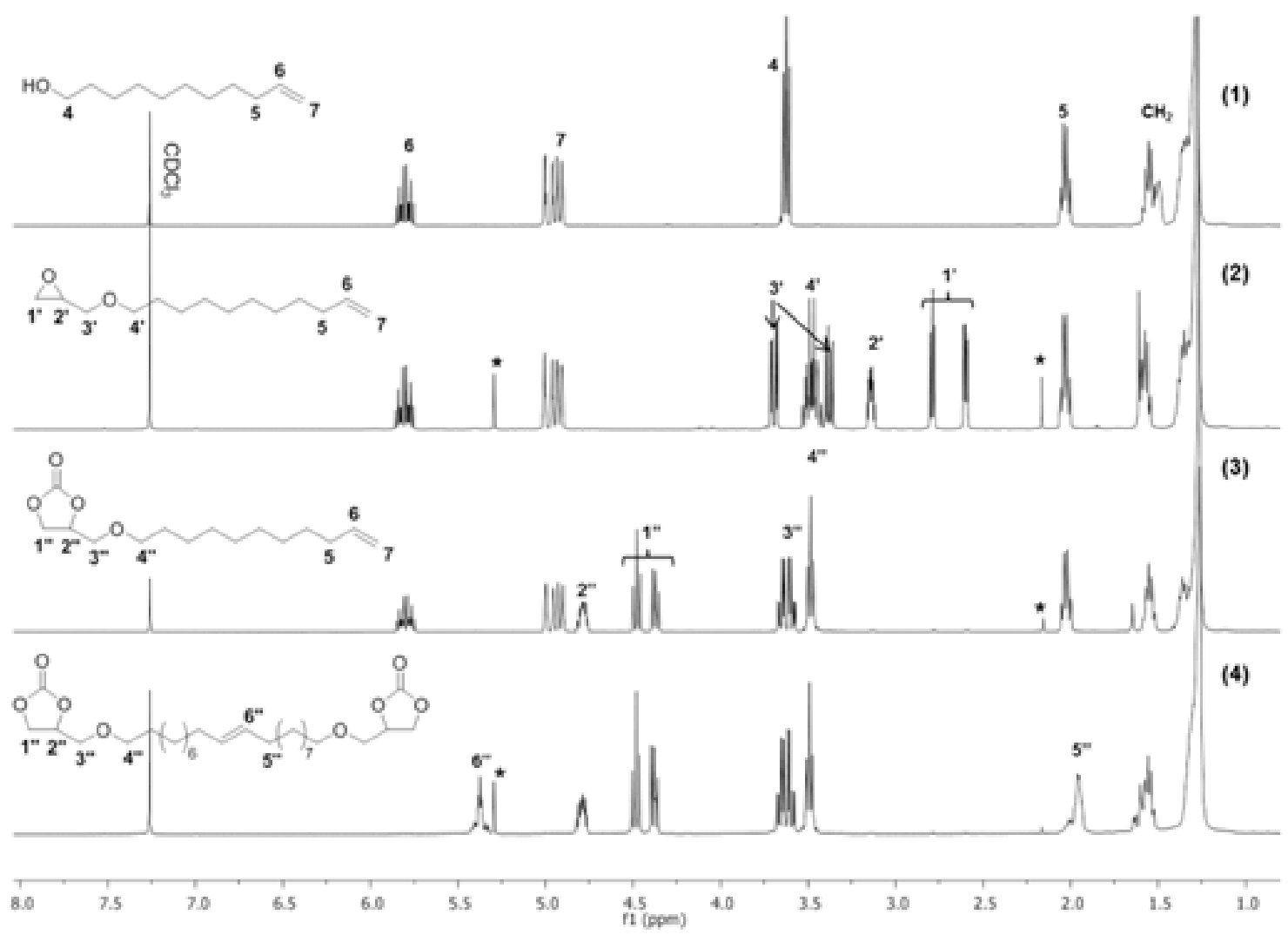

ESI Figure 4 - Stacked ${ }^{1}$ H NMR spectra of (1) undecen-1-ol, (2) Und-epoxide, (3) UndCC-ether and (4) Und-bCC-ether (All analyses were performed in $\mathrm{CDCl}_{3 .}$ ) (* : residual solvents) 
$\mathrm{uV}$

Chromatogram

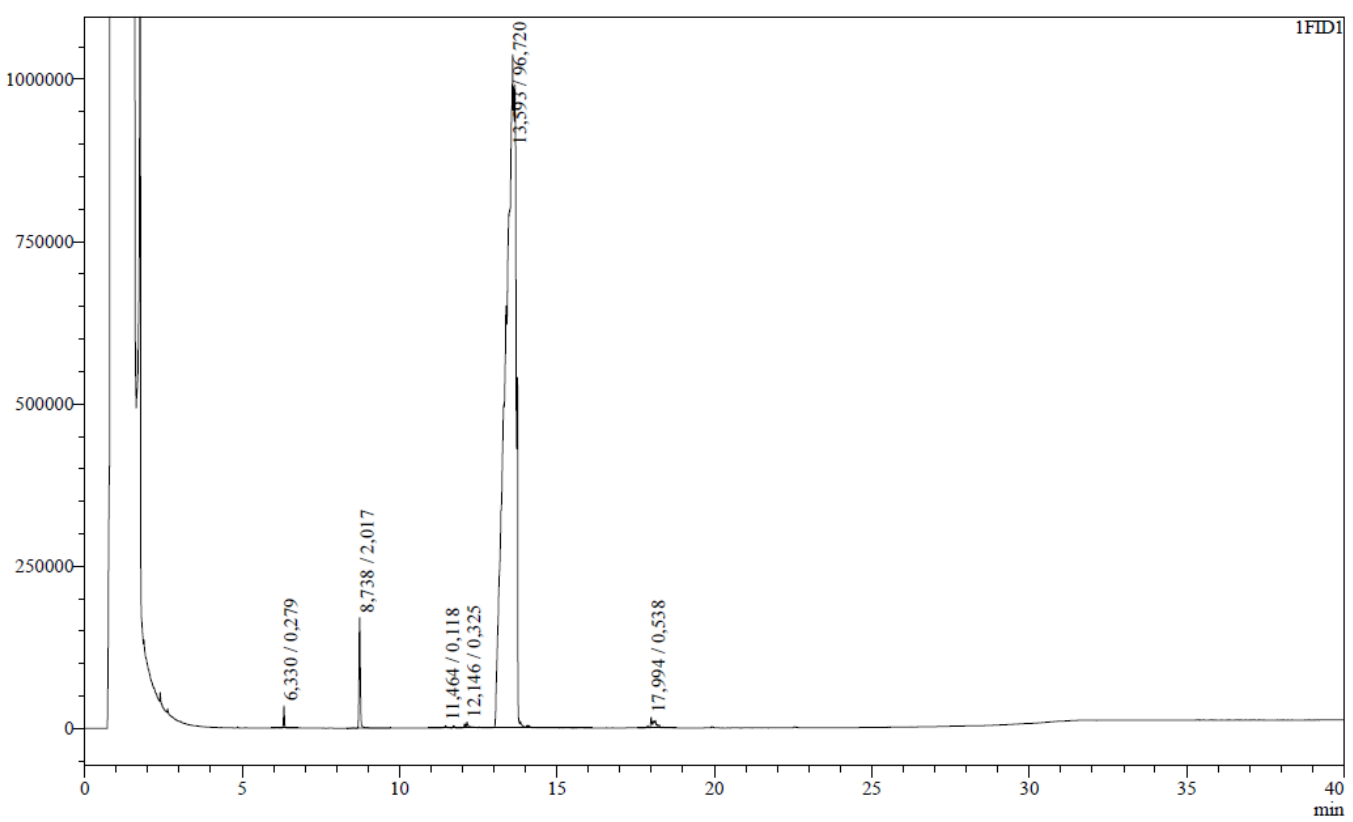

ESI Figure 5- Gas chromatography of UndCC-ether (96,7\% purity).

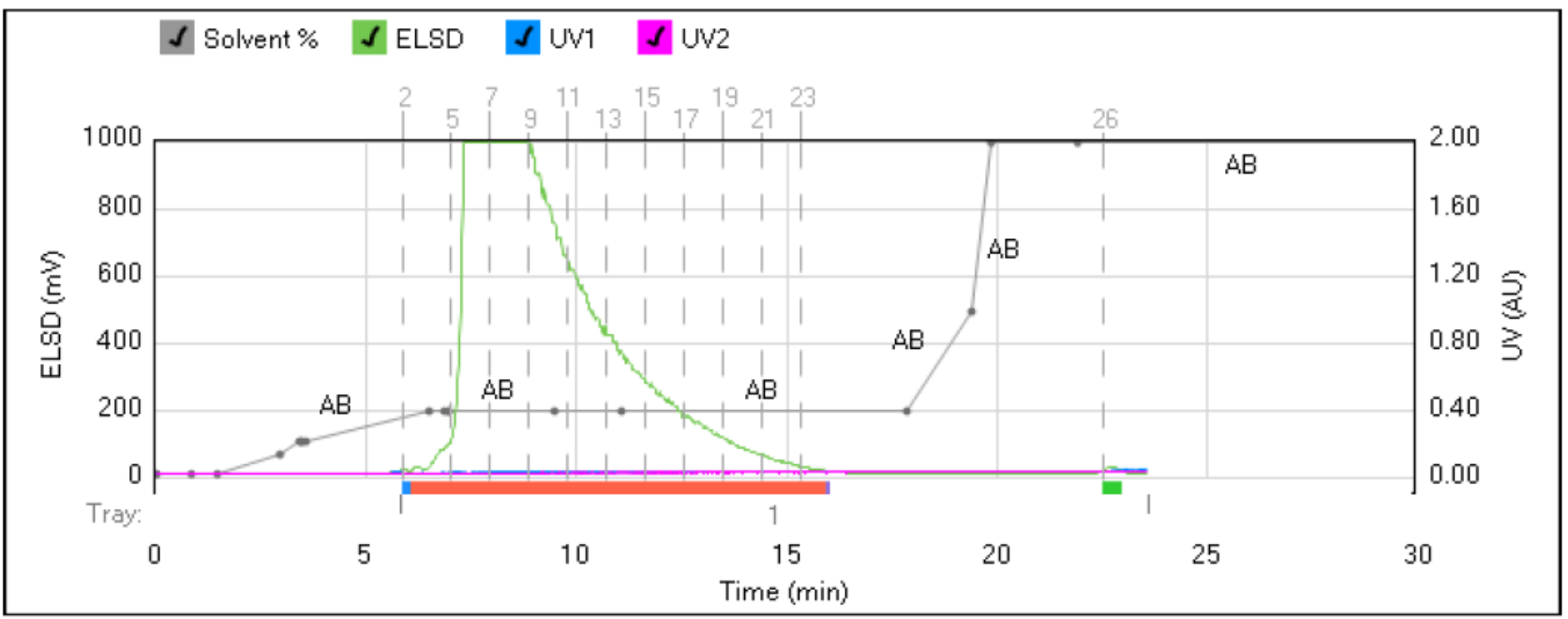

ESI Figure 6- Flash chromatogramm of UndCC-ether. 


\subsection{Und-bCC-ester synthesis}

(1)

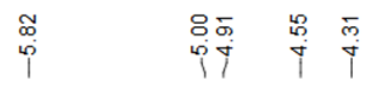<smiles>C=CCCCCCCCCC(=O)OCC1COC(=O)O1</smiles>

$\stackrel{8}{\frac{\Omega}{\omega}}$

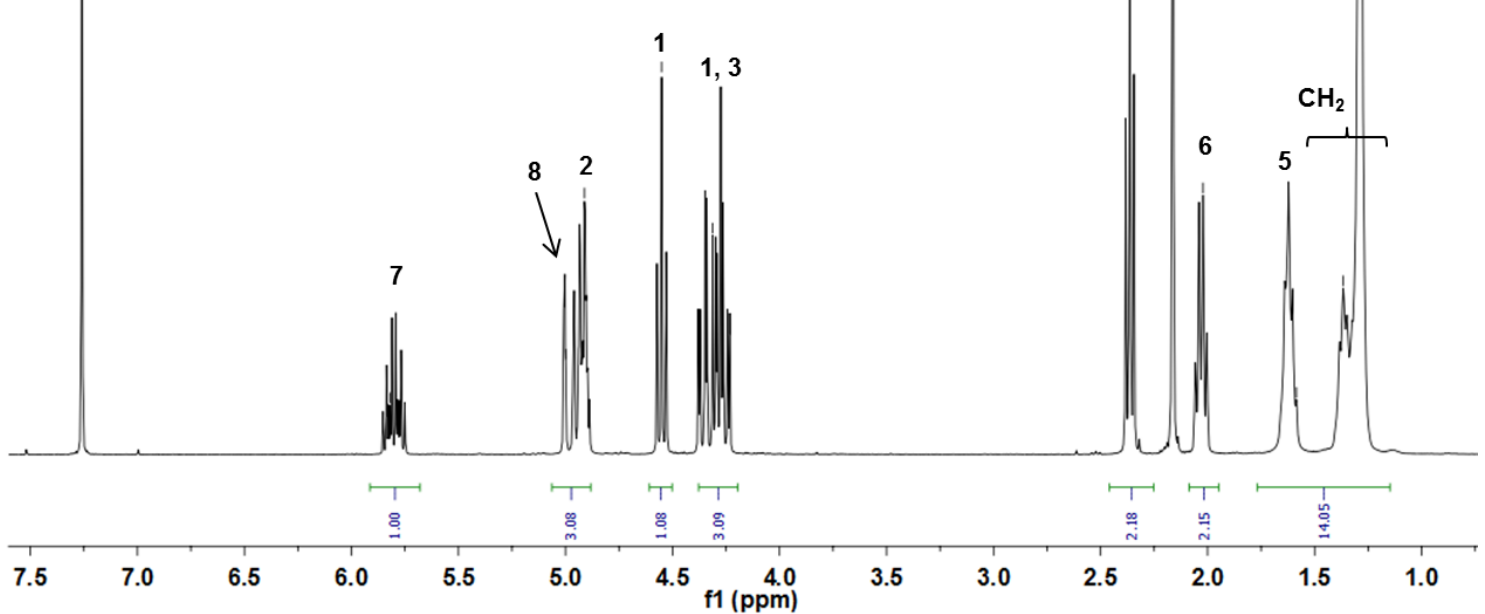

(2)
$\stackrel{\infty}{\stackrel{0}{2}}$

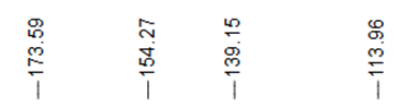<smiles>C=CCCCCCCCCC(=O)OCC1OC(=O)OC1C</smiles>
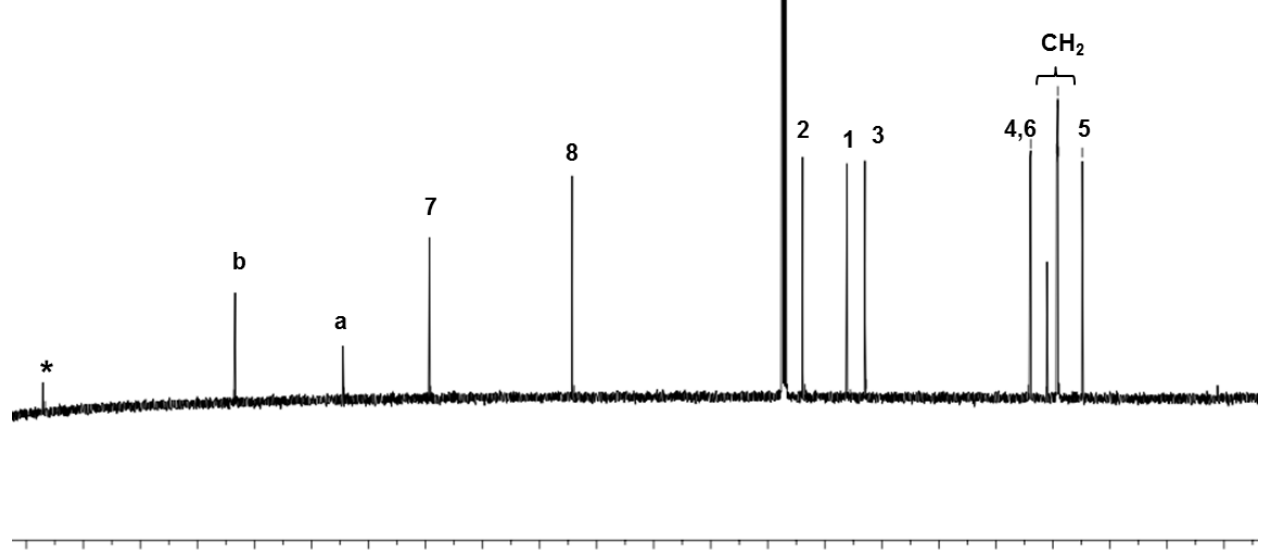

210
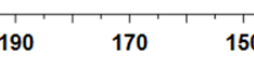

110 f1 (ppm)

$\begin{array}{lllllllllll}90 & 80 & 70 & 60 & 50 & 40 & 30 & 20 & 10 & 0\end{array}$ 

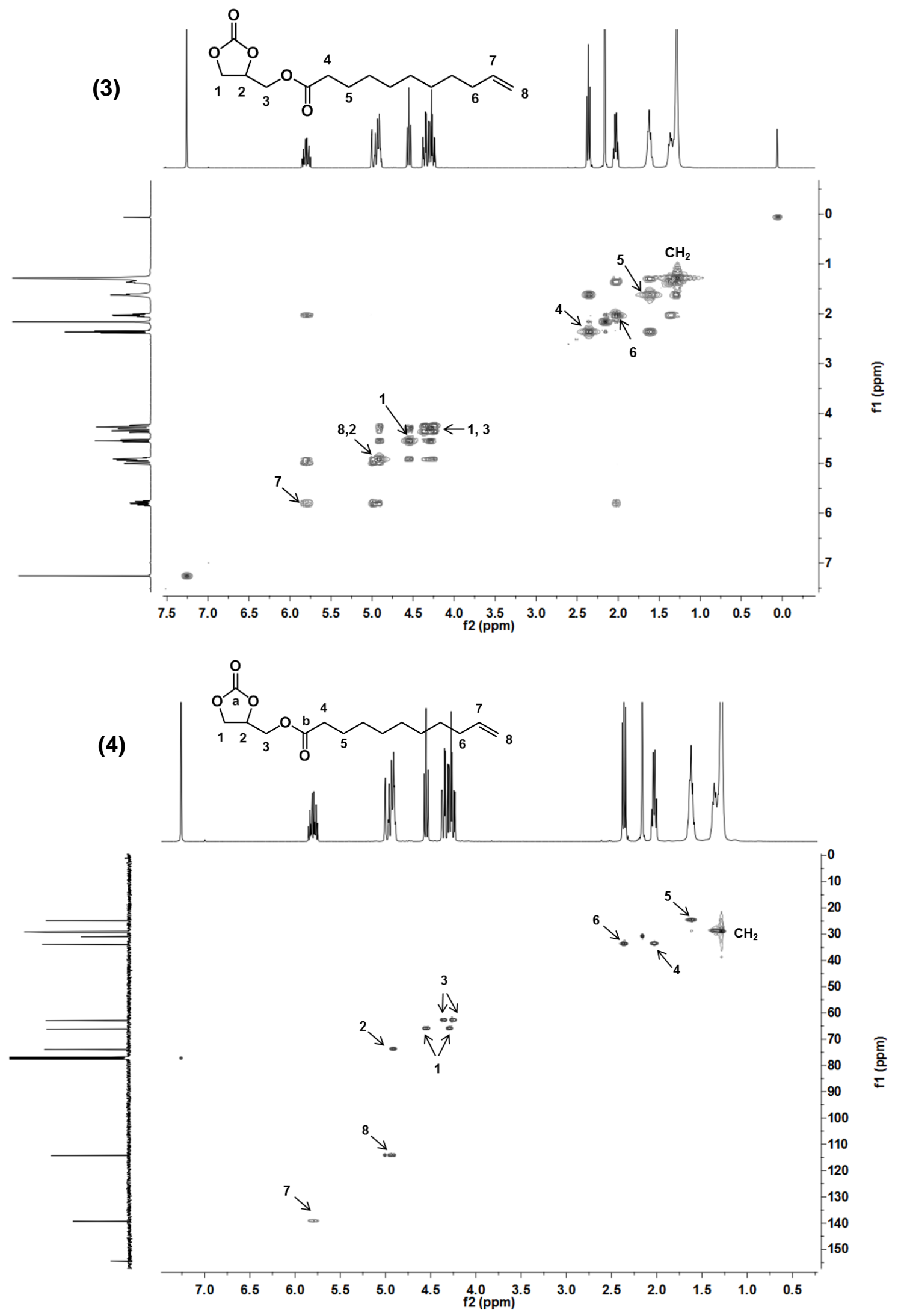

ESI Figure 7- NMR analysis of purified UndCC-ester (1) ${ }^{1} H$ NMR, (2) ${ }^{13} \mathrm{C} N M R,(3){ }^{1} H_{-}{ }^{1} H$ COSY NMR and (4) ${ }^{1} H_{-}{ }^{13} \mathrm{C} H S Q C-N M R$. (Analysis performed in $\mathrm{CDCl}_{3}$.) (* : residual solvents) 
$\mathrm{uV}$

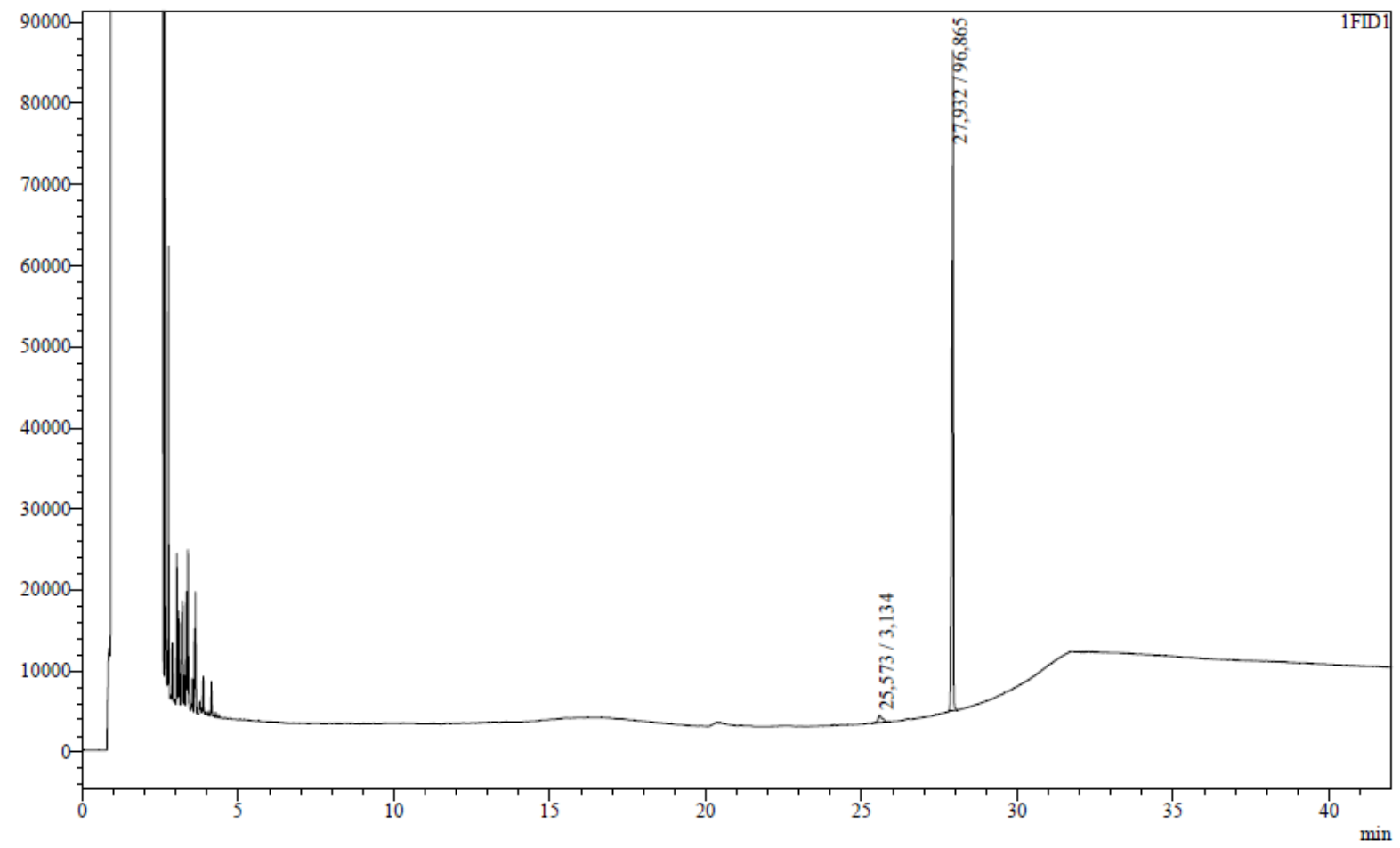

ESI Figure 8- Gas chromatography of UndCC-ester (96.8\% purity).

\subsection{Seb-bCc-ester synthesis}

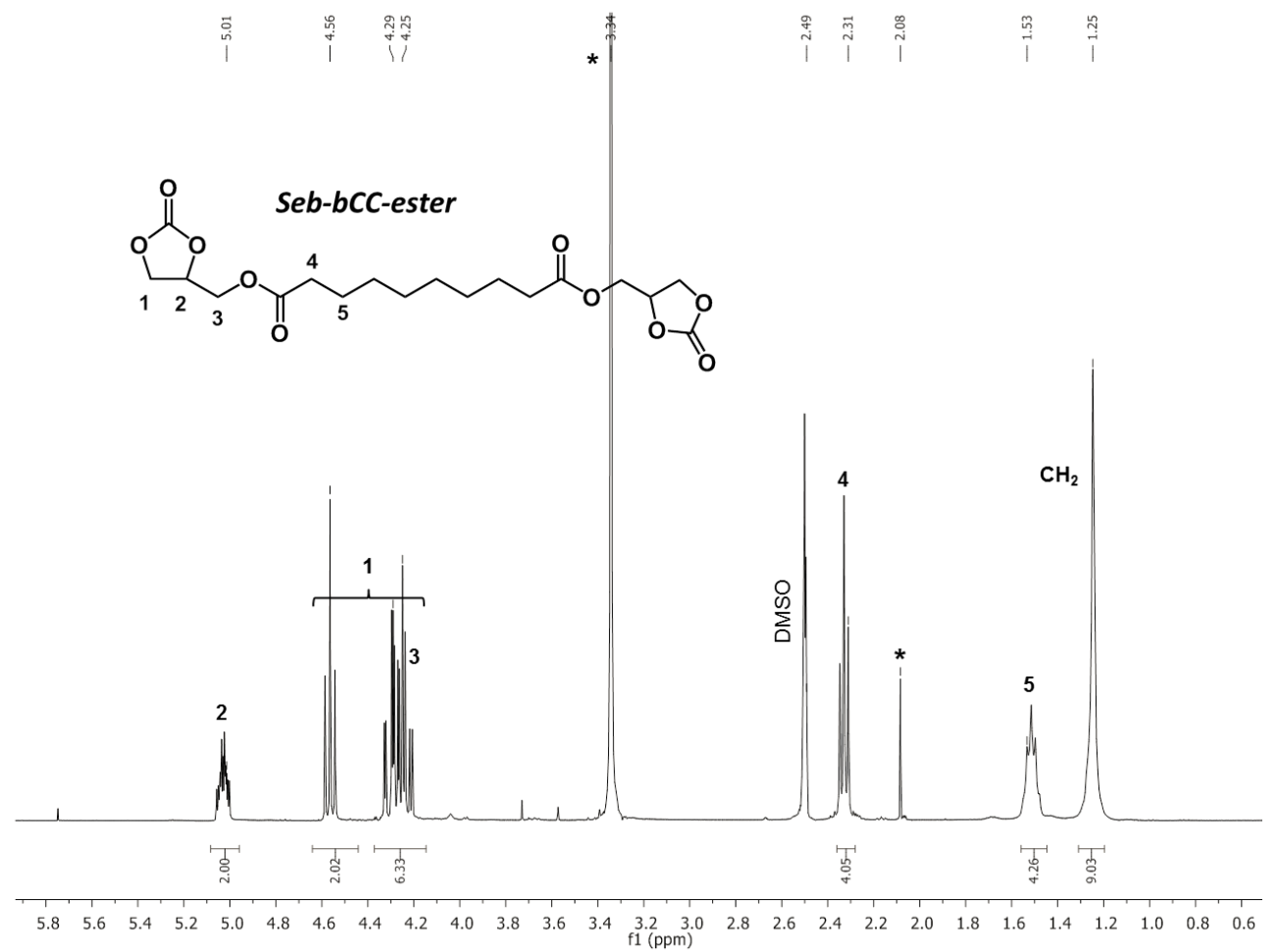

ESI Figure 9- ${ }^{1} \mathrm{H}$ NMR spectrum of Seb-bCC-ester (Analysis performed in DMSO-d6.) (* : residual solvents) 


\subsection{Oley/CC-ether synthesis}
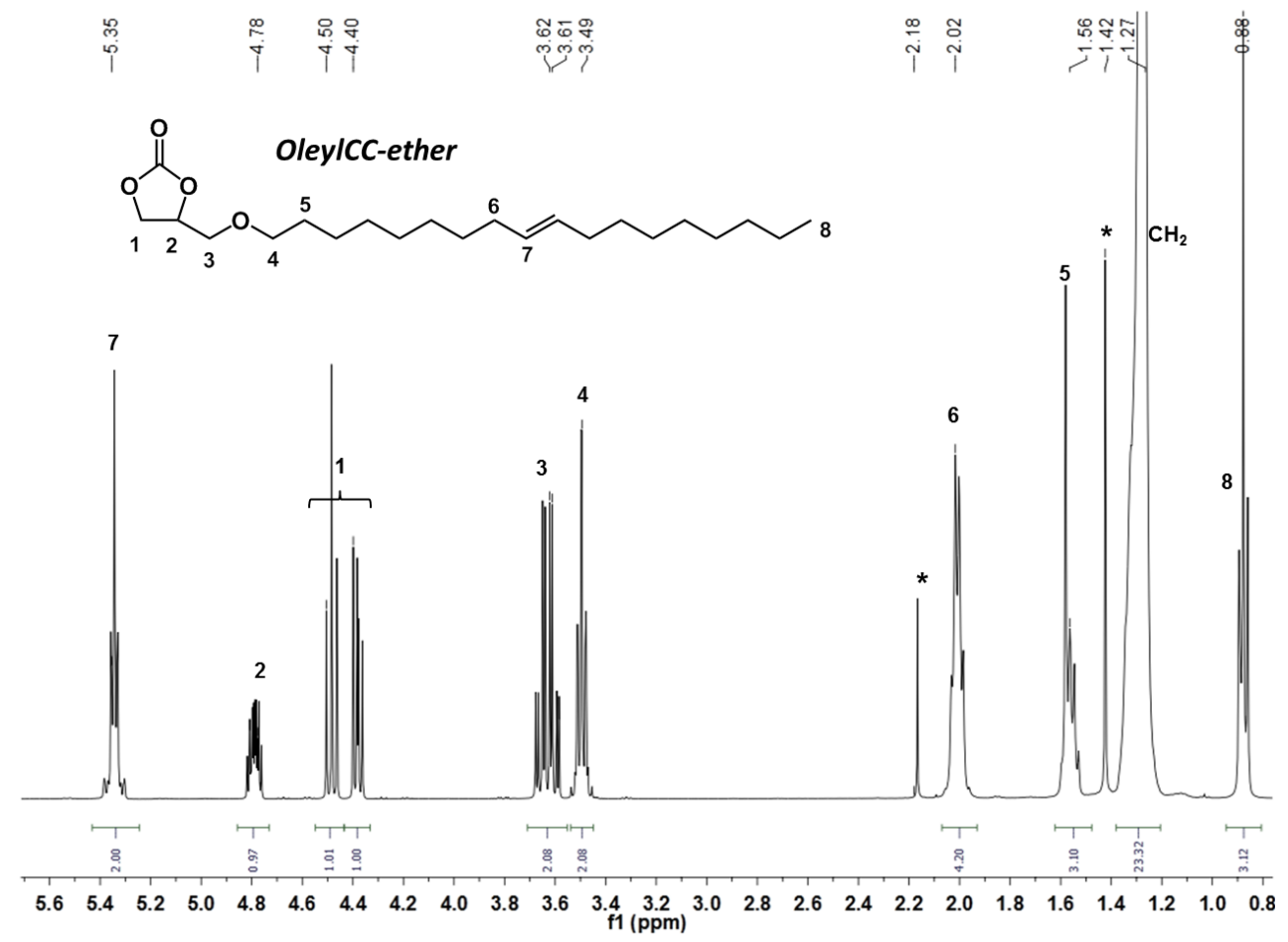

ESI Figure 10- ${ }^{1} \mathrm{H}$ NMR spectrum of OleyICC-ether (Analysis performed in $\mathrm{CDCl}_{3 .}$ ) ( ${ }^{*}$ : residual solvents)

\subsection{OleyICC-ester synthesis}
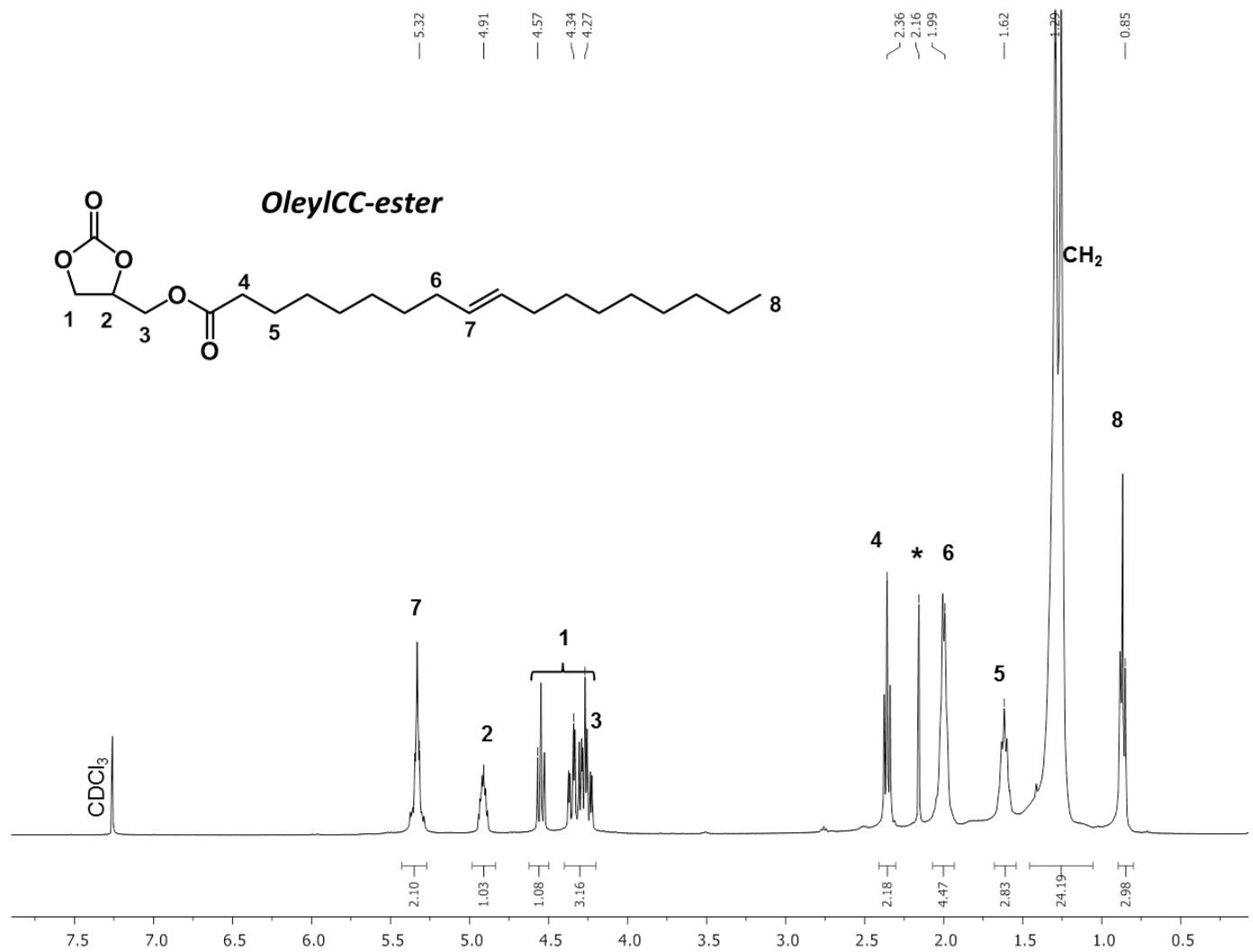

ESI Figure 11- ${ }^{1} \mathrm{H}$ NMR spectrum of OleyICC-ester (Analysis performed in $\mathrm{CDCl}_{3 .}$ ) 
1.6. OleyICC-ester synthesis<smiles>CCCCCCCCCCCCCCCCC(C)(C)C(C)(C)C</smiles>

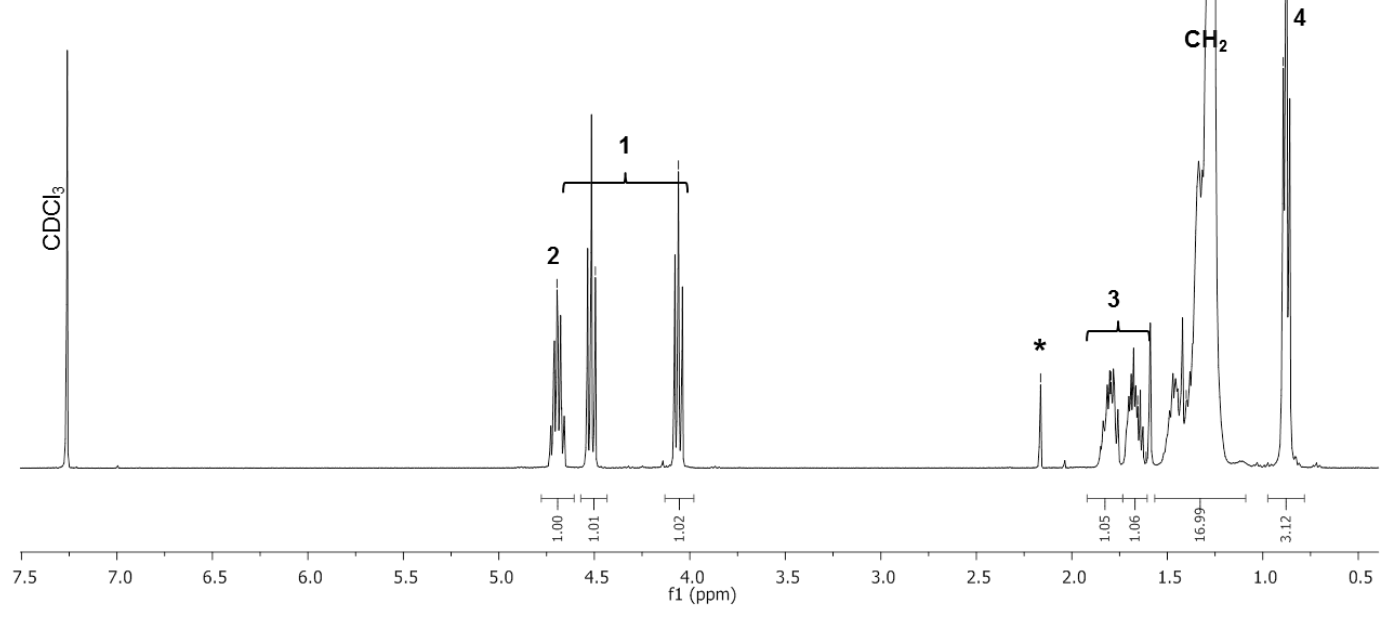

ESI Figure 12- ${ }^{1} \mathrm{H}$ NMR spectrum of Dec-5CC (Analysis performed in $\left.\mathrm{CDCl}_{3 .}\right)\left(^{*}\right.$ : residual solvents)

\section{7. b5CC synthesis}

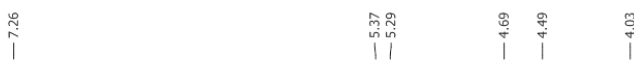

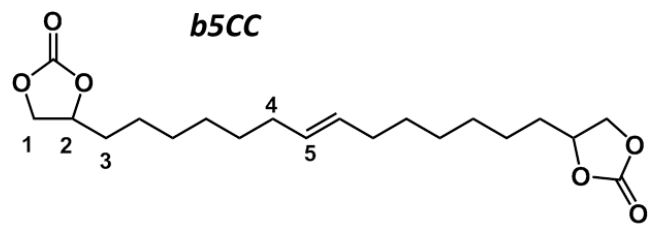

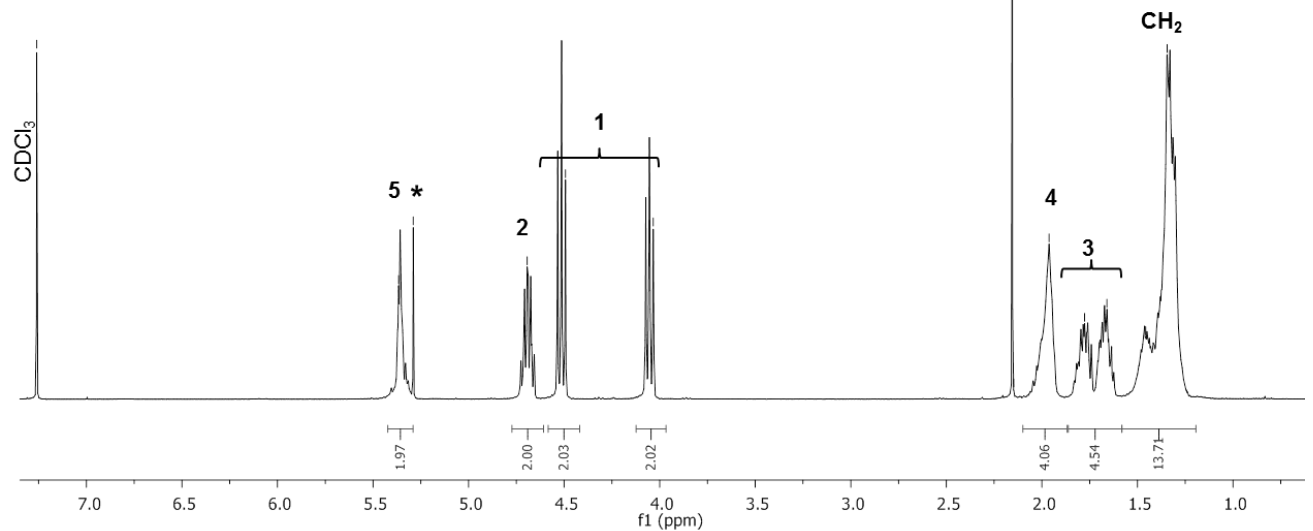

ESI Figure 13- ${ }^{1} \mathrm{H} N \mathrm{NM}$ spectrum of b5CC (Analysis performed in $\left.\mathrm{CDCl}_{3 .}\right)\left({ }^{*}\right.$ : residual solvents) 


\subsection{Und-6CC synthesis}

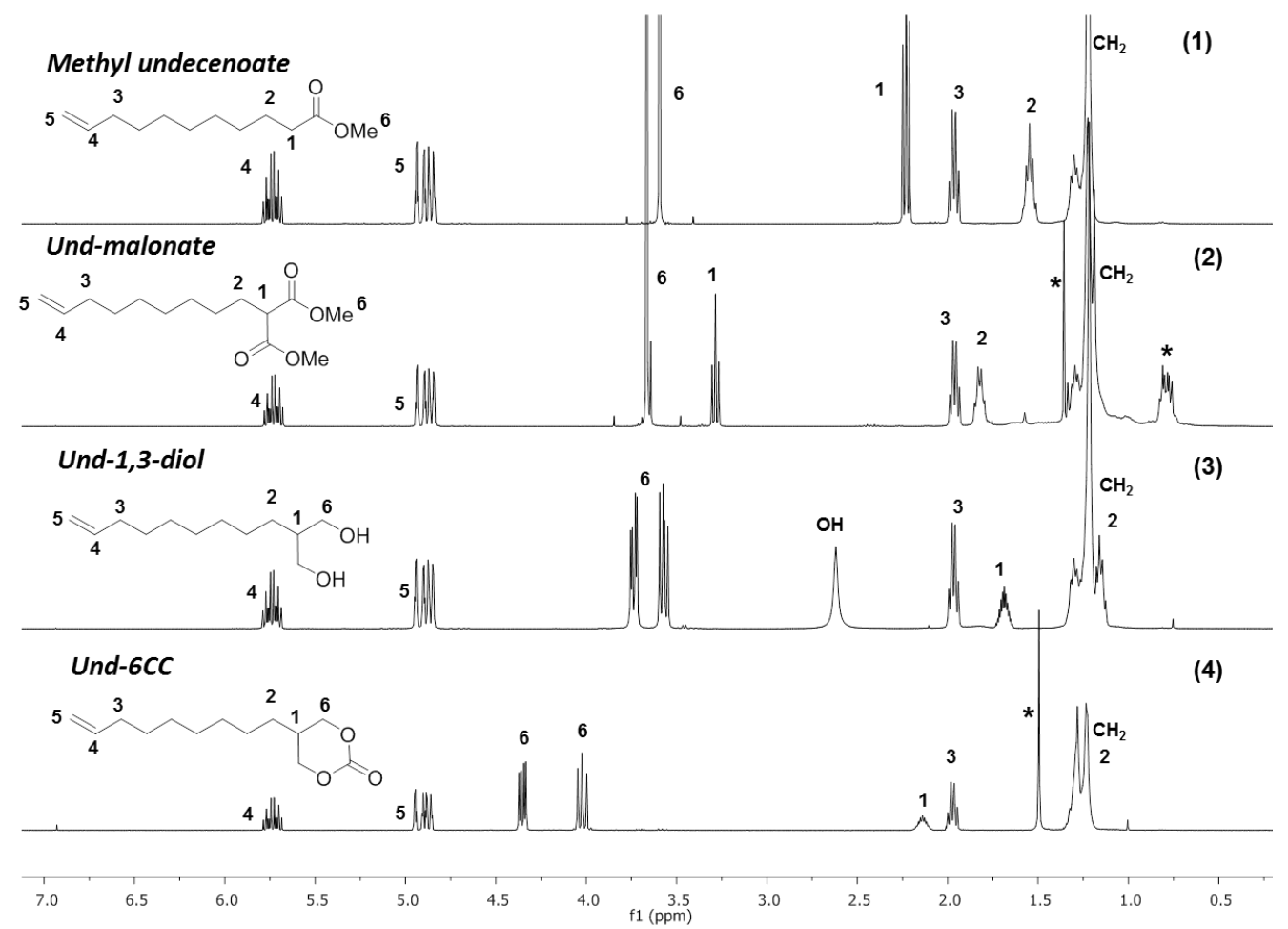

ESI Figure 14- Stacked ${ }^{1}$ H NMR spectra of (1) methyl undecenoate, (2) Und-malonate, (3) Und-1,3-diol and (4) Und-6CC. (All analyses were performed in $\left.\mathrm{CDCl}_{3}\right)(*$ : residual solvents)

\subsection{Oleyl-6CC synthesis}

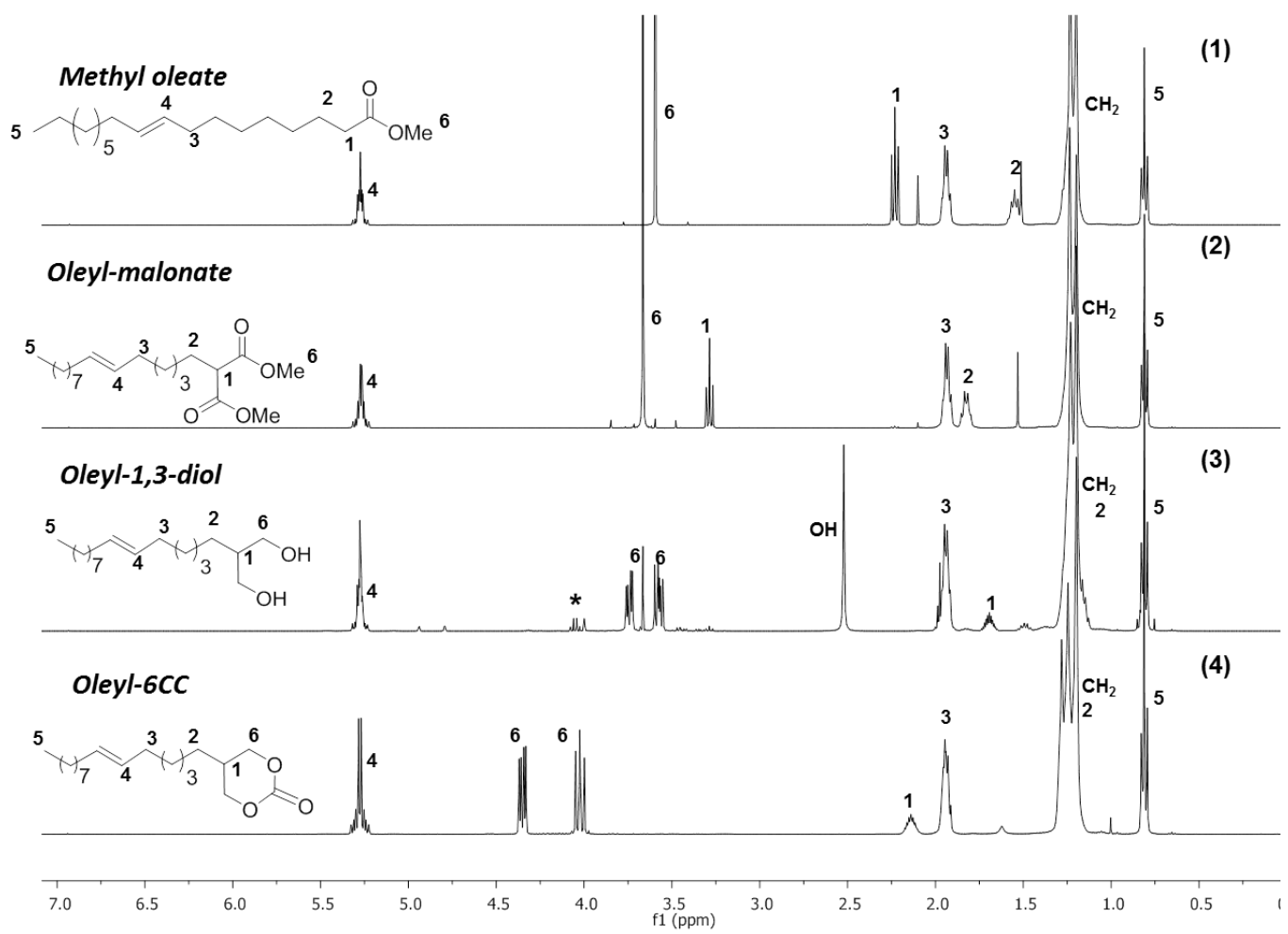

ESI Figure 15- Stacked ${ }^{1}$ H NMR spectra of (1) methyl oleate, (2) Oleyl-malonate, (3) Oleyl-1,3-diol and (4) Oleyl-6CC. (All analyses were performed in $\mathrm{CDCl}_{3}$.)(* impurities). 


\section{Graphical data of kinetic measurements}

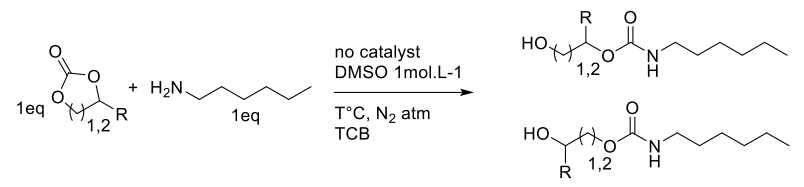

ESI Scheme 1- Model reaction of various cyclic carbonates with hexylamine in different conditions.

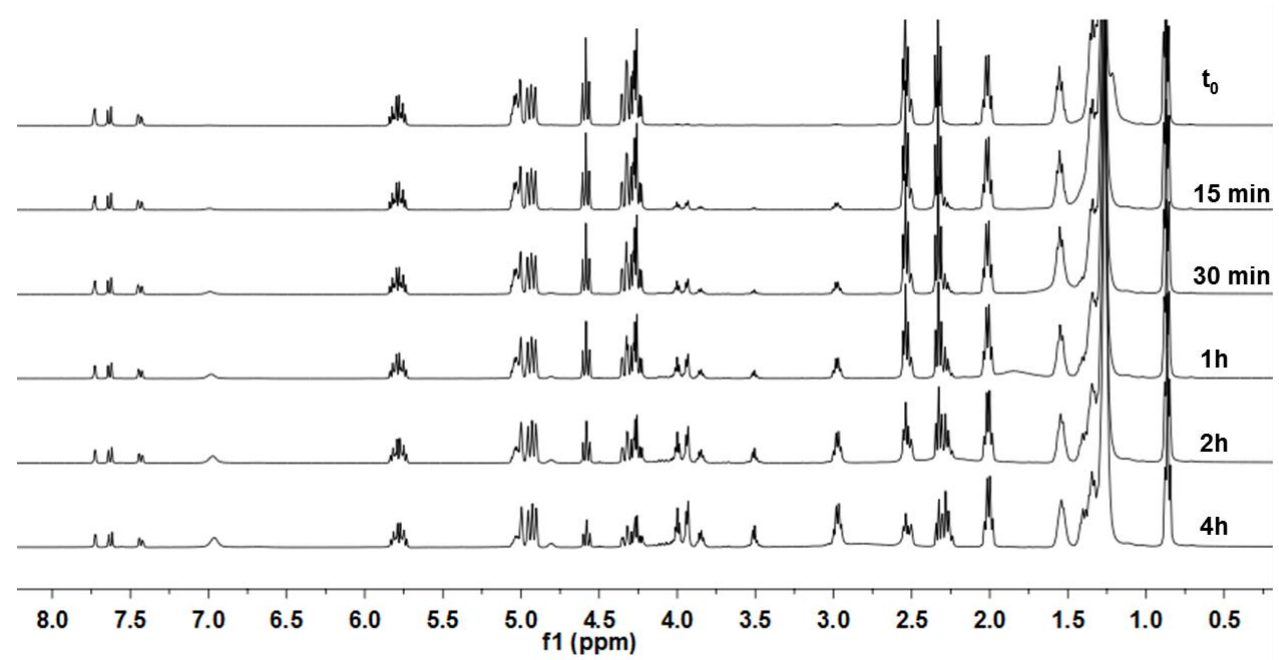

ESI Figure 16- Stacked ${ }^{1} \mathrm{H}$ NMR monitoring of the reaction between UndCC-ester and hexylamine with a ratio $1: 1$, at $50^{\circ} \mathrm{C}$ in DMSO-d6 at 1 mol.L-1.

(1)

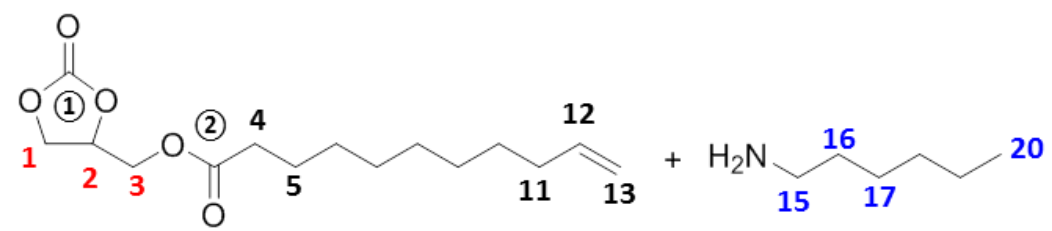<smiles>C=CCCCCCCCCC(=O)OCC(O)COC(=O)NCCCCCC</smiles><smiles>C=CCCCCCCCCC(=O)OCC(C)C(=O)NCCCCCC</smiles>
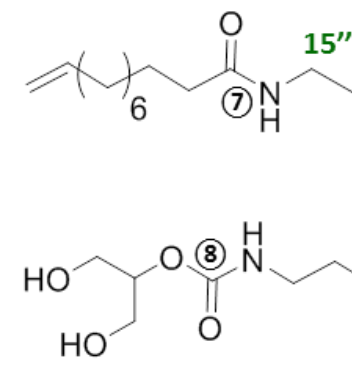<smiles>C=CCCCCCCCCC(=O)OCC(O)CO</smiles><smiles>CCCCCCNC(N)=O</smiles> 
(2)

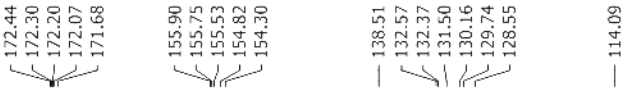
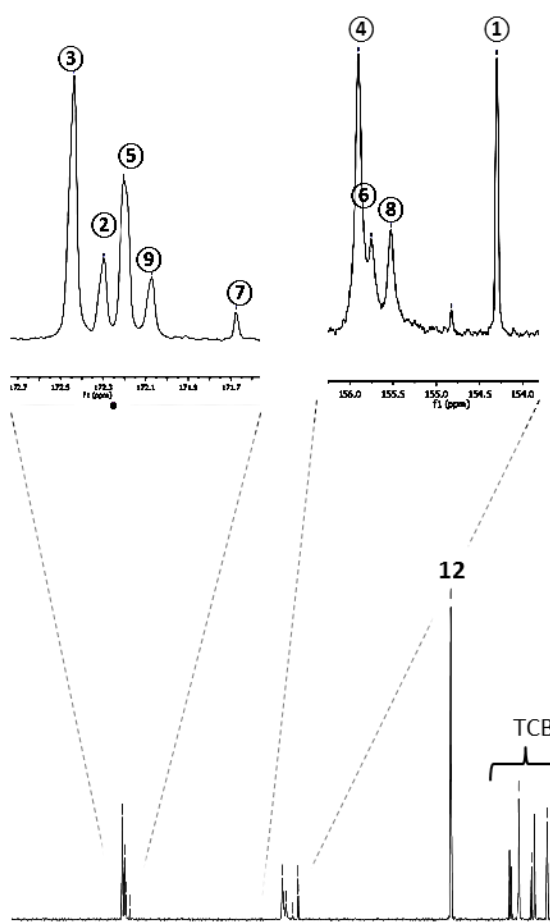

13

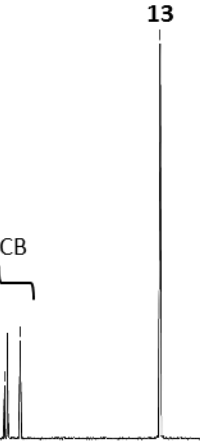

180

150

130

120

$180 \quad 170 \quad 160$

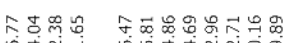

$\mathrm{f1}(\mathrm{ppm})^{90}$

80

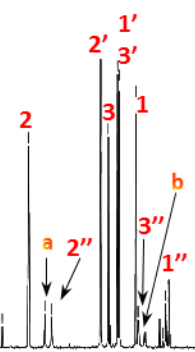

11

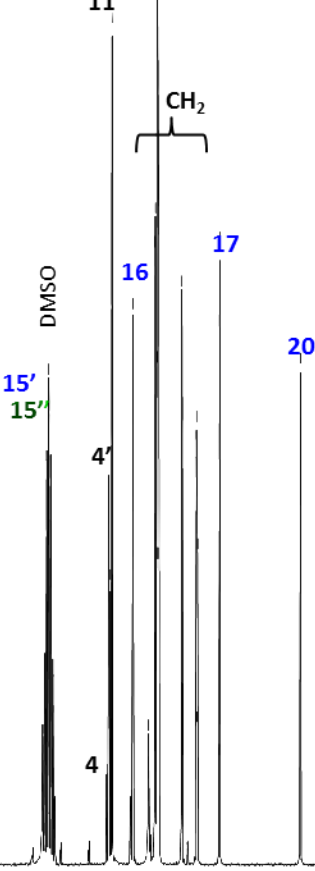

(3)

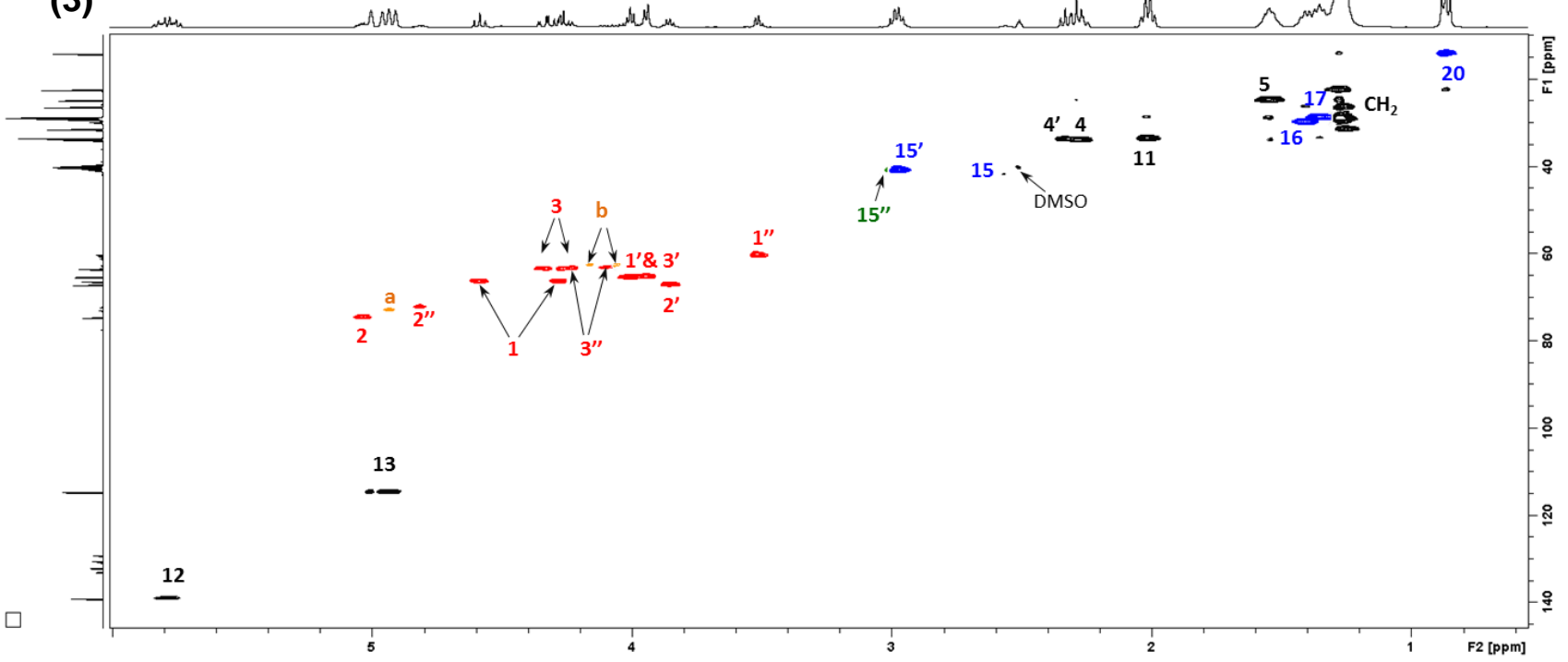

ESI Figure 17 - (1) Scheme of the different molecules identified by (2) ${ }^{13} \mathrm{C}$ and (3) ${ }^{1} \mathrm{H}-{ }^{13} \mathrm{C}$ HSQC during the model reaction between UndCC-ester and hexylamine(ratio 1:1, in DMSO-d6 at $50^{\circ} \mathrm{C}$ ). 


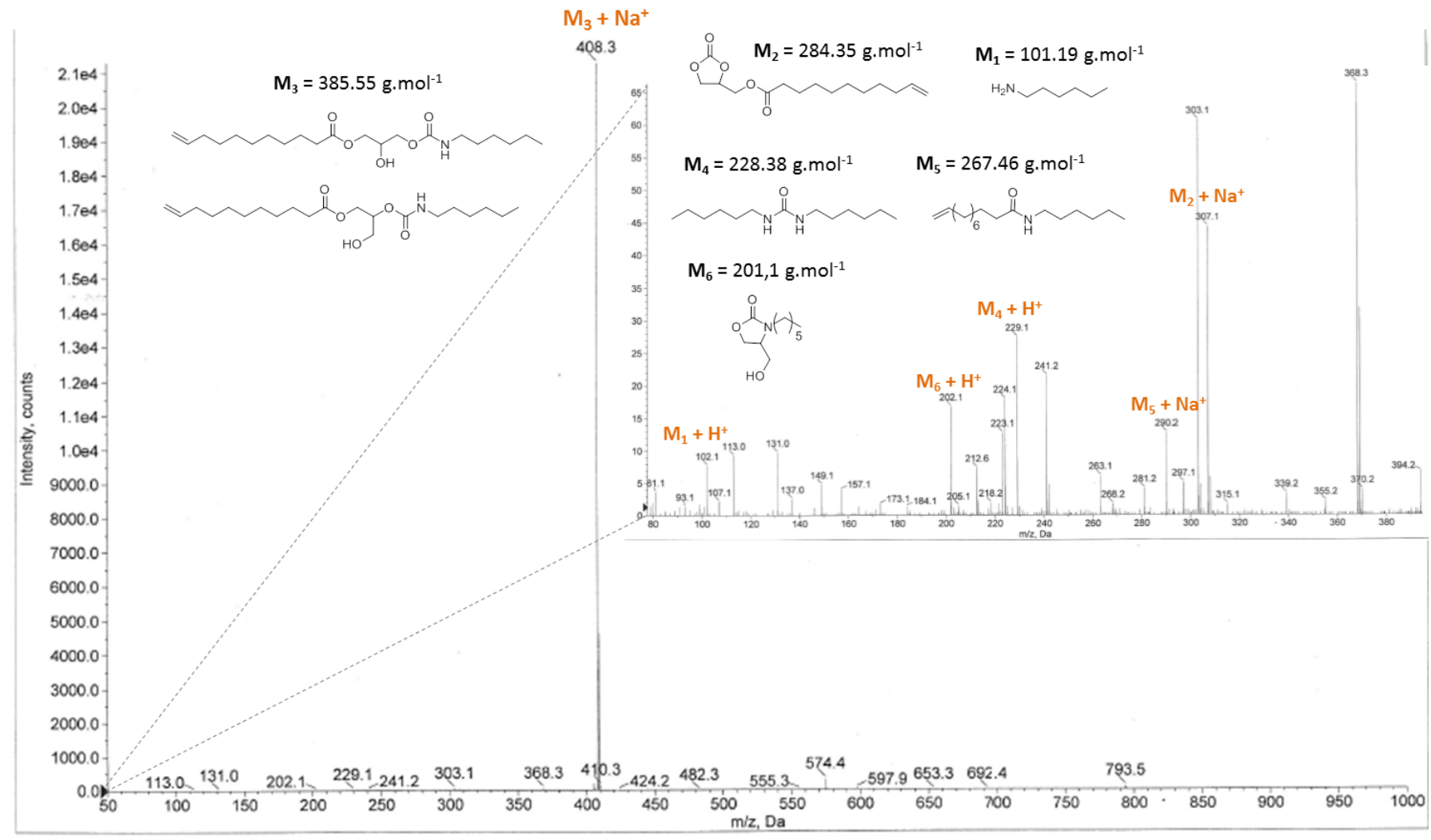

ESI Figure 18 - ESI analysis of the reaction between UndCC-ester and hexylamine at $50^{\circ} \mathrm{C}$ in bulk, with a ratio 1:1.
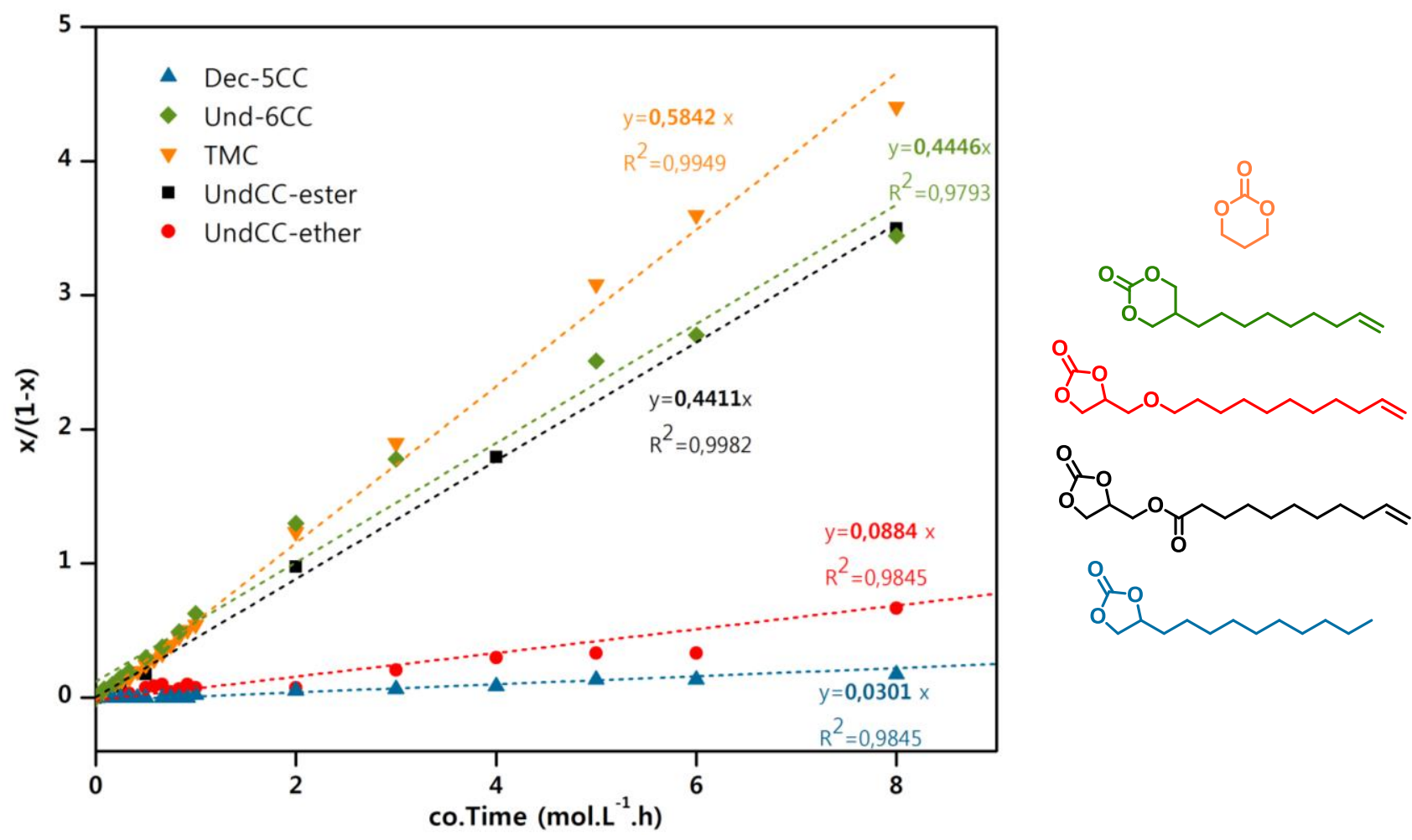

ESI Figure 19- $2^{\text {nd }}$ order Kinetic law: Time- $(x /(1-x))$ relationships for the reactions of cyclic carbonates with hexylamine, at $50^{\circ} \mathrm{C}$ and in DMSO-d6 (1 mol. $\left.\mathrm{L}^{-1}\right)$. 


$$
\begin{gathered}
-\frac{d[C C]}{d t}=k_{a p p}[C C][A]=k_{a p p}[C C]^{2} \\
-\frac{d[C C]}{[C C]^{2}}=k_{a p p} d t \\
\frac{1}{[C C]}-\frac{1}{C_{0}}=k_{a p p} \Delta t \\
\operatorname{or}[C C]=C_{0}-C_{0} x=C_{0}(1-x) \\
\frac{x}{1-x}=k_{a p p} C_{0} \Delta t
\end{gathered}
$$

ESI Formula $1-2^{\text {nd }}$ order Kinetic law formula: Time- $(x /(1-x))$

$$
\begin{aligned}
& \% \text { Urea }=\frac{\int \boldsymbol{H}_{\text {urea }}}{\int \boldsymbol{H}_{\text {urea }}+\int \boldsymbol{H}_{\text {amide }}+\int \boldsymbol{H}_{\text {urethane }}} \\
& \% \text { Amide }=\frac{\int \boldsymbol{H}_{\text {amide }}}{\int \boldsymbol{H}_{\text {urea }}+\int \boldsymbol{H}_{\text {amide }}+\int \boldsymbol{H}_{\text {urethane }}} \\
& \% \text { Urethane }=\frac{\int \boldsymbol{H}_{\text {urethane }}}{\int \boldsymbol{H}_{\text {urea }}+\int \boldsymbol{H}_{\text {amide }}+\int \boldsymbol{H}_{\text {urethane }}}
\end{aligned}
$$

ESI Formula 2 - Formula used for the calculation of \% of urea, amide and urethane formed during kinetic measurements and polymerization, using ${ }^{1} \mathrm{H} N \mathrm{NR}$ integrations of labile protons $\left(H_{\text {urea }}, H_{\text {amide }}\right.$ and $\left.H_{\text {urethane }}\right)$ in DMSO-d6.

$$
\boldsymbol{k}_{\text {app }}=A_{\text {app }} e^{\frac{-E a}{R T}}
$$

Note: The activation energy is not the only parameter to take into account in kinetic analysis. In the Arrhénius equation, $A_{a p p}$ is the pre-exponential factor that indicates the rate of efficient collision. The bigger $A_{a p p}$, the more reactive the monomer is. $A_{a p p}$ was calculated for $5 C C$ and $6 C C$ synthesized by Endo and coll.(reference 13) and for UndCC-ester. Aapp (6CC) $=13570 \mathrm{~L}^{\mathrm{mol}} \mathrm{mol}^{-1} \cdot \mathrm{h}^{-1}$

Aapp $(5 C C)=1.72 \mathrm{~L} \cdot \mathrm{mol}^{-1} \cdot \mathrm{h}^{-1}$

Aapp (UndCC-ester) $=10282 \mathrm{~L} \cdot \mathrm{mol}^{-1} \cdot \mathrm{h}^{-1}$.

ESI Formula 3 - Arrhénius equation and calculation of $A_{a p p}$ for 5CC, $6 C C$ (Endo and coll.) and UndCC-ester. 


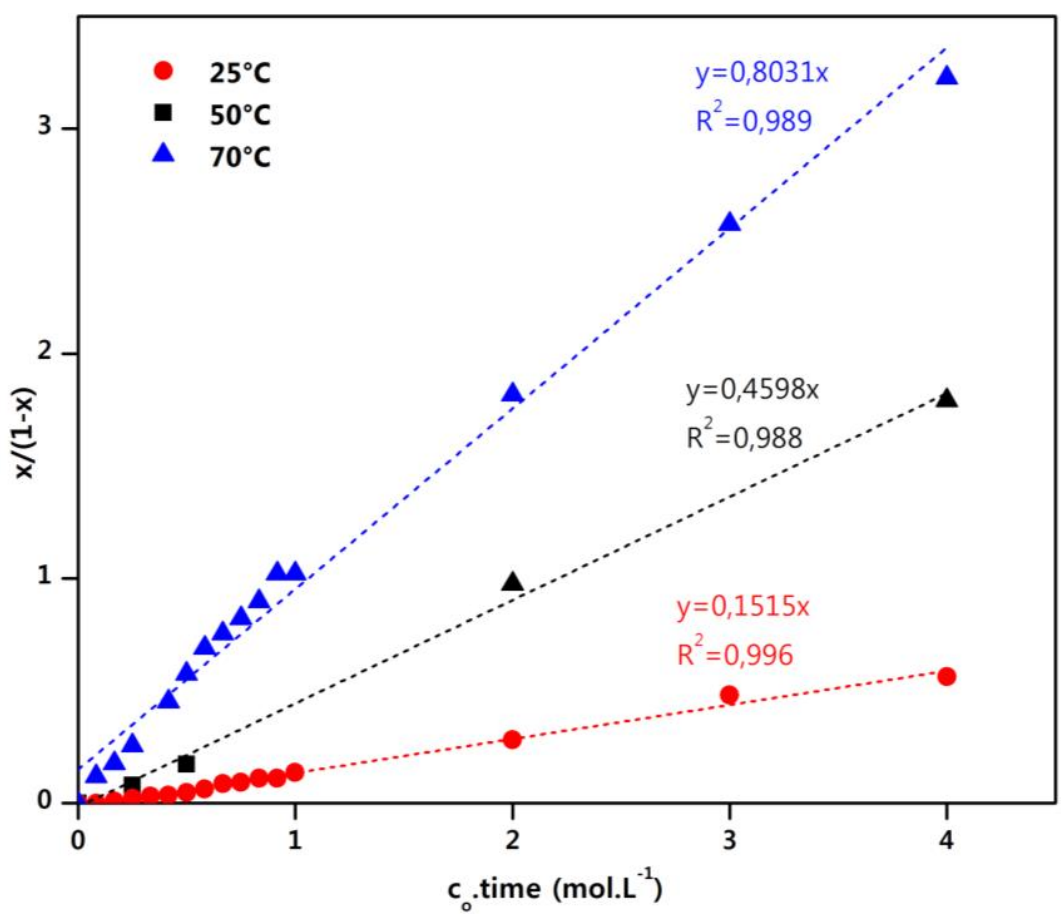

ESI Figure 20 - Effect of the temperature on the kinetic of the reactions between UndCC-ester and hexylamine. (1 mol.L-1 in DMSO-d6, ratio 1:1)

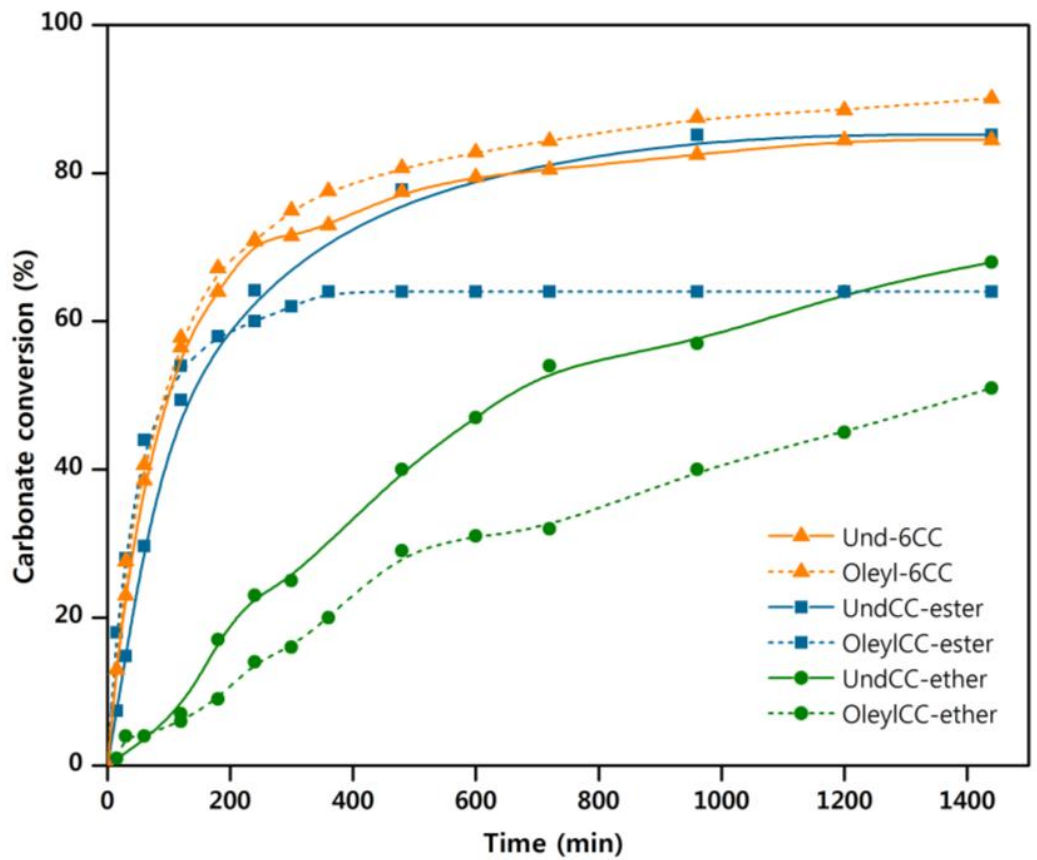

ESI Figure 21 - Chain lengh effect on the kinetic of the reactions between reactive cyclic carbonates and hexylamine (1 mol. $\mathrm{L}^{-1}$ in DMSO-d6, ratio $1: 1,25^{\circ} \mathrm{C}$ ) 


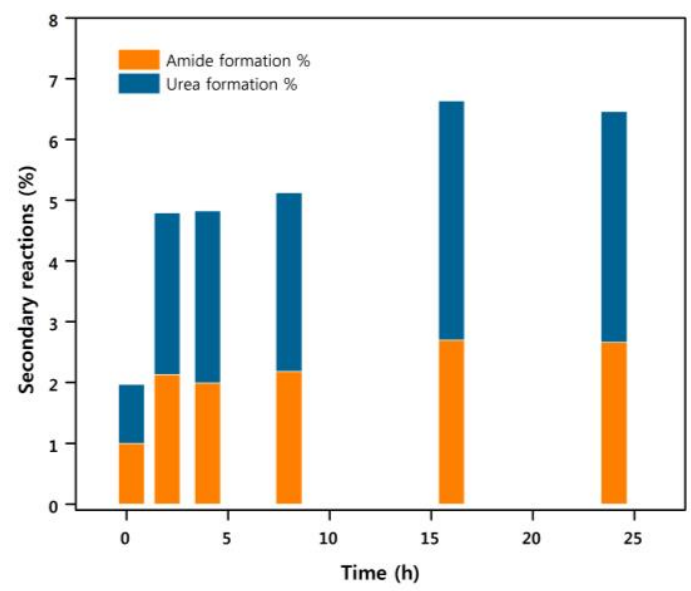

ESI Figure 22 - Proportions of side reactions obtained during the reactions between UndCC-ester and hexylamine over $24 \mathrm{~h}$ (1 mol. $L^{-1}$ in DMSO-d6, $50^{\circ} \mathrm{C}$, ratio 1:1).

\section{Graphical data of Poly(hydroxyurethane)s}

PHU-1[b5CC + 10DA] : ${ }^{1} \mathrm{H}$ NMR (DMSO-d6, $\left.25^{\circ} \mathrm{C}, 400 \mathrm{MHz}\right) \delta(\mathrm{ppm}):($ see ESI $\dagger) . I R\left(\mathrm{~cm}^{-1}\right): 3600-3100$, 2920, 2848, 1685, 1532.

PHU-2 [Und-bCC-ether + 10DA]: ${ }^{1} \mathrm{H}$ NMR (DMSO-d6, $\left.25^{\circ} \mathrm{C}, 400 \mathrm{MHz}\right) \delta(\mathrm{ppm}):\left(\right.$ see ESI†). IR $\left(\mathrm{cm}^{-1}\right)$ : 3600-3100, 2928, 2853, 1663, 1505, 1093.

PHU-3 [Und-bCC-ester + 10DA]: ${ }^{1} \mathrm{H}$ NMR (DMSO-d6, $\left.25^{\circ} \mathrm{C}, 400 \mathrm{MHz}\right) \delta(\mathrm{ppm}):\left(\right.$ see ESI†). IR $\left(\mathrm{cm}^{-1}\right)$ : 3600-3100, 2923, 2848, 1709, 1663, 1545.

\begin{tabular}{|c|c|c|c|}
\hline PHU families & Description & Reaction & $\begin{array}{c}\text { PHU } 1 \\
\left(\mathrm{M}_{\text {unit }}=712.49 \mathrm{~g} \cdot \mathrm{mol}^{-1}\right)\end{array}$ \\
\hline $\mathbf{F 1}$ & $C-\left(C_{n-1}-A_{n}\right)-C$ & $\begin{array}{c}\text { Polyaddition : urethane } \\
\text { formation }\end{array}$ & $\mathrm{n} *\left(\mathrm{M}_{\text {unit }}\right)+\mathrm{M}_{\mathrm{C}}+\mathrm{M}_{\mathrm{Na}}$ \\
\hline $\mathbf{F} 2$ & $C-\left(C_{n}-A_{n-1}\right)-A$ & $\begin{array}{l}\text { Polyaddition : urethane } \\
\text { formation }\end{array}$ & $\mathrm{n} *\left(\mathrm{M}_{\text {unit }}\right)+\mathrm{M}_{\mathrm{A}}+\mathrm{M}_{\mathrm{Na}}$ \\
\hline F3 & $A-\left(C_{n}-A_{n}\right)-C$ & $\begin{array}{c}\text { Polyaddition : urethane } \\
\text { formation }\end{array}$ & $(n+1) *\left(M_{\text {unit }}\right)+M_{N a}$ \\
\hline F4 & $C-\left(C_{n-1}-U^{A}-A_{n}\right)-C$ & 1 Urea linkage within the chain & $\mathrm{n} *\left(\mathrm{M}_{\text {unit }}\right)+\mathrm{M}_{\mathrm{C}}+\mathrm{M}_{\text {urea }}+\mathrm{M}_{\mathrm{Na}}$ \\
\hline F5 & $C-\left(C_{n-1}-U^{A}-U^{A}-A_{n}\right)-C$ & 2 Urea linkages within the chain & $n^{*}\left(M_{\text {unit }}\right)+M_{C}+2 M_{\text {urea }}+M_{N a}$ \\
\hline $\mathbf{F 1} *$ & $A_{\text {amide }}-\left(C_{n-1}-A_{n}\right)-C$ & $\begin{array}{c}\text { Transamidification at the chain } \\
\text { end or by cyclisation }\end{array}$ & $\mathrm{n} *\left(\mathrm{M}_{\text {unit }}\right)-\mathrm{M}_{\mathrm{GC}}+\mathrm{M}_{\mathrm{amine}}+\mathrm{M}_{\mathrm{Na}}$ \\
\hline F3* & $A-\left(C_{n}-A_{n}\right)-C_{G C}$ & Transamidification intra-chain & $(n+1) *\left(M_{\text {unit }}\right)+M_{G C}+M_{N a}$ \\
\hline $\mathrm{F} 1 * *$ & $\begin{array}{l}\mathrm{C}-\left(\mathrm{C}_{n-1}-\mathrm{A}_{n}\right)-\mathrm{C}^{\mathrm{OH}} \\
\mathrm{C}^{\mathrm{OH}}-\left(\mathrm{C}_{n-1}-\mathrm{A}_{n}\right)-\mathrm{C}^{\mathrm{OH}}\end{array}$ & $\begin{array}{l}\text { Urea formation intra-chain } \\
\text { resulting in the formation of } \\
\text { hydroxyl groups at the chain-end }\end{array}$ & $\begin{array}{l}n^{*}\left(M_{\text {unit }}\right)+M_{C}-M_{C=0}+2 M_{H}+M_{N a} \\
n *\left(M_{\text {unit }}\right)+M_{C}-2 M_{C=O}+4 M_{H}+M_{N a}\end{array}$ \\
\hline $\mathrm{F} 3 * *$ & $U^{A}-\left(C_{n}-A_{n}\right)-C$ & Urea formation at the chain end & $(n+1) *\left(M_{\text {unit }}\right)+M_{\text {urea }}+M_{N a}$ \\
\hline
\end{tabular}

*amide formation

** urea formation

Abbreviations are as followed: $C=$ Und-bCC-ester with $M_{C}=540.29 \mathrm{~g} \cdot \mathrm{mol}^{-1} ; A=$ decane-1,10-diamine with $\mathrm{M}_{A}=172.19 \mathrm{~g} \cdot \mathrm{mol}^{-1}$; $U^{A}=$ urea linkage on $A$ with $M_{\text {urea }}=M_{A}+M_{C=0}-2 M_{H}=198.19$ g.mol ${ }^{-1} ; G C=$ glycerol carbonate and equivalents in mass, with $\mathrm{M}_{\mathrm{GC}}=118.3 \mathrm{~g} \cdot \mathrm{mol}^{-1} ; \mathrm{C}^{\mathrm{OH}}$ : chain end produced by urea formation : $\mathrm{M}_{\mathrm{COH}}=\mathrm{M}_{\mathrm{C}}-\mathrm{M}_{\mathrm{C}=\mathrm{O}}+2 \mathrm{M}_{\mathrm{H}}=514.29 \mathrm{~g} \cdot \mathrm{mol}^{-1}$ 


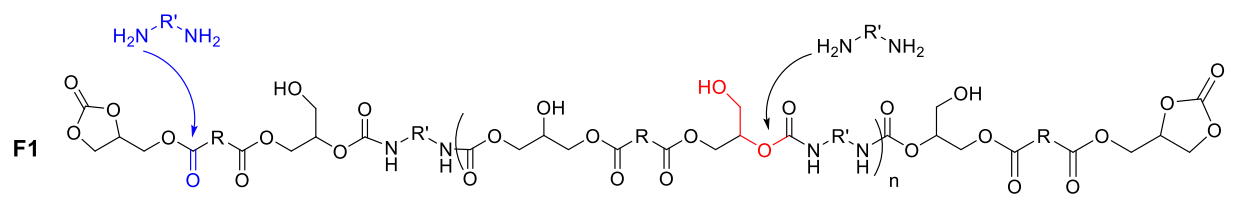

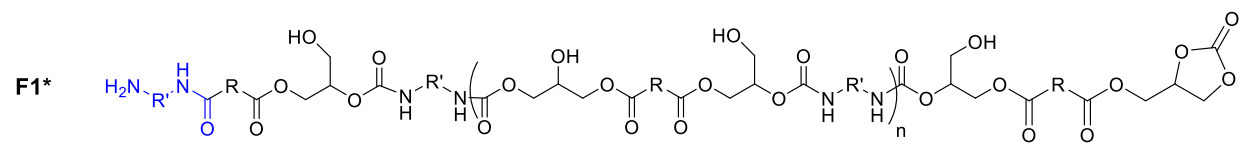

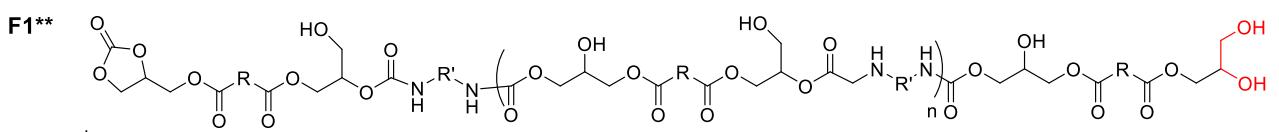

and

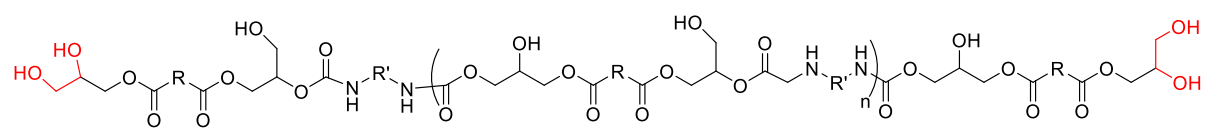

$\mathrm{H}_{2} \mathrm{~N}^{-\mathrm{R}^{\prime}} \mathrm{NH}_{2}$

F3

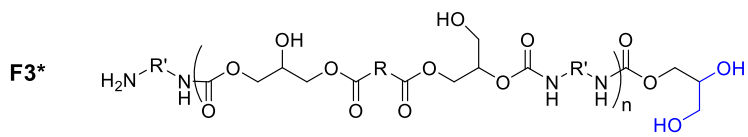

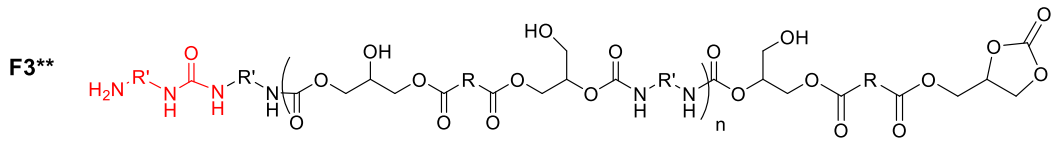

(n)

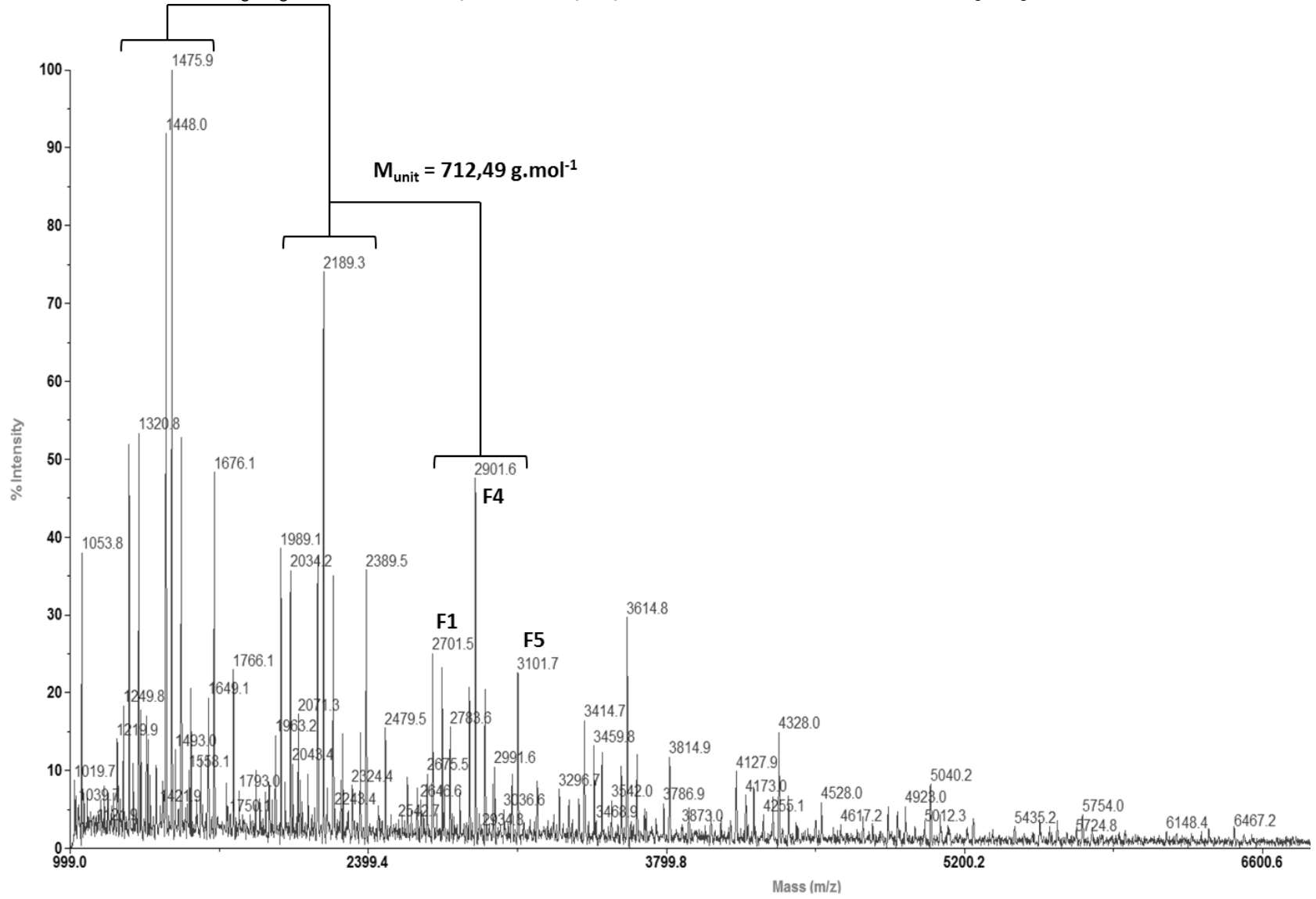




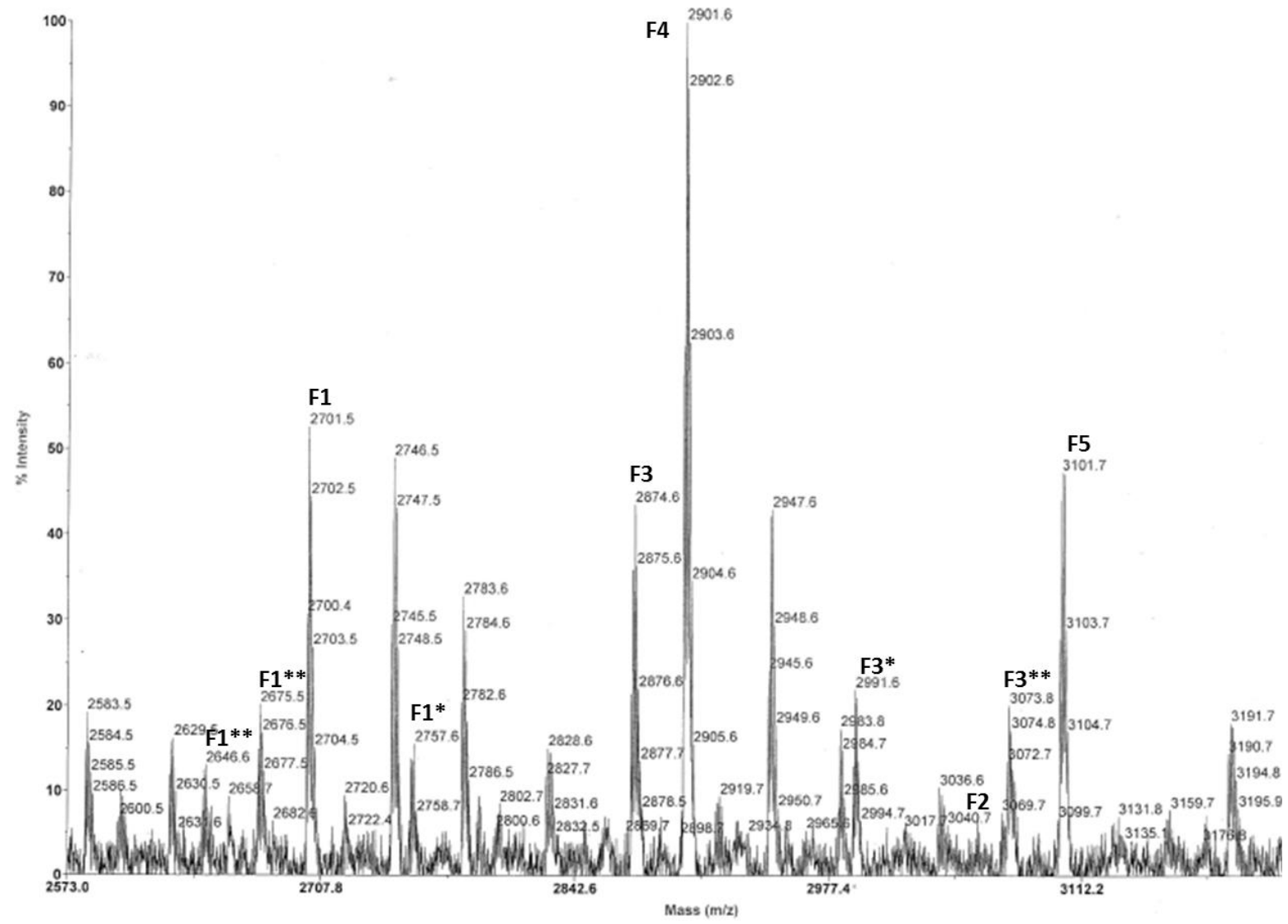

Figure 23 - Different PHU families in the sample PHU1 visible in MALDI-TOF MS

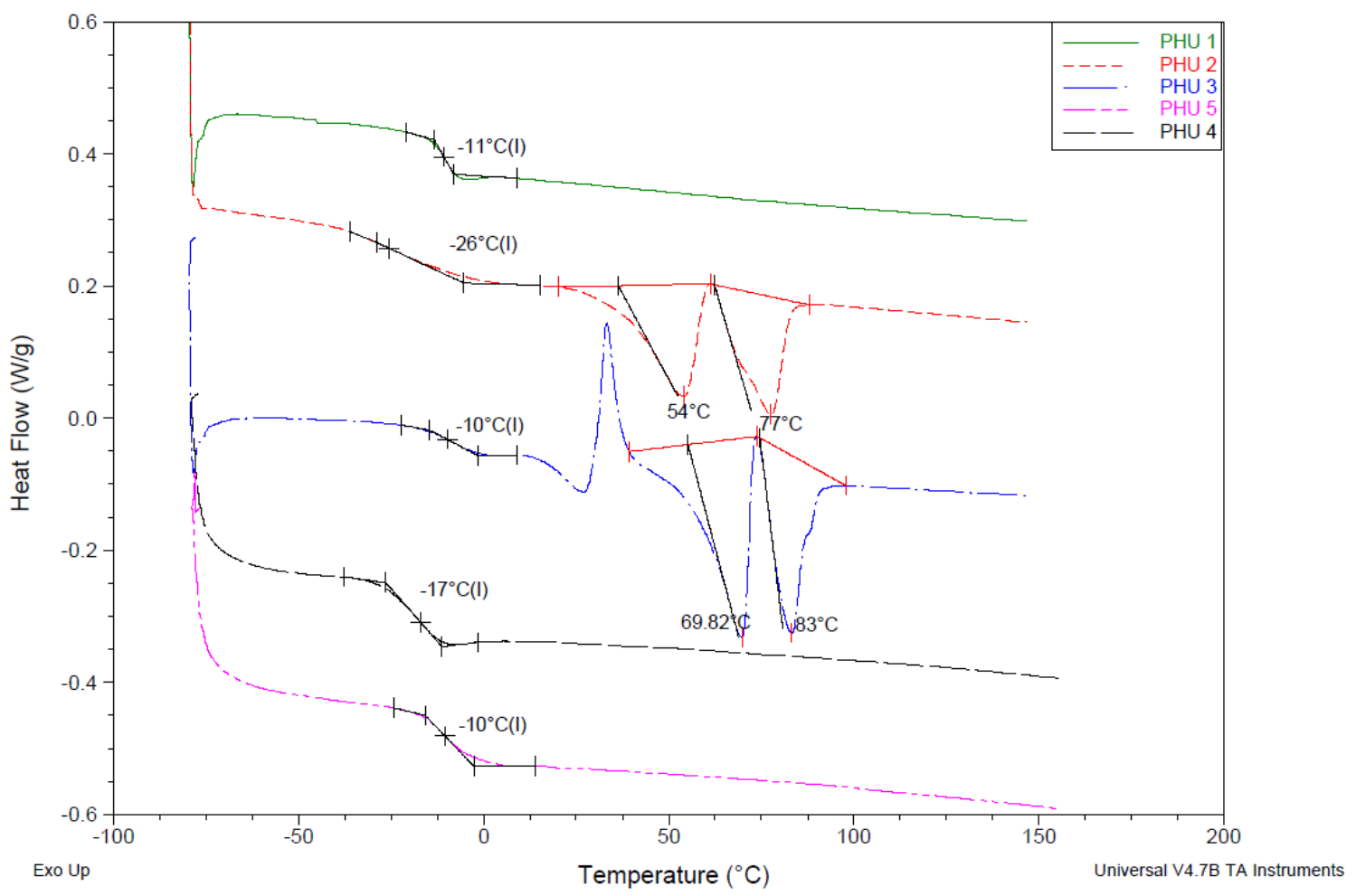

Figure 24-DSC curves of the synthesized PHU (PHU 1-PHU 5). 


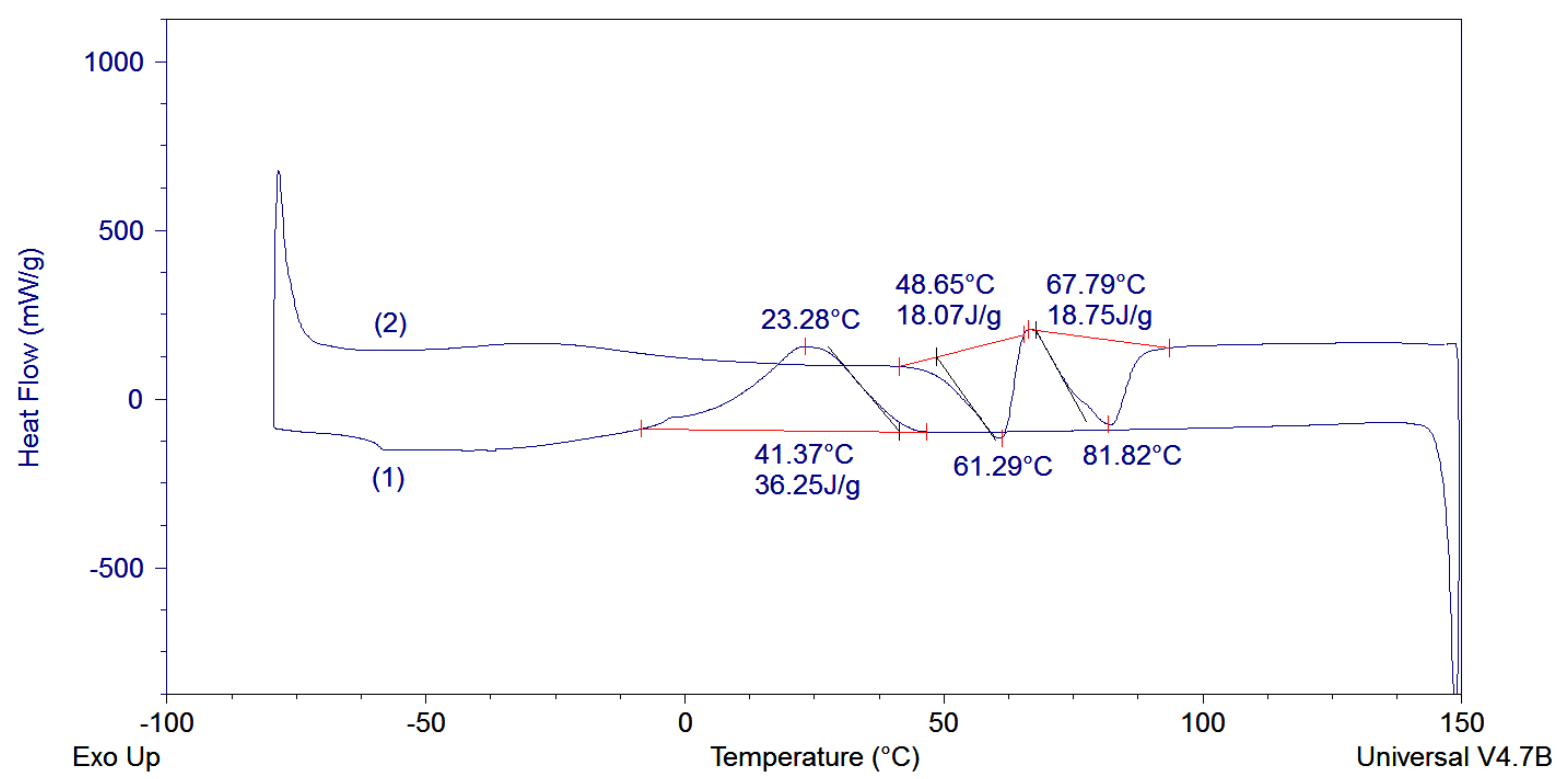

Figure $25-D S C$ curves of the synthesized PHU 2 showing (1) the first cooling run and (2) the $2^{\text {nd }}$ heating run.

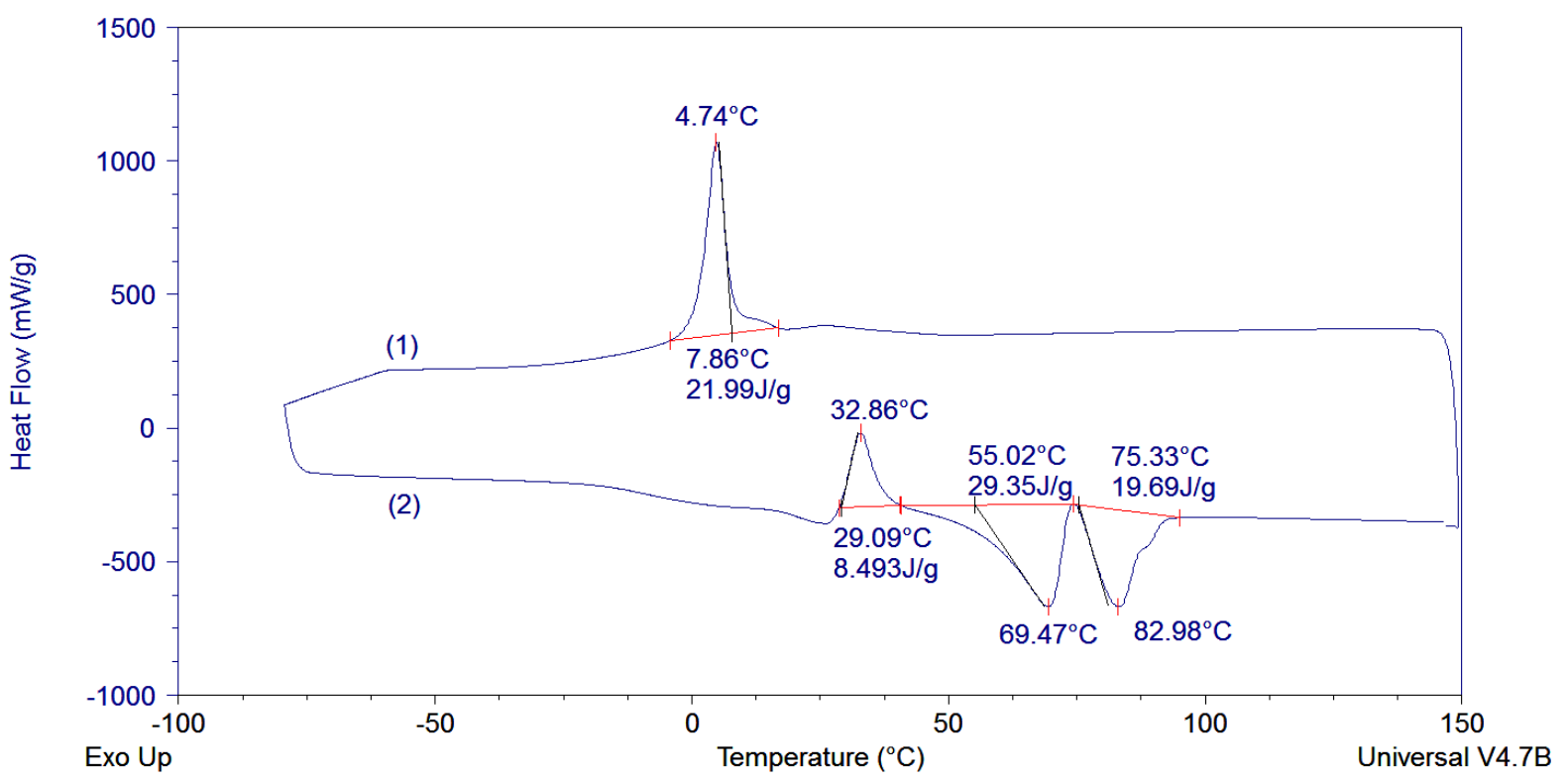

Figure 26 - DSC curves of the synthesized PHU 3 showing (1) the first cooling run and (2) the $2^{\text {nd }}$ heating run. 


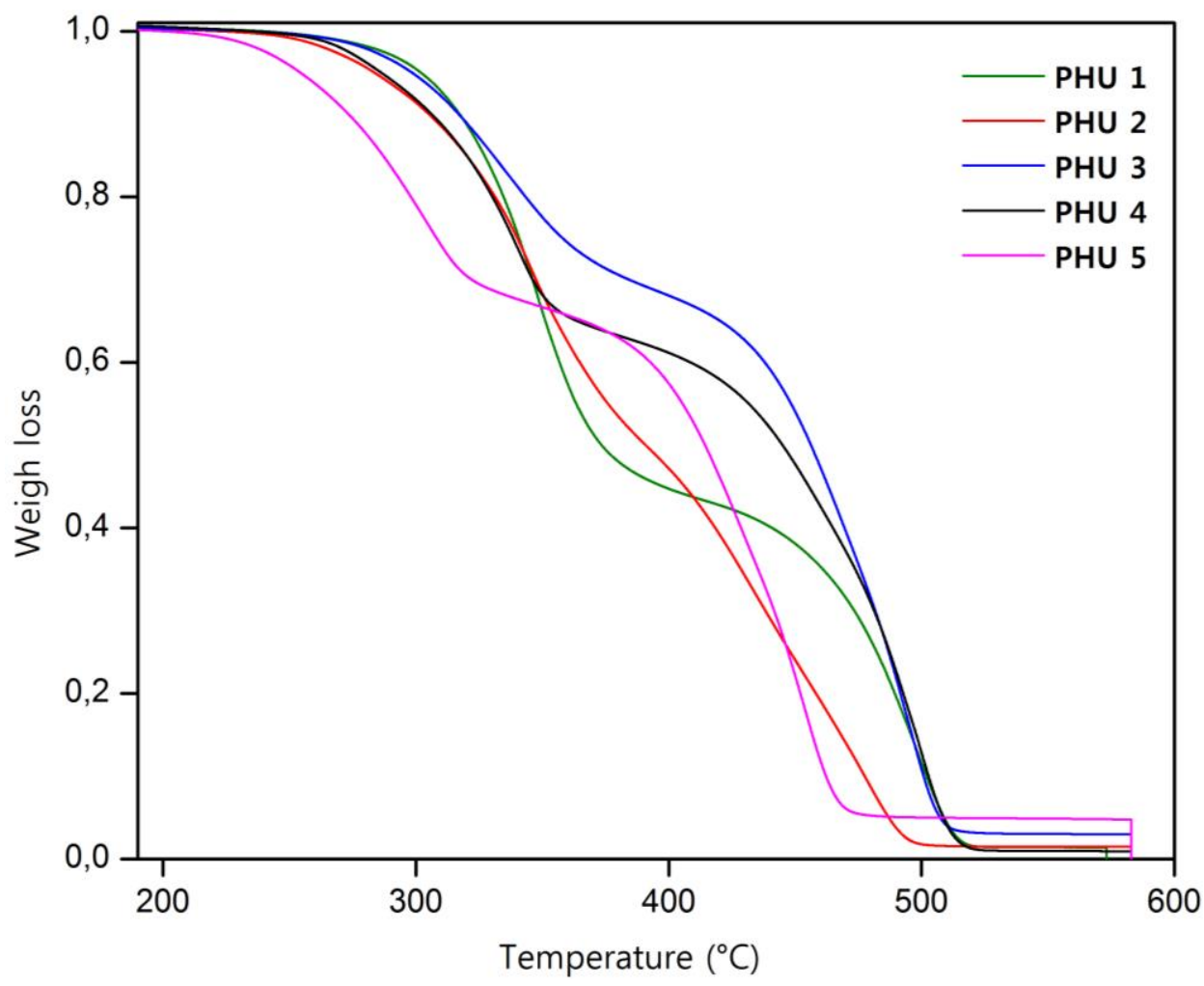

Figure 27 - TGA curves of the synthesized PHU (PHU 1-PHU 5) from $200^{\circ} \mathrm{C}$ (after DMF removal) to $600^{\circ} \mathrm{C}$. 